Editores:
José Migue
Túnez
Francisco
Alba
López
Campos
Silva
Freire
Rodríguez

Prólogo: Rosario de Mateo Pérez

\title{
Estudios sobre legislación, financiación e innovación en la Televisión Pública
}

Cuadernos Artesanos de Latina / 126

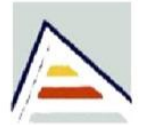

Universitat d'Alacant Universidad de Alicante
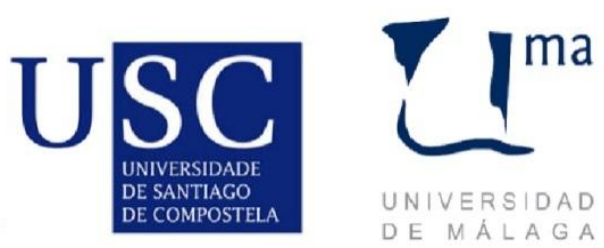

UNIVERSIDAD

DE MALAGA

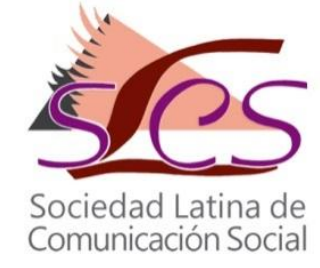




\section{Cuadernos Artesanos de Comunicación}

Coordinador editorial: José Manuel de Pablos - jpablos@ull.edu.es

Comité Científico

Presidencia: José Luis Piñuel Raigada (UCM)

Secretaría: Alberto Ardèvol (ULL)

- José Antonio Meyer (Benemérita Universidad Autónoma de Puebla, BUAP)

- Ramón Reig (Universidad de Sevilla, US)

- Miquel Rodrigo Alsina (Universidad Pompeu Fabra, UPF)

- Victoria Tur (Universidad de Alicante, UA)

- Miguel Vicente (Universidad de Valladolid, UVA)

- Ramón Zallo (Universidad del País Vasco, UPV-EHU)

- Núria Almiron (Universidad Pompeu Fabra, Barcelona, UPF)

- José Cisneros (Benemérita Universidad Autónoma de Puebla, BUAP)

- Bernardo Díaz Nosty (Universidad de Málaga, UMA)

- Carlos Elías (Universidad Nacional de Educación a Distancia, UNED)

- Paulina B. Emanuelli (Universidad Nacional de Córdoba, UNC)

- Marisa Humanes (Universidad Rey Juan Carlos, URJC)

- Juan José Igartua (Universidad de Salamanca, USAL)

- Maricela López-Ornelas (Universidad Autónoma de Baja California, AUBC)

- Javier Marzal (Universidad Jaume I, UJI)

* Queda expresamente autorizada la reproducción total o parcial de los textos publicados en este libro, en cualquier formato o soporte imaginables, salvo por explícita voluntad en contra del autor o autora o en caso de ediciones con ánimo de lucro. Las publicaciones donde se incluyan textos de esta publicación serán ediciones no comerciales y han de estar igualmente acogidas a Creative Commons. Harán constar esta licencia y el carácter no venal de la publicación.

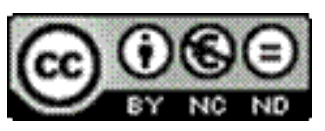

Este libro y cada uno de los capítulos que contiene (en su caso), así como las imágenes incluidas, si no se indica lo contrario, se encuentran bajo una Licencia Creative Commons Atribución-No Comercial-Sin Derivadas 3.0 Unported. Puede ver una copia de esta licencia en http://creativecommons.org/licenses/by-nc-nd/3.0/ Esto significa que Ud. es libre de reproducir y distribuir esta obra, siempre que cite la autoría, que no se use con fines comerciales o lucrativos y que no haga ninguna obra derivada. Si quiere hacer alguna de las cosas que aparecen como no permitidas, contacte con los coordinadores del libro o con el autor del capítulo correspondiente.

* La responsabilidad de cada texto es de su autor o autora. 
José Miguel Túñez López/Francisco Campos Freire/

Alba Silva Rodríguez: Editores

Prólogo: Rosario de Mateo Pérez

\section{Estudios sobre legislación, financiación e innovación en la Televisión Pública}

Para citar: Túñez-López, M., Campos-Freire, F. \& Silva, A. (Eds.) (2017). Estudios sobre financiación, legislación e innovación en la Televisión Pública. Cuadernos Artesanos de Comunicación, $\mathrm{n}^{\circ}$ 126. La Laguna (Tenerife): Latina.

Cuadernos Artesanos de Latina / 126

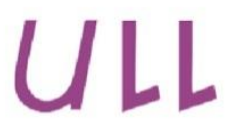

Universidad de La Laguna

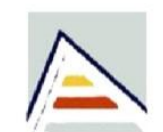

Universitat d'Alacant Universidad de Alicante

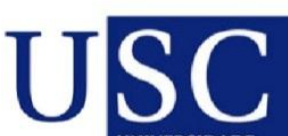

UNIVERSIDADE DE SANTIAGO DE COMPOSTELA

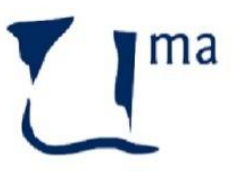

UNIVERSIDAD DE MALAGA

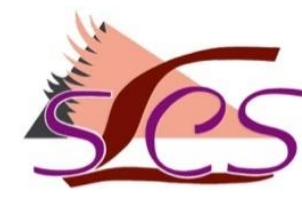

Sociedad Latina de Comunicación Social 
CAC 126 - Estudios sobre legislación, financiación e innovación en la Televisión Pública

Autor o coordinador | Precio social: 8,15€ | Precio en librería. 10,60€ |

Editores: Javier Herrero y Milena Trenta

Diseño: F. Drago

Ilustración de portada: Fragmento del cuadro Mujer con bernegal, de Pedro de Guezala (1958).

Imprime y distribuye: F. Drago. Andocopias S. L.

c/ La Hornera, 41. La Laguna. Tenerife.

Teléfono: 922250554 | fotocopiasdrago@,telefonica.net

Edita: Sociedad Latina de Comunicación Social - edición no venal - La Laguna (Tenerife), 2017 - Creative Commons

http://www.revistalatinacs.org/12SLCS/portada2014.html

Descargar en pdf:

http://www.cuadernosartesanos.org/\#126

Protocolo de envío de manuscritos:

http://www.cuadernosartesanos.org/protocolo.html

ISBN - 13: 978-62-2

DL: TF-954-2017

DOI: $10.4185 / \operatorname{cac} 126$ 


\section{Estudios sobre legislación, financiación e innovación en la Televisión Pública}

José Miguel Túñez López, Francisco Campos Freire y Alba Silva,

\section{Editores}

Este Cuaderno Artesano surge a partir de algunas de las mejores ponencias que han sido presentadas al VIII Congreso Internacional Latina en 2016 Del verbo al bit en la mesa de debate número 819: Gobernanza y transparencia de la radiotelevisión pública en la sociedad digital y en la mesa número 823: Comunicar televisión: transparencia, credibilidad, sostenibilidad y manejo de relaciones con la sociedad. Tambien incorpora resultados de investigaciones hasta ahora inéditos. Todos ellos suponen una interesante puesta en común sobre financiación, legislación e innovación en la gestión de televisores públicas, preferentemente en Europa.

Este libro se enmarca en las actividades de difusión del proyecto Indicadores de gobernanza, financiación, rendición de cuentas, innovación, calidad y servicio público de las RTV europeas aplicables a España en el contexto digital (Referencia CSO2015-66543-P) del Programa estatal de Fomento de la Investigación Científica y Técnica de Excelencia, subprograma estatal de Generación de Conocimiento del Ministerio de Economía y Competitividad de España, cofinanciado por el Fondo Europeo de Desarrollo Regional (FEDER) de la Unión Europea.

Palabras clave: televisión publica, gobernanza, transparencia, credibilidad, sostenibilidad, relaciones con la sociedad.

\section{Forma de citar este libro}

Túñez López, M.; Campos-Freire, F. y Silva Rodríguez A. (Eds.). (2017). Estudios sobre legislación, financiación e innovación en la Televisión Pública. Cuadernos Artesanos de Comunicación, cac126. La Laguna (Tenerife): Latina.

DOI: $10.4185 / \operatorname{cac} 126$ 


\section{Índice}

Prólogo: Cinco retos presentes y futuros del servicio audiovisual público europeo

Rosario de Mateo Pérez, Catedrática de Periodismo en la Universidad Autónoma de Barcelona.

1. Las reformas legislativas de los medios de servicio público en la Unión Europea

Tania Fernández-Lombao

2. La gobernanza en la radiotelevisión pública europea. El modelo español

Ana María López Cepeda

3. Public Value Test. La adaptación de la gobernanza a los nuevos medios

Marta Rodríguez Castro.

4. Competitividad de la televisión pública en la distribución de contenidos

Verónica Crespo-Pereira.

5. Programación de contenidos en las televisiones públicas y privadas europeas

Finocha Formoso Barro

6. Las técnicas inmersivas en televisiones públicas: aplicaciones y evolución

Sara Pérez Seijo, Francisco Campos Freire

7. Comunicación online y trafico web de las televisiones públicas en Europa

Miguel Túñez-López, Carmen Costa-Sánchez

8. Posicionamiento en Facebook de las televisiones autonómicas con lengua propia

Clide Rodríguez-Vázquez, Valentín-Alejandro Martínez-Fernández, María-Magdalena Rodríguez-Fernández, Oscar Juanatey- Boga .........143

9. Modelos de financiación de los canales de televisión pública en Latino América

Mónica López-Golán, Nancy Graciela Ulloa Erazo

Los autores y las autoras. 


\title{
Prólogo
}

\section{Cinco retos presentes y futuros del servicio audiovisual público europeo}

\author{
Rosario de Mateo Pérez \\ Universidad Autónoma de Barcelona
}

T OS ESTUDIOS, debates y noticias que se difunden en estos Lúltimos años de la segunda década del siglo XXI sobre la radiotelevisión pública en Europa giran en torno cinco grandes temas o retos, que podrían resumirse en uno solo consistente en la adaptación de este servicio audiovisual a la presente realidad social, económica, tecnológica, de consumo, acceso y competitividad de los medios de comunicación.

El modelo europeo de la radiotelevisión pública, nacida en el siglo XX y que cumplirá cien años en 2022 (BBC, Londres), ha cambiado mucho y tendrá que hacerlo todavía más para adaptarse a la realidad actual y a la nueva ecología de medios de comunicación social, dominada por una hiperfragmentación de la producción y una megaconcentración de plataformas de distribución de los contenidos audiovisuales. 
El primer cambio semántico de concepto lo consolidan las políticas europeas de la primera década de este siglo, a través de las Directivas 2007/65/CE y 2010/13/UE, al pasar de la denominación y descripción de la radiotelevisión a los servicios de comunicación audiovisual. El concepto de radiodifusión lineal se amplía al de todos los otros servicios de acceso no lineal que se han propagado y multiplicado. Esas dos directivas europeas, que inspiraron la Ley 7/2010 General del Audiovisual de España, están en revisión y abrirán a partir de 2017 el obligado proceso de transposición y reforma de la legislación nacional de los estados, entre ellas la española, que deberá ser aprobada antes de 2020.

Por lo tanto, en este ámbito audiovisual, la tercera y nueva década del siglo XXI tendrá que afrontar y arrancar con un nuevo marco regulador que comprenderá también a las plataformas de distribución de contenidos, nuevas formas de publicidad y el horizonte temporal de la televisión digital terrestre. La TDT, clave para la universalidad del servicio público, sólo tiene asegurado el uso de la banda sub 700 (470694Mhz) hasta 2030 porque ese espacio radioeléctrico lo requieren los operadores de telefonía para los servicios $5 \mathrm{G}$ y otros.

En ese mismo escenario temporal hay que incluir la eclosión del Brexit y la sustitución del Programa de Europa Creativa (que reemplazó al P. Media), aspectos ambos estrechamente ligados porque afectan al reparto de las ayudas a la producción y distribución audiovisual europea, así como al inevitable movimiento de las compañías satélites de la industria norteamericana, asentadas en Londres para beneficiarse de los fondos comunitarios. La política comunitaria de apoyo al audiovisual, desde la directiva de televisión sin fronteras de 1989, se asienta en las ayudas directas e indirectas a la producción cinematográfica y a la protección de la emisión de contenidos europeos.

La realidad europea de acceso a la distribución de servicios audiovisuales es muy competitiva y diversa, penetrada por marcas extranjeras y concentrada por 44 empresas matrices, 26 de ellas de la Unión Europea, 15 de Estados Unidos y tres de otros países (MAVISE, 2017). Solo uno de cada 10 canales extranjeros que se difunden en la UE es de servicio público. Cuando el Reino Unido salga de la Unión Europea esta correlación se romperá porque Inglaterra es 
la productora de 758 canales que se difunden en la mayor parte del resto de los mercados de los otros países europeos.

Los otros grandes países distribuidores de canales son República Checa (91 canales), Francia (77), Países Bajos (73), España (57) y Luxemburgo (56). Las compañías de servicios bajo demanda ajenas a Europa asientan sus plataformas distribuidoras principalmente en Reino Unido (152), Países Bajos (64), Irlanda (30), Suecia (16) y República Checa (15).

Las multinacionales distribuidoras de canales de televisión organizan su política europea de difusión de servicios audiovisuales en base a los grandes países y a clústeres de mercados de proximidad idiomática o cultural (bálticos, nórdicos, ibéricos o centroeuropeos). En 10 países europeos, donde se distribuyen entre 300 y 600 canales audiovisuales extranjeros, su audiencia acumulada absorbe entre el 10 y el 30 por ciento de la cuota global de cada uno de esos mercados.

Esta situación de penetración y competición pone de relieve la discusión tanto de la eficacia como de la necesidad de las políticas europeas y nacionales, así como la reflexión contextual sobre el servicio audiovisual público ante este panorama, en el que hay que situar también las nuevas formas de acceso, regulación y consumo que propician las tecnologías digitales convergentes, así como los cambios sociales, demográficos y políticos que se están produciendo en los distintos países.

\section{Cinco retos del SAP}

Por eso pensamos que, como introducción a este volumen de estudios y reflexiones sobre la radiotelevisión pública europea, era pertinente poner encima de la mesa de discusión también cinco temas o retos del servicio audiovisual público en el contexto actual. No hay espacio ni es el objetivo de esta presentación analizar cada uno de ellos, sino simplemente enunciarlos para alimentar su debate y discusión.

El debate no se cubre ni se pretende agotar con los aspectos abordados en esta publicación, sino que quiere quedar vivo y abierto a todos y todas, pero en particular también para otras sesiones y publicaciones de Latina. Con esta sugerencia planteamos esos retos en forma de 
preguntas abiertas de investigación para tratar de ser fieles al objetivo que abarca la iniciativa de esta investigación:

- ¿Está en riesgo hoy en día la supervivencia del servicio audiovisual público en el contexto de una nueva ecología digital de medios?

- ¿Es sostenible la financiación del servicio audiovisual público en España y en el resto de los países europeos?

- ¿Es necesario reformar el sistema de gobernanza para adaptarlo a las exigencias sociales y para mejorar su función, representación, transparencia, rendición de cuentas y reputación?

- ¿Las organizaciones prestadoras del servicio audiovisual público deben afrontar procesos de innovación para afrontar los retos de futuro de la próxima década?

- ¿La comunicación del valor del servicio audiovisual público necesita la evaluación de su impacto social y del establecimiento de indicadores integrados, cuantitativos y cualitativos, para medirlo?

El proyecto de investigación (referencia CSO2015-66543-P) del Programa estatal de Fomento de la Investigación Científica y Técnica de Excelencia, subprograma estatal de Generación de Conocimiento del Ministerio de Economía y Competitividad de España, cofinanciado por el Fondo Europeo de Desarrollo Regional (FEDER) de la Unión Europea, que motiva esta publicación y el equipo de trabajo que forma parte de él tienen como objetivo el estudio de un modelo de "Indicadores de gobernanza, financiación, rendición de cuentas, innovación, calidad y servicio público de las RTV europeas aplicables a España en el contexto digital”.

\section{Contenidos de la publicación temática}

Este Cuaderno Artesano forma parte de las actividades de divulgación del proyecto mencionado y selecciona algunas de las mejores ponencias presentadas al Congreso Internacional Latina en 2016 pero también incorpora trabajos aún inéditos que globalmente, suponen una valiosa aportación sobre el estado de la cuestión en torno a la financiación, la legislación y la innovación en la gestión de televisores públicas. 
El primero de los trabajos, la profesora Tania Fernández Lombao aporta una revisión de los cambios que se han producido en los últimos diez años en las leyes estatales de radiodifusión púbica a partir de la Directiva Europea de Medios Audiovisuales de 2007, por la que se modificaron las disposiciones legales, reglamentarias y administrativas de los estados miembros relativas al ejercicio de las actividades de radiodifusión televisiva.

Este análisis, que revisa los ajustes legislativos en cada estado miembro, se complementa en el segundo capítulo con la revisión de marco legal europeo sobre gobernanza y las reflexiones de Ana López-Cepeda sobre como el conjunto de mecanismos que determinan la organización y estructura de una entidad se vislumbra como pilar fundamental para que las emisoras públicas de radiodifusión se enfrenten a un escenario cambiante.

Marta Rodríguez-Castro recoge el testigo en el capítulo 3 y revisa las denominadas pruebas de valor público, Public V alue Test, que han sido desarrolladas en el Reino Unido en 2007 y adaptadas por doce países siguiendo las recomendaciones de la Comisión Europea.

La panorámica que supone este Cuaderno continúa con la revisión de la evolución de los contenidos a partir del nacimiento de nuevas cadenas en el proceso de digitalización de la señal. Finocha Formoso, profesora en la Universidade de Coruña concluye que el avance esperado por ese aumento de canales se ha quedado mayoritariamente en técnicas de programación orientadas a distribuir repeticiones de contenidos para poder emitir más barato.

Entre estas variadas innovaciones en contenidos, las técnicas inmersivas han irrumpido recientemente como posibilidad de mayor implicación con la audiencia. Francisco Campos y Sara Pérez Seijo, de la Universidade de Santiago de Compostela, analizan cómo esta corriente de periodismo inmersivo surgida en septiembre de 2014 y el calado de las técnicas 360 grados y de realidad virtual en las radiodifusoras públicas europeas. 
Los profesores Carmen Costa y Miguel Túñez analizan las páginas web de los principales canales públicos de Europa y se detienen en revisar el manejo de las redes sociales generalistas en las que apenas hay actitudes proactivas y de participación 2.0 por parte de las cadenas públicas que siguen manteniendo una comunicación unidireccional con aparentes simulaciones de retorno comunicativo que casi nunca acaban por ser un dialogo con las audiencias.

En el papel de las redes profundizan, desde la Universidade de Coruña, los profesores Clide Rodríguez-Vázquez, Valentín MartínezFernández, Magdalena Rodríguez-Fernández y Oscar Juanatey- Boga que revisan los contenidos, la interactividad y la visibilidad en Facebook de los perfiles de radiodifusoras públicas españolas con lengua propia.

Finalmente, Mónica López y Nancy Ulloa analizan la diversidad de modelos de financiación de canales de titularidad pública que existen en Latinoamérica y realizan, tanto desde el punto de vista de la propiedad como de la financiación, una valoración general de las situaciones estructurales de las emisoras y de su relación con los índices de audiencias.

\section{Referencias bibliográficas}

De Mateo Pérez, Rosario y Bergés Saura, Laura (2009): Los retos de las televisiones públicas: financiación, servicio público y libre mercado. Zamora: Comunicación Social.

Campos Freire, Francisco (2015). Estrategia, gobernanza y financiación de los medios audiovisuales públicos autonómicos ante el 2020. En Nerekan Umaran, Amaia; Casado, Miguel Ángel; Zallo, Ramón; y Miguel de Bustos, Juan Carlos. Comunicación de proximidad: cada vez más lejos. Marco, experiencias y regulación. Bilbao: Universidad del País Vasco.

COIT (2017). Televisión Abierta. Situación y tendencias de futuro de la TDT. Coordinación de Eladio Gutiérrez. Madrid: Colegio Oficial de Ingenieros de Telecomunicación. 
EAO (2016). Yearbook 2015. Key Trends. Television, cinema, video on demand audiovisual services. The Pan-European Picture. Estrasburgo: European Audiovisual Observatory.

MAVISE (2017). Audiovisual Services in Europe. Focus on services targeting other countries. Estrasburgo: European Audiovisual Observatory

Marzal Felici, Javier; Izquierdo Castillo, Jéssica; Casero Ripollés, Andreu, eds. (2015): La crisis de la televisión pública. El caso de RTVV y los retos de una nueva gobernanza. Barcelona: Aldea Global.

Cómo citar: De Mateo, R (2017). Cinco retos presentes y futuros del servicio audiovisual público europeo. En Túñez López, M.; Campos-Freire, F. y Silva Rodríguez A. (Eds.). Estudios sobre financiación, legislación e innovación en la Televisión Pública. Cuadernos Artesanos de Comunicación, cac126, pp 07-13. La Laguna (Tenerife): Latina. DOI: $10.4185 / \operatorname{cac} 126$ 



\title{
Las reformas legislativas de los medios de servicio público en la Unión Europea
}

\author{
Tania Fernández-Lombao \\ Universidade Santiago de Compostela
}

Cómo citar: Fernández-Lombao, T. (2017). Las reformas legislativas de los medios de servicio público en la Unión Europea. En Túñez López, M.;

Campos-Freire, F. y Silva Rodríguez A. (Eds.). Estudios sobre financiación, legislación e innovación en la Televisión Pública. Cuadernos Artesanos de Comunicación, cac126, pp 15-39. La Laguna (Tenerife): Latina.

DOI: $10.4185 / \operatorname{cac} 126$

L

OS MEDIOS de servicio público europeos se regulan y coordinan a través de la Directiva Europea de Medios Audiovisuales de 2007, por la que se modificaron las disposiciones legales, reglamentarias y administrativas de los estados miembros relativas al ejercicio de las actividades de radiodifusión televisiva, que conformaban la Directiva de Televisión sin Fronteras. La transposición de esta directiva europea ha provocado notables cambios en los últimos años en las leyes estatales de las radiotelevisiones públicas de los estados miembros, que afectan sobre todo a la publicidad y a los servicios bajo demanda. El objetivo de este capítulo es presentar los cambios en cada Estado miembro.

Palabras clave: medios de servicio público; reformas legislativas; Unión Europea. 
Los medios de servicio público europeos se regulan y coordinan a través de la Directiva Europea de Medios Audiovisuales, del 11 de diciembre de 2007, por la que se modificaron las disposiciones legales, reglamentarias y administrativas de los Estados miembros relativas al ejercicio de las actividades de radiodifusión televisiva, que conformaban la Directiva de Televisión sin Fronteras, vigente entre 1989 y 2007, y la revisión de 2009 de la Comunicación de 2001 sobre la aplicación de las normas comunitarias para las ayudas estatales al Servicio Público de Radiodifusión. La Directiva de 2007 fue revisada en 2010 y esta última versión está en proceso de reforma en 2016.

Con la Directiva de 2007 se diferencia por primera vez en Europa los servicios lineales -emisión continuada de programas de flujo- de los no lineales -vídeo y televisión bajo demanda, de catálogo o a la carta-. Los primeros se refieren a la comunicación audiovisual ofrecida por un prestador para el visionado simultáneo a un número indeterminado de espectadores potenciales, mientras que los segundos se componen de una oferta de contenidos elaborados para el visionado en el momento elegido por el usuario, a título individual y sobre la base de un catálogo. Se excluyen expresamente en este apartado las versiones electrónicas de periódicos, revistas, transmisiones de audio y servicios de radio.

La nueva normativa comunitaria se asienta en unos principios orientados a favorecer la libre competencia, la separación de la publicidad del contenido editorial, la protección de los menores, la prohibición de la incitación al odio, la defensa de los consumidores, el pluralismo en los medios de comunicación, la lucha contra la incitación al odio racial y religioso, la gestión de nuevas formas de publicidad, la promoción de obras europeas y producciones independientes y recomendaciones para la garantía de la independencia.

La publicidad se ve limitada en términos horarios, es decir, la Directiva elimina el tope diario y mantiene la limitación del veinte por ciento de anuncios de publicidad televisiva y de televenta por cada hora natural. Otra de las grandes novedades es la autorización con respecto al emplazamiento de productos en todos los programas, excepto los informativos, infantiles, espacios de consejos y documentales, aunque 
esta modalidad deberá ser siempre advertida como "emplazamiento del producto".

Con la finalidad de garantizar el pluralismo de los medios, se aplican tres medidas: la obligación de cada Estado miembro de reforzar la independencia de la autoridad de regulación nacional encargada de poner en práctica las disposiciones de la Directiva; el derecho de los organismos de radiodifusión televisiva de emplear los extractos breves de forma no discriminatoria en el acceso a la información de interés general; y la promoción de los contenidos realizados por empresas de producción audiovisual independientes de Europa.

La diversidad cultural se promueve con la reafirmación del compromiso a favor de las obras audiovisuales europeas al permitir a los Estados miembros imponer a los organismos de radiodifusión televisiva cuotas de contenido que las favorezcan y que permitan la estimulación de la producción de contenidos independientes.

Con el fin de armonizar la legislación europea con el panorama tecnológico emergente, en 2010 se aprobó la revisión de la Directiva Europea de Medios Audiovisuales. El documento nació para simplificar el contexto normativo de la radiodifusión con la flexibilización en el encaje de la publicidad, introducir reglas mínimas para los servicios de comunicación audiovisual no lineales, garantizar el principio de reglamento por parte del país de origen de los servicios difundidos para terceros países y apoyar la neutralidad tecnológica independientemente del soporte de difusión.

Con esta normativa, las reglas dejan de ser aplicables en función de la plataforma de entrega para serlo en base a la naturaleza del servicio, de modo que solo la futura legislación hará la distinción entre servicios lineales y no lineales. Por otra parte, establece que los Estados miembros adoptarán medidas para velar por los servicios bajo demanda ofrecidos por los prestadores bajo su jurisdicción que puedan dañar gravemente el desarrollo de los menores. En materia de publicidad, los operadores dejan de estar obligados a respetar el intermedio de veinte minutos entre pausas para pasar a escoger el momento en el que emitir sus anuncios. En cuanto a las restricciones, 
las películas, los programas infantiles y los informativos solo podrán ser interrumpidos cada treinta y cinco minutos. De todos modos, el límite del veinte por ciento de publicidad por hora sigue siendo aplicable, excepto en telepromociones y televenta.

\section{La normativa europea que está por venir}

A día de hoy se resuelve un debate sobre la actualización de la modificación de 2010 de la directiva inicial de 2007, en torno a ocho ejes esenciales. El primero de ellos es el relativo al principio de país de origen (PPO), que se mantendrá para facilitar a los miembros simplificar las normas que determina el país que tiene jurisdicción sobre un proveedor y clarificar los procedimientos de cooperación entre los Estados. Sobre las comunicaciones comerciales, la Comisión trabaja en mantener el límite del veinte por ciento de la programación para publicidad, pero con flexibilidad para que los medios decidan cuándo y dónde ubicarla dentro de sus parrillas.

El tercer punto está relacionado con la promoción de la producción europea, para la que se prevén nuevas normas para servicios bajo demanda. Asimismo, las plataformas para compartir contenido audiovisual serán competencia de la directiva siempre y cuando se trate de luchar contra la incitación al odio y la difusión de contenidos no aptos para menores. En este apartado, se aboga por la corregulación entre industria y comercio electrónico.

Precisamente las líneas de trabajo cinco y seis se refieren, por un lado, a la protección de menores con una simplificación de las normas -todo lo que sea perjudicial debe restringirse independientemente del servicio y la plataforma- al tiempo que se apuesta por medidas como códigos PIN y encriptación. Por otra parte, se profundiza en la prohibición de la incitación a la violencia y al ocio.

En lo que afecta a la regulación, el debate se centra en las acciones para velar que la independencia de los reguladores esté reglada y puedan desvincularse del gobierno y la industria. Además, se sitúa en el centro del tablero a los ERGA (European Regulators Group for Audiovisual 
Media Services) como elementos esenciales para la preservación del mercado interior.

El Grupo de Alto Nivel para Medios Libres y Plurales como garantía de la Democracia reconoció en 2013 el esfuerzo armonizador de la Directiva, pero resaltó que continúan existiendo diferencias estatales, como son las leyes de difamación, las legislaciones sobre fiscalidad, subvenciones financieras y protección de datos. Asimismo, reclamó uniformidad con respecto a la composición y el rol de los órganos reguladores, en tanto que la Directiva tan solo requiere la cooperación de los reguladores independientes.

La existencia de divergencias entre las normas propias de cada uno de los Estados miembros, entre ellas y con respecto a la normativa europea, provocan que el marco legislativo no sea más que un espejo de sombras desdibujadas que afectan a las actividades transfronterizas y sobre todo a los servicios no lineales, menos regulados por ser más recientes.

Gilliam Doyle criticó de esta normativa la imposición de las mismas normas a los servicios no lineales que a las emisoras convencionales en tanto que creará, según advirtió, incertidumbres que frenarán la inversión en servicios de nuevos medios, poniendo a los actores europeos en desventaja con respecto a los Estados Unidos y Japón. Por otro lado, reprochó la voluntad liberal de la normativa por flexibilizar algunas restricciones de publicidad y emplazamiento del producto frente a la Directiva de Televisión sin Fronteras (Doyle, 2012). El descontento también se asocia a la desregulación y en el apoyo a la industria y al comercio en lugar de buscar la sintonía en cuestiones culturales y ciudadanas (Wheeler, 2007).

\section{Legislación para medios públicos en los estados miembros de la UE}

A partir de 2007 se produjo un goteo continuo de nuevas leyes reguladoras de la radiotelevisión pública en los Estados miembros de 
la Unión Europea con la única finalidad de lograr la transposición de los dictámenes de la Directiva Europea de Medios Audiovisuales.

Esta fecha coincide con el inicio de la crisis económica y financiera que condujo a numerosas corporaciones europeas a tomar decisiones caracterizadas por la austeridad para paliar las dificultades de antemano, sin prever las consecuencias. Esas nuevas normativas también fueron aprovechadas, con carácter general, para revisar las legislaciones de los medios públicos e incluso modificar sus estructuras organizativas y reordenar la financiación.

Entre las acciones más destacadas se sitúa la supresión de la publicidad de la televisión pública estatal en países como Francia y España o las restricciones en sus horarios de emisión. Además, se implantaron nuevas modalidades de emplazamiento del producto, como se contemplaba en la Directiva Europea de Medios Audiovisuales de 2007.

En tanto en cuanto son los Estados miembros los encargados de llevar a la práctica la Directiva, Michalis dispone que la Unión Europea es la principal responsable de las consideraciones de la política económica, mientras que los Estados conservan la responsabilidad de los objetivos de servicio público. En consecuencia, advierte que son las normativas estatales las que han de equilibrar los objetivos democráticos, sociales y culturales, pero siendo la UE la que supervise que el balance sea correcto (Michalis, 2011).

Las leyes estatales de los medios de servicio público de los Estados miembros de la Unión Europea experimentaron notables cambios en los últimos años que afectan sobre todo a la publicidad y los servicios bajo demanda, debido a la transposición de la Directiva Europea de Medios Audiovisuales. Buena parte de las reformas se produjeron entre 2008 y 2010, con el fin de ajustarse a las normativas europeas y afianzar la figura de los consejos de control y supervisión.

Reino Unido, Alemania, España, Francia, Italia, Portugal, Bulgaria y Hungría desarrollaron nuevas normativas con el fin de actualizar sus textos con respecto a los nuevos servicios digitales de oferta de 
contenidos, mientras que otros, como Rumanía, aprobaron leyes que se centran en la independencia y la prohibición de la censura. Asimismo, algunos países han optado por crear nuevos órganos de regulación, supervisión y control a partir de 2009, mientras que otros, como Reino Unido, ya se habían dotado de ellos con mucha anterioridad.

La protección de los menores y el pluralismo son conceptos repetidos en todas las leyes, con posturas más contundentes que las del pasado. En términos de transparencia, algunas normativas obligan a publicar la información concerniente a la gestión en la página web, como la portuguesa y la general de España referente a todo tipo de Administración pública.

\section{Metodología}

El objetivo de esta investigación es analizar las últimas reformas legislativas de todos los Estados miembros de la Unión Europea en lo relativo al funcionamiento de los medios de servicio público. El estudio se circunscribe al espacio temporal de la última década, para abarcar por completo el periodo posterior a la entrada en vigor en 2007 de la Directiva Europea de Medios Audiovisuales.

La metodología utilizada en esta investigación es el estudio de contenido de las leyes de comunicación y de radiotelevisión pública de cada uno de los estados miembros de la Unión Europea. La tabla de análisis se centra en dos elementos: la fecha de la reforma legislativa y los argumentos que la motivaron.

El objetivo es comparar el modo de proceder de los medios de servicio público europeos a la hora de implementar la Directiva Europea de Medios Audiovisuales, de obligado cumplimiento, y desgranar el grado de ambición en cada caso.

La muestra del estudio abarca veintisiete de los veintiocho estados miembros de la Unión Europea, es decir, todos excepto Luxemburgo, por carecer de una radiotelevisión con las características propias de los medios de servicio público. 


\section{Tabla 1. Reformas legislativas que afectan a los medios de servicio público en la última década en los estados de la UE}

\begin{tabular}{|c|c|c|c|}
\hline \multicolumn{4}{|c|}{ REFORMAS LEGISLATIVAS } \\
\hline Corporación & Estado & Año & Motivo \\
\hline ZDF/ARD & Alemania & 2016 & $\begin{array}{l}\text { Publicidad y producción de } \\
\text { contenidos }\end{array}$ \\
\hline ORF & Austria & 2012 & $\begin{array}{l}\text { Gobernanza y difusión de } \\
\text { contenidos }\end{array}$ \\
\hline RTBF/VRT & Bélgica & 2009 & Transposición Directiva Europea \\
\hline BNT & Bulgaria & 2009 & Transposición Directiva Europea \\
\hline $\mathrm{CyBC}$ & Chipre & 2013 & Transposición Directiva Europea \\
\hline HRT & Croacia & 2010 & Mandato marco y TVP \\
\hline DR & Dinamarca & 2010 & Transposición Directiva Europea \\
\hline RTS & Eslovaquia & 2011 & Financiación \\
\hline RTVS & Eslovenia & 2016 & Difusión de contenidos \\
\hline RTVE & España & 2010 & Transposición Directiva Europea \\
\hline ERR & Estonia & 2010 & Transposición Directiva Europea \\
\hline YLE & Finlandia & 2012 & Financiación y TVP \\
\hline FT & Francia & 2009 & Publicidad y financiación \\
\hline ERT & Grecia & 2013 & Creación nuevo medio público \\
\hline MTV & Hungría & 2010 & Transposición Directiva Europea \\
\hline RTÉ & Irlanda & 2009 & Transposición Directiva Europea \\
\hline RAI & Italia & 2010 & Transposición Directiva Europea \\
\hline $\mathrm{LTV}$ & Letonia & 2012 & Creación nuevo medio público \\
\hline LRTV & Lituania & 2013 & Financiación \\
\hline PBS & Malta & 2011 & Transposición Directiva Europea \\
\hline NPO & Países Bajos & 2014 & Producción de contenidos \\
\hline TVP & Polonia & 2012 & Transposición Directiva Europea \\
\hline RTP & Portugal & 2011 & Transposición Directiva Europea \\
\hline $\mathrm{BBC}$ & Reino Unido & 2009 & Transposición Directiva Europea \\
\hline CT & Rep. Checa & 2016 & Cine \\
\hline TVR & Rumanía & 2011 & Transposición Directiva Europea \\
\hline SVT & Suecia & 2011 & Transposición Directiva Europea \\
\hline
\end{tabular}

Fuente: Elaboración propia

A partir de los datos de la investigación, se presentarán los resultados con la división de las corporaciones en dos bloques, aquellas que 
aprobaron reformas de sus normativas entre 2007 y 2011 y las que lo hicieron desde ese año hasta 2016. Se parte de la premisa de que las reformas más antiguas tenían por objeto la transposición de la directiva europea, mientras que las más actuales, una vez asumidos los cambios dictados por Europa, avanzan en novedades de gestión y producción o difusión de contenidos.

Las novedades legislativas se resumen en la tabla1.

\section{Resultados}

Las reformas legislativas de dieciséis de los estados miembros investigados son del año 2011 o anteriores, con motivaciones, en prácticamente todos los casos, relativas a la transposición de la Directiva Europea de Medios Audiovisuales. El resto de modificaciones en normativas se produjeron después de ese año e incluso tres de ellas este 2016.

\subsection{Reformas acometidas entre 2009 y 2011}

En Bélgica, el último Decreto de Medios de la comunidad francesa fue publicado el 18 de marzo de 2009 y representó la transposición de la Directiva Europea de Medios Audiovisuales, que se adaptó para la comunidad flamenca por un decreto del mismo mes. El documento de la comunidad francesa ya había anticipado esta normativa al distinguir de antemano los servicios lineales y no lineales en el congreso de gestión de la radiotelevisión pública RTBF en 2006 y en la legislación de la publicidad digital. Este decreto presenta nuevas definiciones y distingue los regímenes de ambos modelos de servicio, por lo que precisa el criterio de responsabilidad editorial y apuntala mecanismos de corregulación con un refuerzo del panel de opinión del Consejo Superior del Audiovisual.

El decreto especifica que la publicidad no superará el veinte por ciento de cada hora de emisión, pero no establece condiciones para los anuncios en radio. La normativa contempla el patrocinio y la colocación de productos y prohíbe interrumpir programas religiosos y filosóficos. Además, la RTBF también responde al texto de un decreto 
de 1997, en el que se especifica su misión y su potestad para tomar participación directa $\mathrm{o}$ indirecta en sociedades, asociaciones $\mathrm{O}$ instituciones de derecho público o privado, belgas o extranjeras siempre que sean compatibles con su misión de servicio público.

La corporación búlgara BNT se regula por medio de la Ley de Comunicaciones de 1998, que sufrió varias modificaciones hasta la enmienda de 2009 para adaptarse a la Directiva Europea de 2007. Este último borrador hace mención por primera vez en este Estado a los servicios de comunicación bajo demanda e introduce la corregulación como mecanismo alternativo de gestión. Lo mismo sucedió en el caso de los medios de servicio público de Dinamarca -DR- un año después, en 2010, con la reforma de la Ley de Televisión y Radio para la transposición de las encomiendas europeas.

La Ley de Medios Electrónicos de 2010 de Croacia adoptó las disposiciones de la Directiva de 2007 para referirse por primera vez a los servicios de comunicación bajo demanda y regular la emisión de comunicaciones comerciales, patrocinios y colocación de productos. La normativa contempla la promoción de programas de radio y televisión sin fines de lucro impulsados por otras instituciones o asociaciones.

El Parlamento croata aprobó en diciembre de 2010 la nueva Ley de Radio y Televisión de Croacia, en la que se estipula la creación de la figura del contrato entre la corporación pública y el Estado por un periodo de cinco años, en el que se estipularán los servicios y la financiación. En aras de más transparencia, exige la publicación en la web de la HRT del contrato, el programa de trabajo anual y el plan financiero de cada ejercicio.

Sin referirse explícitamente al Test de Valor Público, la normativa contempla un mecanismo de evaluación para la introducción de nuevos Medios audiovisuales, que se centra en el análisis de las condiciones del mercado y la competencia y el lanzamiento de una consulta pública, con cuyos resultados la dirección general debe presentar una propuesta. 
El Parlamento eslovaco aprobó en octubre de 2011 una enmienda a la Ley de Radio y Televisión, de 2010, para diseñar un nuevo modelo de financiación de la corporación pública RTS, nacida ese mismo año por la fusión de las compañías de radio y televisión. En concreto, certificó la supresión de tasas de licencia y los ingresos procedentes de los contratos estatales a partir de 2013, para depender exclusivamente de las aportaciones procedentes de los presupuestos del Estado, con una cantidad mínima garantizada de 90 millones de euros, a representar el 0,142 por ciento del PIB del país. Por otra parte, sitúa el límite diario de publicidad en un uno por ciento del total de la programación, que se incrementa hasta el cinco por ciento para los anuncios de televenta.

En España, el Parlamento aprobó en 2010 la Ley General de Comunicación Audiovisual para la transposición de la directiva europea de 2007. El texto presenta como principal novedad la creación del Consejo Estatal de Medios Audiovisuales como autoridad independiente supervisora y reguladora de la actividad de los medios públicos para velar por el cumplimiento del libre ejercicio de la comunicación audiovisual, la transparencia, el pluralismo, la independencia y la imparcialidad. Este organismo fue sustituido en 2013 por la Comisión de Telecomunicaciones y Audiovisual de la Comisión Nacional de los Mercados de la Competencia.

En el apartado de reglas básica, presta atención a la esponsorización, la publicidad y el emplazamiento del producto y establece que los prestadores podrán emitir contenidos publicitarios durante doce minutos cada hora de emisión. Por otra parte, define la televisión de movilidad, que necesitará de licencia, y la de alta definición, que podrán emitir los prestadores que ya gozan previamente de permiso.

Asimismo, promueve reglas para la emisión en abierto de todos o parte de los contenidos considerados de interés público. Por cuanto a la corporación pública RTVE, certifica que seguirá obteniendo financiación de la subvención pública y a través de las tasas de los operadores de telecomunicaciones que ofrecen medios audiovisuales y las televisiones comerciales que emiten contenidos de pago o gratuitos vía cable, satélite o redes terrestres. 
La Ley de la Radio y la Televisión de Titularidad Estatal de 2006 atribuye a RTVE la gestión directa de los servicios públicos de radiodifusión y televisión. El texto estipula que sus responsabilidades son promover el conocimiento y la difusión de los principios constitucionales, garantizar la información objetiva, facilitar el debate democrático y libre de expresión de opiniones, además de promover la participación, la cohesión social y la pluralidad y diversidad lingüística y cultural del Estado.

La normativa compromete a RTVE a participar en el proceso tecnológico con el uso de tecnologías y vías de difusión interactivas en su programación. Además, impide que la corporación acuda a terceros para la producción y edición de los programas informativos.

El Parlamento español aprobó en 2009 la Ley de Financiación de la Corporación de Radio y Televisión Española para la supresión de la publicidad a partir del uno de enero de 2010.

El texto dispone que la financiación procederá de compensaciones consignadas en los Presupuestos Generales del Estado; un porcentaje del ochenta por ciento sobre el rendimiento de la tasa sobre reserva de dominio público radioeléctrico, la aportación del 0,9 por ciento de los ingresos brutos que deben realizar los operadores de telecomunicaciones de ámbito geográfico estatal o superior al de una Comunidad Autónoma y la cuota del 3 por ciento de los ingresos brutos de las concesionarias y prestadoras de servicio de televisión de ámbito estatal y el 1,5 por ciento de las de acceso condicional o de pago. En todos los casos se establecen límites máximos de ingreso. Además, la corporación puede obtener ingresos del ejercicio de sus actividades, incluyendo la comercialización de sus contenidos a excepción de la publicidad.

Esta normativa también establece obligaciones de servicio público relativas a la subtitulación del noventa por ciento de la programación y la emisión de al menos diez horas semanales de interpretación con lengua de signos y otras diez audiodescritas. El treinta por ciento de la programación debe estar dirigida a menores, mientras que el sesenta por ciento de la franja de máxima audiencia a cine. 
El mismo año, el Parlamento de Estonia aprobó en 2010 la Ley de Servicios Audiovisuales, como medio para el desarrollo de la Directiva Europea de 2007. De esta forma, asume una postura más liberal con respecto a la publicidad mientras que también se simplifica el acceso a la obtención de licencias de emisión. No obstante, no se contempla la creación, como recomienda la normativa europea, de ningún cuerpo regulador independiente $y$ se apuesta por un modelo de autorregulación.

La Autoridad Reguladora de Correos y Comunicaciones Electrónicas de Francia aprobó en 2007 la Ley de modernización de la difusión audiovisual $y$ de la televisión del futuro, en la que se diseñó el calendario para la supresión de la televisión analógica, cuya fecha final fue noviembre de 2011, aunque con la concesión de ventajas a los operadores analógicos de ámbito estatal con asignación de nuevos canales. Con respecto a la alta definición y la recepción de televisión móvil, prevé la expedición de permisos por editor y no por distribuidor, sin alterar lo estipulado en la normativa de 1986, en tanto que se considera que es el mejor sistema para garantizar el pluralismo en la oferta de servicios.

Francia también dio luz verde en marzo de 2009 la Ley relativa a la Comunicación Audiovisual y al nuevo Servicio Público de Televisión, cuyos ejes fundamentales fueron la supresión de la publicidad en los canales públicos y la reorganización institucional en una única corporación de capital íntegramente estatal. Asimismo, refuerza el canon o "contribución a la difusión pública", de 120 euros en 2010 y la previsión de actualización según el índice de precios al consumo.

Para afrontar la supresión de la publicidad y asegurar la financiación permanente y sostenible del servicio público, se determina la creación de un impuesto sobre la difusión publicitaria por los canales de televisión privados, que se aplica sobre una base imponible calculada a partir de sus ingresos publicitarios, sin grabar directamente al usuario. También se crea una tasa sobre los servicios ofertados por los operadores de telecomunicaciones de Francia, con un tipo porcentual del 0,9 por ciento. 
El Parlamento húngaro adoptó en 2010 la Ley de Servicios de los Medios de Comunicación y Medios de Masas, que sustituyó a la Ley de Radio y Televisión de 1996, con el objetivo de completar la reforma impulsada por la Directiva Europea de Medios Audiovisuales. Esta normativa otorgó relevancia a los medios bajo demanda y dio luz verde a la colocación del producto en cuanto a la publicidad.

En febrero de 2013, el gobierno presentó otro proyecto de ley para dar respuesta a las demandas del Consejo de Europa sobre los medios húngaros y exigir una cobertura equilibrada aplicable a todos los servicios.

En el caso irlandés, el Parlamento aprobó en octubre de 2009 la Ley de Televisión, que prevé el suministro de contenidos digitales, la emisión de servicios a las comunidades irlandesas residentes fuera de la isla y la discontinuidad de ciertos servicios de televisión emitidos de forma analógica. Las obligaciones de la radiodifusión se concretan en prohibir la publicidad que se corresponda con propaganda política, religiosa o relacionada con conflictos labores.

La Ley de Televisión de 2003 marcaba el objetivo de destinar al menos el cinco por ciento de los ingresos netos recaudados a través del cobro del canon para financiar programas de televisión y radio y otros proyectos relacionados con la cultura irlandesa, el patrimonio y la experiencia histórica y aquellos destinados a la alfabetización de adultos y los elaborados en lengua gaélica.

Malta aprobó en 2010 una actualización de su ley de radiotelevisión para transponer el contenido de la Directiva Europea de Medios Audiovisuales. En la misma línea, Portugal dio luz verde en 2011 a la nueva Ley de Televisión de 2011 con la voluntad de acometer la transposición de la directiva europea e introducir cambios con respecto a la normativa de 2007 en materia de propiedad de medios, publicidad -con la exigencia de un intervalo mínimo de veinte minutos entre dos espacios de anuncios y transparencia. Asimismo, establece que la Entidad Reguladora para la Comunicación Social debe promover mecanismos de autorregulación y corregulación entre los operadores. 
En materia de publicidad admite lo establecido en la Directiva Europea de 2007 sobre los anuncios comerciales, el patrocinio y el emplazamiento de productos, siempre con identificación expresa de cada una de estas fórmulas. También se permite la inclusión de funcionalidades en espacios publicitarios insertados en servicios bajo demanda que permitan la transferencia de un ambiente interactivo que contenga publicidad, excepto en programas infantiles y en los cinco minutos previos y posteriores a su transmisión.

Por cuanto a los medios de servicio público, la televisión y la radio se regulan a través de dos leyes del año 2010, enmendadas en 2014 para ampliar el periodo de concesión a catorce años. Se incluye esta normativa en las reformas anteriores a 2012, en tanto que la enmienda de 2014 no es relevante en cuanto al funcionamiento o gestión del ente. En esta ley se da cuenta de las características temáticas que han de cumplir los productos y servicios ofrecidos y los procedimientos para concursos públicos, también en el ámbito digital.

El Parlamento británico aprobó en julio de 2003 la Ley de Comunicaciones, cuyo principal eje fue la creación de la Oficina de Comunicaciones (OFCOM), para asumir las labores de supervisión del servicio televisivo y de las telecomunicaciones además de convertirse en la entidad responsable de la concesión de licencias. En esencia, consistió en la puesta en marcha de un órgano aglutinador de todas las instituciones de control audiovisual que existían hasta el momento. Asimismo, todos los operadores fueron obligados a elaborar anualmente una declaración de planificación, con los planes para conseguir sus objetivos.

En 2009 se aprobó la Regulación de Medios Audiovisuales para la transposición de los enunciados de la Directiva Europea de Medios Audiovisuales. La principal novedad fue la definición de los servicios no lineales o bajo demanda, la concreción los mecanismos de actuación que les afectan y la creación de los cuerpos de regulación.

La corporación de radiodifusión pública británica, BBC, se rige por lo expuesto en la Carta Real, un documento que establece los fines públicos y el concepto de independencia del medio de servicio público. 
La Secretaría de Estado de Medios presentó al Parlamento en mayo de 2016 el White Paper (Libro Blanco) y abrió nuevos debates a través del Green Paper sobre las bases de la novena Carta Real. Desde el punto de vista del funcionamiento interno de la $\mathrm{BBC}$, concede a la corporación libertad para gastar los fondos, excepto en lo relativo a la división BBC World, y la faculta para encargar producciones externas con la excepción de la producción de noticias y programas de actualidad.

En Rumanía, en 2011 se presentó un borrador de enmienda a la Ley Audiovisual de 2002, centrado en la protección de menores y la regularización de la esponsorización y el emplazamiento del producto. Además, se mantiene el límite de publicidad por hora en la televisión pública, pero se alteró la frecuencia de los cortes para anuncios al acortarse de los cuarenta y cinco minutos a los treinta en el caso de películas. Por su parte, en junio de 2015, el gobierno rumano promulgó un proyecto de ley para la radiotelevisión pública.

El gobierno sueco aprobó en 2010 la Ley de Radio y Televisión para la aplicación de los enunciados de la Directiva Europea de 2007. El principal cambio es la liberalización en la emisión de anuncios y los mensajes esponsorizados, además de la extinción de la regla por la cual la publicidad se situaba como separadora de programas. El emplazamiento de productos queda prohibido excepto en películas, series, programas deportivos y algunos espacios de entretenimiento.

\subsection{Reformas acometidas entre 2012 y 2016}

Alemania renovó el Contrato de Estado para la Radiodifusión en enero de 2016, que dedica el Título II a los medios de servicio público, es decir, las cuatro cadenas de ZDF y las nueve operadoras que conforman la red regional ARD, además de las emisoras de radio. Especifica que la radiotelevisión pública tiene limitada la publicidad a veinte minutos por día hábil -nunca después de las ocho de la tarde, domingos y festivos nacionales- y prohibida la compra de servicios si existe capacidad para la producción propia. Además, obliga a las corporaciones a ofrecer todos sus contenidos en portales digitales. 
El documento informa de que tanto ZDF como ARD deben publicar cada dos años un informe de desempeño de su misión de servicio público y poner en marcha el test de valor público (TVP) para el lanzamiento o modificación de todos los productos en base a tres preguntas: ¿en qué medida se corresponde con las necesidades democráticas, sociales y culturales de la sociedad?, ¿en qué medida respeta la competencia editorial? y ¿qué gastos requiere? El procedimiento arranca de una propuesta de la Dirección General en la que se especifica el objetivo, contenido, dirección y duración del programa para la revisión por parte del Consejo de Radiodifusión. La resolución de este organismo deberá ser revisada por la autoridad de supervisión legal, es decir, la Cancillería del Estado.

En el capítulo económico, apela al principio de compensación económica, en tanto que los medios públicos -ZDF y ARD- deben hacer frente a sus gastos a partir del canon, la publicidad -incluidos patrocinios y colocación de productos- y otros ingresos. Asimismo, este documento reconoce su potestad para ejecutar actividades comerciales de producción, explotación y comercialización, además de arrendamiento de estaciones transmisoras.

Previamente, en 2008, entro en vigor la décima enmienda del Contrato de Radiodifusión de la Alemania Unificada, que define al operador como la plataforma que se vale de todos los métodos digitales de transmisión, en base a lo dictado en la Directiva Europea de 2007. La décimo quinta modificación está en vigencia desde 2010 e incluye la materialización de la modificación de las leyes de concentración y una mayor protección de menores con la prohibición de incluir contenidos en Internet susceptibles de ser perjudiciales. La última enmienda es de junio de 2015 y en ella se incluyen restricciones de compatibilidad para los miembros del Consejo de la Televisión pública ZDF y se reafirma la representatividad sectorial y territorial de sus miembros.

En el caso austríaco, el Parlamento aprobó en febrero de 2012 las últimas enmiendas a la Ley de Medios Audiovisuales y a la Ley de la ORF, sobre la radiotelevisión pública. Con respecto a la primera, la principal novedad se refiere a la emisión de competiciones deportivas. En concreto, con el fin de evitar distorsiones de competencia con las 
privadas, prohíbe a la pública difundir campeonatos que ya reciben alto nivel de cobertura en el resto de medios.

La Ley de la ORF destaca en el artículo 4 la competencia de la Dirección General para establecer un sistema de garantía de calidad de los productos y servicios ofrecidos -a través de un test en tres pasos-, basado en la independencia y la responsabilidad, para lo que además contempla la creación de un Comité de Calidad, en lo que viene a ser un ejemplo de test de valor público.

Por otra parte, enumera los veintiocho servicios en línea que no podrá prestar la corporación pública: portales de anuncios; registros y directorios de la industria; programas y portales de cálculo de comparación de precios; webs de servicios y productos sin referencia a una misión específica o una oferta concreta; contactos de socios; espacios de intercambio de archivos, a menos que sean designados con fines benéficos; redes empresariales; servicios de telecomunicaciones; servicios eróticos; facturación de otras empresas; juegos y apuestas; software; direcciones; espacios de descarga de música y producciones comerciales extranjeras; juegos y entretenimiento; servicios de SMS, con excepción de los relativos a un programa propio; servicios de búsqueda, excepto los propios; subastas en línea; comercio y banca electrónica; tonos de llamada y tarjetas electrónicas; descarga de fotos sin referencia de envío; calendario de eventos; foros y chats; enlaces que no conducen a la explicación de los contenidos; redes sociales; ofertas para la audiencia a través de una oferta no especializada; guías de webs sin referencia de envío; ofertas diseñadas para dispositivos móviles.

Por cuanto a la publicidad, la radiofónica no debe exceder un máximo diario de 172 minutos y la televisiva los 42 minutos de media. En ambos casos, se permite una desviación de no más del veinte por ciento cada día. Además, está contemplada la colocación de productos y el patrocinio.

En Chipre, la Ley de Radio y Televisión de 1998 fue enmendada por última vez en 2013 con el fin de adaptarla a la Directiva Europea de Medios Audiovisuales. Se trata de una actualización tardía con respecto a otras 
corporaciones europeas, cuyas modificaciones principales son la clasificación de bienes y servicios para los que se impide la publicidad en tramos específicos en radio y televisión, reglas sobre protección de menores, tipología de la programación, representación sexual, juegos de azar y prohibición de consejos médicos. Por otra parte, la Autoridad Reguladora de Servicios de Comunicación Audiovisual extiende sus poderes a los medios de comunicación no lineales.

En Grecia, el Parlamento aprobó en 2013 una nueva ley de radio, internet y televisión para la creación de un nuevo servicio público de radiodifusión bajo el nombre Nerit, que empezó a funcionar en mayo de 2014. El gobierno entrante en 2015 decidió recuperar la ERT, anterior medio de servicio público que fue cerrado para dar respuesta al paquete de medidas de austeridad impuestas por la Unión Europea a Grecia con motivo de la crisis económica.

La Asamblea Nacional de Eslovenia aprobó en enero de 2016 una enmienda a la Ley de Medios para incrementar hasta un veinte por ciento las cuotas de música eslovena en la radio y la televisión privada y un cuarenta por ciento en la pública. La modificación de la normativa también establece criterios de moderación de los comentarios en los servicios en línea. Esta ley fue rechazada en votación parlamentaria en julio de 2011, lo que obligó al Ministerio de Cultura a preparar un proyecto de ley de servicios de comunicación audiovisual dirigida a la transposición de la Directiva de Servicios de Comunicación Audiovisual para afrontar el procedimiento de infracción iniciado por la Comisión Europea por obviar precisamente la normativa europea.

La Yleisradio es la compañía de servicio público de Finlandia que opera con cuatro canales de televisión y seis de radio, además de veinticinco canales regionales. Se rige por la Ley de Ileysradio, cuya última modificación data de 2012, en la que se especifica que la licencia anual por televisión es de 252,25 euros por hogar.

La revisión de ley tiene la voluntad de garantizar la financiación de la corporación y establecer los procedimientos de supervisión del ente. Se estipula en el documento el abanico de servicios que puede producir y emitir la corporación, incluyendo el apartado digital. 
Con respecto a la financiación, señala que la licencia anual por televisión -de 252,25 euros por hogar en 2013- será revisada cada año con vista a actualizar y adaptar los costes. El régimen de canon modifica el sistema anterior -operativo durante ochenta años- en tanto que incluye un impuesto del 0,68 por ciento del salario de los trabajadores de YLE, nunca superior a 140 euros al año, además de una tasa de 350 euros para personas jurídicas cuyo volumen de negocio supere los 400.000 euros -si supera el millón de euros el impuesto asciende a 700 euros-.

En lo que afecta a los productos, el Consejo de Administración es el órgano facultado para desarrollar la evaluación previa de los nuevos servicios para asegurar que no competirán con el sector privado y que responden a los parámetros de calidad. La Autoridad Reguladora de Comunicaciones de Finlandia es la encargada de supervisar que no existe una subvaloración de precios o subsidios cruzados.

Finlandia aprobó en 2003 un nuevo paquete de leyes para el sector audiovisual a través de la Ley de Mercado de las Comunicaciones y Ley de Operaciones de Radio y Televisión, normativas que estipulan que los operadores de cable están obligados a distribuir sin cargo los programas del servicio público de la YLE.

En el caso italiano, en marzo de 2015, el gobierno aprobó un proyecto de ley para la reforma del servicio público de radiodifusión, por el cual se incrementó la duración del contrato programa de tres a cinco años, se modificaron las características del Consejo de Administración de la RAI y se propusieron cambios en el sistema de financiación.

Los servicios de televisión italianos están regulados por la Ley sobre emisiones de radio y televisión de 1975, sobre la cual se aprobó un borrador de enmienda en 2010 para implementar la directiva europea de Medios Audiovisuales. El objetivo era incluir los medios bajo demanda en la normativa y revisar las normas de promoción de obras europeas, con la reserva del diez por ciento de la emisión a proyectos europeos elaborados en los últimos cinco años - un veinte por ciento en el caso de la RAI. 
El Ministerio de Cultura de Letonia aprobó para debate en abril de 2012 un documento del Consejo nacional de Medios Electrónicos para la creación de un nuevo medio público para atajar su posición de debilidad en el mercado letón, la financiación insuficiente y la falta de autoridad y visibilidad con la convergencia de las empresas de radio y televisión que hasta el momento operaban de forma independiente. Pese a mantener la autonomía editorial de ambos medios, se apostó por la fusión de la administración, funciones técnicas y gestión a través de una única infraestructura. Por cuanto a la financiación, el documento apuesta por la introducción de un impuesto o canon en sustitución del subsidio estatal y la publicidad.

En Lituania, la Ley de Provisión Púbica de Información de 2013 modifica las normas de financiación de los medios, de modo que las tasas pagadas por las emisoras, radiodifusoras y proveedores de vídeo bajo demanda, con excepción de la cadena pública, se reduce del 0,8 al 0,6 por ciento de sus ingresos en publicidad, cuotas de suscripción y otras actividades.

Una reforma de la Ley de Telecomunicaciones de 2012 convirtió a los Países Bajos en el segundo país del mundo en aceptar el principio de neutralidad de la red, que implica tratar por igual a todos los operadores de servicios. Con respecto al servicio público de radiodifusión, la Secretaría de Estado para Educación, Cultura y Ciencia publicó en 2014 un documento con la previsión de obligar a los medios públicos a derivar el cincuenta por ciento de su presupuesto a la producción externa, para garantizar la supervivencia de productores e instituciones sociales y culturales.

En octubre de 2012, el Parlamento de Polonia aprobó una enmienda de la Ley de Radiodifusión para la transposición de la Directiva de Medios Audiovisuales, con el fin de regular los contenidos bajo demanda, sin establecer obligación alguna de autorización, registro o modificación para los proveedores de este tipo de servicios a la carta, más allá de garantizar la protección de menores y la promoción de las obras europeas. Se trata de una de las transposiciones de la directiva europea más tardías. 
La autoridad reguladora es el Consejo Nacional de Radiodifusión, encargado de supervisar el mercado de vídeo a la carta con el fin de identificar a los proveedores y comprobar la conformidad con las obligaciones establecidas en la normativa. Las tareas del Consejo también incluyen el impulso de acciones de autorregulación y corregulación a través de la elaboración de códigos de buenas prácticas.

El Parlamento checo modificó en 2016 la Ley de Comunicación Audiovisual para, esencialmente, afianzar el apoyo a la cinematografía a través de una financiación previsible por parte del Fondo Estatal de Cinematografía que permita desarrollar estrategias a largo plazo. Con la enmienda de 2011 se suprimió la publicidad de la radiotelevisión de servicio público, excepto la relacionada con la programación, los deportes y los eventos culturales cuya adquisición de derechos de emisión requiera inclusión de anuncios.

\section{Conclusiones}

Todas las radiotelevisiones públicas de la Unión Europea han visto actualizada la normativa que las rige en los últimos diez años, bien a través de cambios en las leyes generales de comunicación audiovisual o bien por medio de la renovación de la legislación propia de los medios de servicio público.

Con todo, existen diferencias notables en el espacio geográfico europeo, entre aquellas que se han limitado a la transposición de la directiva europea y las que están dando pasos más allá de cara al fortalecimiento del servicio público ante los nuevos retos de la comunicación, cuyo origen se encuentra en el incremento de la competencia, la explosión de los medios digitales, la fragmentación de las audiencias y los multidispositivos de recepción.

En el caso de las corporaciones que han sufrido las consecuencias de cambios legislativos en 2011 o antes, se produce la situación de que catorce de las dieciséis actualizaciones han sido para adaptarse al marco europeo y asumir los preceptos de la directiva europea de 2007, que fue revisada en 2010. Las dos restantes centran las revisiones de sus leyes en otras cuestiones y con muy diferentes motivos y marchas en 
cuanto a velocidad de adaptación al marco europeo. En el caso de la HRT de Croacia, la actualización de 2010 tiene como objetivo introducir la figura del mandato marco, plenamente consolidada en prácticamente todas las corporaciones públicas europeas. Además, contempla la introducción de una herramienta similar al test de valor público para el análisis previo de los nuevos contenidos y servicios.

La normativa de Eslovaquia se vio modificada en 2010 para asumir cambios en la financiación de la corporación. No se considera un cambio relacionado estrictamente con la directiva europea, en tanto que la transposición se produjo en 2009. Sin embargo, un año después se introdujo esta enmienda para determinar el plano económico del servicio público luego de la fusión de la radio y la televisión pública en un nuevo ente ese mismo año.

Cabe señalar, que algunos estados miembros, cuyas modificaciones legislativas en materia de radiotelevisión de servicio público es posterior a 2011, también tenían la voluntad de implementar las recomendaciones de la directiva europea. Los estados miembros más tardíos en este sentido han sido Chipre y Polonia.

Las últimas modificaciones se corresponden al año 2016 y afectan a tres corporaciones. En el caso alemán, la revisión está relacionada con la limitación de publicidad en la radiotelevisión pública ZDF, mientras que el cambio normativo en Eslovenia ha tenido que ver con el incremento de las cotas de emisión de contenido cultural nacional. En la misma línea, la República Checa ha actualizado la legislación para aumentar el apoyo estatal a la cinematografía del país.

Por tratarse de la corporación que suele situarse en la vanguardia, es preciso subrayar el caso de la BBC del Reino Unido por resultar engañoso el dato de 2009 para advertir el último cambio normativo. La British Broadcasting Corporation desarrolla su misión de servicio público de acuerdo a los preceptos de la Carta Real y el Agreement, bajo la supervisión de la Oficina de Comunicación (OFCOM), con una vigencia de diez años, cuya octava actualización expira en diciembre de 2016, tras una vigencia de diez años. 
En el mes de mayo de este año, la Secretaría de Estado de Medios presentó el White Paper, con la propuesta de reforma y modernización de la BBC para la próxima década. El libro blanco es consecuencia de una amplia consulta con las industrias creativas y el público sobre las vías para mejorar la misión de servicio público de la $\mathrm{BBC}$ a partir de su identidad y calidad. El 15 de septiembre de 2016 ha culminado en la publicación del borrador de la Carta Real para la próxima década. Esto significa que, pese a que la última reforma legislativa fue de 2009, los documentos que rigen la $\mathrm{BBC}$ han experimentado cambios de cara a los siguientes diez años.

\section{Bibliografía}

Consejo Europeo (2010). Directiva 2010/13/UE, del 10 de marzo, sobre la coordinación de determinadas disposiciones legales, reglamentarias y administrativas de los Estados miembros relativas a la prestación de servicios de comunicación audiovisual. Disponible en: http:/ / eurlex.europa.eu/legalcontent/ES/TXT/HTML/uri=C ELEX:32010L0013\&from=ES

Consejo Europeo (2009). Recomendación sobre regulación de servicios audiovisuales. Dispoñible en: http://www.coe.int/t/dghl/standardsetting/media/ttt/_asse mbly.coe.int_Documents_Ad optedText_ta09_EREC1855.pdf

Consejo Europeo (2007). Directiva Europea 2007/65/CE de Medios Audiovisuales. Disponible en:

http://eurlex.europa.eu/smartapi/cgi/sga_doc?smartapicelexpl usprodDocNumber\&lg=es\&type_doc $=$ Directive\&an_doc $=200$ $7 \&$ nu_doc $=65$

Doyl, G. (2012). Economía audiovisual: los mercados audiovisuales en la Unión Europea. Quaderns del CAC, 38, 15(1).

Michalis, M. (2011). La política europea de comunicación y su impacto en los medios de radiodifusión. En Campos Freire, F. (coord.), El nuevo escenario mediático (29-47). Zamora:

Comunicación Social Ediciones y Publicaciones.

Wheeler, M. (2007). Whither Media Diversity: The European Union's market vision for the Review of Television Without Frontiers 
Directive., European Studies "Media and Cultural Policy in the EU: the quest for diversity", 227-49.

Reconocimientos: Los resultados de este artículo forman parte de las actividades de difusión del proyecto del Programa estatal de Fomento de la Investigación Científica y Técnica de Excelencia, subprograma estatal de Generación de Conocimiento del Ministerio de Economía y Competitividad de España sobre "Indicadores de gobernanza, financiación, rendición de cuentas, innovación, calidad y servicio público de las RTV europeas aplicables a España en el contexto digital" (Referencia CSO2015-66543- P). 



\title{
La gobernanza en la radiotelevisión pública europea. E1 modelo español
}

\author{
Ana María López Cepeda \\ Universidad de Castilla-La Mancha
}

Cómo citar: López Cepeda, A.M. (2017). La gobernanza en la radiotelevisión pública europea. El modelo español. En Túñez López, M.; Campos-Freire, F. y Silva Rodríguez A. (Eds.). Estudios sobre financiación, legislación e innovación en la Televisión Pública. Cuadernos Artesanos de Comunicación, cac126, pp 41-58. La Laguna (Tenerife): Latina.

DOI: $10.4185 / \mathrm{cac} 126$

— L NUEVO digital comporta la necesidad de cambios en la urgencia de aplicar un nuevo marco de gobernanza, entendida como el conjunto de mecanismos que determinan la organización y estructura de una entidad. En este contexto, la finalidad de este artículo es hacer una primera aproximación teórica y legal del marco de gobernanza de la radiotelevisión pública que ha sentado la Unión Europea a través del análisis de sus principales políticas audiovisuales sobre este tema y de la literatura científica. El nuevo modelo europeo, basado en tres ejes (estructura, gestión eficaz y cultura de servicio público) se vislumbra como uno de los pilares fundamentales para que los medios públicos puedan enfrentarse al escenario cambiante actual. Se parte de la hipótesis de que a pesar de que existe un marco europeo, en Estados miembros como el nuestro aún no se ha aplicado el mismo en su totalidad.

Palabras clave: identidad corporativa; televisión; televisión pública; estrategia de comunicación. 
La radiotelevisión pública en Europa se está enfrentando a nuevos retos que suponen la necesidad de una reconversión, al tiempo que la discusión y el debate en la Academia se ha reabierto para buscar un nuevo modelo de medios audiovisuales públicos, acorde con las reivindicaciones y demandas sociales y ante un nuevo escenario cambiante propiciado por la digitalización y las tecnologías.

Los medios audiovisuales públicos "deberían afrontar estos retos antes de 2020 porque los sistemas de comunicación y las formas de uso social de los mismos están cambiando a una velocidad mucho más alta de lo que ocurría hace dos o tres décadas" (Campos, 2015a: 9).

Pero para poder afrontar estos desafíos se hace necesario un cambio en el modelo de radiotelevisión pública que defina su gobernanza. La concreción de ésta se ha convertido en una de las cuestiones pilares a la hora de definir el marco de la radiotelevisión pública, y en definitiva en un punto estratégico para recuperar la credibilidad de la misma. Es importante porque si no se define correctamente un patrón de gobernanza acorde con las nuevas exigencias sociales de responsabilidad, independencia, transparencia y rendición de cuentas, la sociedad dejará de creer en la radiotelevisión pública y esto pondrá (y de hecho lo está haciendo en algunos países como el nuestro) en duda el mantenimiento de los servicios públicos audiovisuales.

La finalidad de este artículo es hacer una primera aproximación teórica y legal del marco de gobernanza de la radiotelevisión pública que ha sentado la Unión Europea. Se toma como referencia la Recomendación CM/Rec (2012)1 del Comité de Ministros del Consejo de Europa a los Estados miembros sobre la gobernanza de los medios de comunicación de servicio público. Sin embargo, el análisis se completa con otras políticas audiovisuales europeas y con la aportación de European Broadcasting Union (en adelante, EBU) a través fundamentalmente del informe de Wagner y Berg (2015) ${ }^{1}$, de los

\footnotetext{
${ }^{1}$ Este informe (EBU, 2015) está basado en el análisis de las políticas audiovisuales europeas pero también en los resultados de proyectos de referencia como MEDIADEM (2010-2013), INDIREG (2011) o OSF'MAPPING DIGITAL MEDIA (2011-2014). Por lo tanto, para un análisis pormenorizado de los principios de gobernanza de la radiotelevisión pública en la UE, ver el mismo.
} 
informes Vision 2020 y PSM V alues Review. The Tool o de autores como Ferrell (2016) y Zankova (2013 y 2014). Una vez conocido el marco de gobernanza que señala la UE se realizará una breve aproximación del modelo español, con el objetivo de conocer si este se localiza en un marco con una reforma urgente o si por el contrario se están siguiendo las recomendaciones europeas.

\section{La Directiva de la Televisión sin Fronteras y sus modificaciones}

La política audiovisual, entendida como el equilibrio entre el intervencionismo y el liberalismo de los mercados en materia audiovisual, debe estudiarse desde una doble perspectiva: la regulación de los objetivos económicos e industriales, por un lado; y el prisma cultural, social y democrático, por otro. (Michalis, 2014). En Europa esta dicotomía social-económica se ha resuelto con una clara división: "La UE es la principal responsable de las consideraciones de política económica mientras que los Estados miembros conservan la responsabilidad esencial de los objetivos de servicio público" (Michalis, 2011: 44). Esta disyuntiva ya se vislumbraba en cierta medida en la Directiva de la Televisión Sin Fronteras (89/552/CEE), una de las primeras políticas europeas audiovisuales de gran alcance. Esta sería modificada por la Directiva de Servicios de Medios Audiovisuales (2007/65/CE), con el objetivo de modernizar la estructura legal de la radiotelevisión.

El marco genérico actual en la regulación de los medios de comunicación audiovisual europeos lo marca la Directiva de Servicios de Comunicación Audiovisual (2010/13/UE) que tiene como finalidad la codificación de las diferentes reformas de la Directiva de Televisión Sin Fronteras. Determina las normas sobre cuotas de difusión y promoción, publicidad y patrocinio, protección de menores, incitación al odio, accesibilidad, derecho a la información y derecho de réplica, aplicables a los servicios de comunicación audiovisual (Beceiro, 2012). 


\section{Políticas europeas sobre gobernanza de la radiotelevisión pública}

En lo referente a la regulación de la gobernanza de la radiotelevisión pública, Wagner y Berg (2015:7) destacan como principales políticas europeas la Declaración y la Recomendación CM/Rec (2012)1 del Comité de Ministros del Consejo de Europa a los Estados miembros sobre la gobernanza de los medios de comunicación de servicio público $^{2}$. La recomendación europea indica la necesidad de modificar el modelo de gobernanza de los medios de servicio público en los Estados miembros e implantar un marco basado en tres niveles:

- El primero de ellos se refiere a la estructura, con medidas que garanticen la independencia y transparencia de los órganos de gestión, supervisión, responsabilidad y rendición de cuentas (accountability).

- El segundo nivel se refiere a una gestión eficaz de la organización, entendida ésta desde la perspectiva de la innovación.

- Finalmente, el tercer nivel responde a la necesidad de crear sistemas independientes que en conjunto definan la cultura de la entidad a través de su transparencia, apertura, responsabilidad y rendición de cuentas.

Se trata, por lo tanto, de buscar la eficiencia y eficacia de los medios públicos a través del desarrollo de estos parámetros (Zankova, 2013) y (Wagner y Berg, 2015).

En 2014, EBU publicó un informe para revisar los valores de servicio público audiovisual: PSM Values Review The Tool basado en seis principios (universalidad, excelencia, independencia, rendición de cuentas, diversidad e innovación) y una pluralidad de indicadores de desarrollo (Campos, 2015b: 208), algunos de ellos presentes en el modelo de gobernanza diseñado en la normativa de 2012 de la UE.

\footnotetext{
${ }^{2}$ En adelante se hará referencia a esta norma como Recomendación CM/Rec (2012)1
} 


\subsection{Estructura}

La independencia editorial e institucional es básica para poder redefinir un modelo de gobernanza en la estructura de los medios audiovisuales públicos. Con anterioridad a la Recomendación CM/Rec (2012)1, la UE ya había hecho referencia a la autonomía fundamentalmente en la Recomendación CM/Rec (1996)10 del Comité de Ministros del Consejo de Europa a los Estados miembros para la garantía de la independencia de la radiotelevisión pública; y en La Declaración CM (2006) sobre la garantía de la independencia de la radiotelevisión pública de los Estados miembros (Wagner y Berg, 2015:6)

En la primera de ellas se señala que el marco legal que regula a los organismos de radiodifusión de servicio público en los Estados miembros debe garantizar la independencia fundamentalmente en áreas como la definición y concepción de los programas -en especial de los informativos y de actualidad- en la contratación y gestión del personal laboral, en la gestión de los recursos financieros, en la preparación y ejecución del presupuesto y en la negociación de los actos jurídicos y la representación en los procesos judiciales (Apéndice).

En la segunda se hace hincapié en la necesaria revisión del servicio público, en la regulación de la independencia editorial, basada en un sistema de financiación seguro y transparente, en la protección al empleado y en la apertura a la rendición de cuentas (arts. 7-26). Tal y como señala el informe EBU (2014a) "la independencia puede garantizarse a través de regular garantías que incluyan procedimientos de designación adecuados y una estricta separación entre el gobierno, los órganos de la radiotelevisión y las redacciones".

La Recomendación CM/Rec (2012)1 señala que si bien los Estados tienen libertad para diseñar sus modelos de financiación, no deben al hacerlo, interferir en la autonomía de los medios públicos. EBU (2014b) indica la necesidad de alcanzar independencia en la gobernanza, financiación, decisiones editoriales y en la medición de la responsabilidad y rendición de cuentas. 
Los mecanismos de accountability -el otro elemento del nivel de estructura que debe ser revisado- se pueden definir como aquellos a través de los cuales las empresas públicas rinden cuentas con la ciudadanía. Para ello se hace necesario una estructura de órganos internos y externos transparentes y que rindan cuentas del servicio público audiovisual a través de cuatro preguntas (CM/Rec (2012)1, art. 30); (Ferrell, 2016); (Zankova, 2013: 686): 1. ¿A quién? 2. ¿De qué? 3. ¿Cómo? 4. ¿Cuándo?

Siguiendo el informe EBU (2014b), la medición de la responsabilidad de los medios audiovisuales pasa por la transparencia, apertura y presentación de informes. Por su parte, Wagner y Berg (2015) señalan que un sistema factible sería aquel con mecanismos de rendición de cuentas internos y externos que combinen una supervisión general con una fiscalización especializada, siempre a través de formas independientes en su elección y en la toma de decisiones, que permitan mecanismos profesionales que respondan por el servicio público de la forma más transparente posible y con total apertura a la ciudadanía. Según los dos autores, estos pueden completarse con órganos complementarios como defensores de las audiencias (ombudsman) y mecanismos de representación profesional (consejos de redacción).

\subsection{Gestión eficaz}

En lo referente a la gestión eficaz, la Recomendación CM/Rec (2012)1 (art. 34) se centra en establecer y diseñar un marco de gobierno capaz de afrontar los nuevos retos de la radiotelevisión pública a través de varios mecanismos centrados en la innovación, gestión ante el personal y no discriminación.

El cambio del concepto de la radiodifusión pública tradicional se produce en la Recomendación CM/Rec (2007)3 del Comité de Ministros del Consejo de Europa a los Estados miembros sobre medios de comunicación públicos en la sociedad de la información. En esta, se presenta una idea nueva: la transición de la radiodifusión pública tradicional a los medios de comunicación de servicio público (PSM). "Este nuevo concepto sirvió como base para el 
replanteamiento de la gobernanza en los servicios públicos" (Zankova, 2014).

Son numerosas las políticas de la UE en torno a la innovación como Green Paper on Innovation (1995), la comunicación Innovation in a knowledge-driven economy (2000), la Agenda de Lisboa de 2000 o la Iniciativa i 2010 - Una sociedad de la información europea para el crecimiento y el empleo, entre otras Bonet, Arboledas y Fernández-Quijada, 2013).

Esta última destaca por promover "una economía digital, poniendo el acento en las TIC, ya que se las considera impulsoras de una mejora en la calidad de vida y cuyo principal objetivo era trabajar con un enfoque integrado en las políticas de la Sociedad de la Información y los medios audiovisuales en la Unión Europea” (Bonet, Arboledas y FernándezQuijada, 2013:46). La Resolución del Parlamento de Europa, de 25 de noviembre de 2010, sobre el servicio público de radiodifusión en la era digital: el futuro del sistema dual reitera la necesidad de mantener un servicio público audiovisual acorde con las demandas de la era digital.

EBU (2014b) y Zankova (2013) señalan en este contexto de los medios públicos como indicadores no solo a la innovación técnica y de contenidos, sino también cambios en la industria creativa y en la gestión de la organización, acorde con la Recomendación CM/Rec (2012)1.

\subsection{Cultura}

La contribución a la sociedad debe venir definida por el concepto de servicio público y su control, pero también por el valor que la sociedad le otorga al mismo. Una evaluación del valor de los medios de comunicación públicos para la sociedad es inherente al proceso de definición y a la adaptación de la misión de servicio público (Wagner y Berg, 2015: 30).

Los Estados miembros son los encargados de definir este concepto en base al Protocolo sobre el sistema de radiodifusión pública de los Estados miembros, anejo al Tratado de Ámsterdam, que señala que para que los medios de comunicación públicos puedan recibir ayudas 
públicas es necesario que "lleven a cabo la función de servicio público, que debe ser definida por cada Estado miembro; y que esta financiación no sea contraria al interés común de la Comunidad, perjudicando la libre competencia y las condiciones de comercio" (Casado, 2008: 71). En esta misma línea se mueve la Comunicación de la Comisión Europea sobre aplicación de las normas en materia de ayudas estatales a los servicios públicos de radiodifusión.

La Recomendación CM/Rec (2012)1 señala la necesidad de las entidades públicas de dar respuesta a las demandas de la sociedad a través de una cultura de transparencia, apertura, capacidad de respuesta y responsabilidad.

\section{a. Transparencia y participación}

La transparencia es una de las preocupaciones europeas en la definición de un nuevo modelo de gobernanza. La Recomendación CM/Rec (2012)1 señala la necesidad de que los medios de comunicación públicos den a conocer la información financiera; los acuerdos de la junta y asuntos de otros órganos de toma de decisiones; y la difusión del control de contenido (arts. 39-40). Para Wagner y Berg (2015: 27) a esto podría añadírsele la publicación de los riesgos previsibles, la definición de misión de servicio público, normas de contratación, políticas de igualdad y diversidad y la contribución del medio a la sociedad. EBU (2014b: 12) señala como indicadores de transparencia a mayores de los señalados un repositorio de quejas y plataformas de desarrollo del derecho de réplica.

Respecto a la regulación de la participación en los medios audiovisuales públicos y según Azurmendi, Llorens, López y Bas (2015), la Directiva de Servicios de Medios Audiovisuales (2010/13/UE) se refiere a este derecho a través del acceso de determinados colectivos (personas con discapacidad o de edad avanzada) o de acontecimientos concretos (de especial importancia). Sin embargo, "se puede concluir que la participación activa de las audiencias en los medios audiovisuales no está regulada más allá de las directivas que afectan a la protección de los derechos de los consumidores y el derecho a rectificación. Tampoco en las resoluciones sobre el servicio público de radiodifusión del Parlamento Europeo se encuentran referencias a la participación de 
la audiencia como función esencial o importante de su misión" (Azurmendi, Llorens, López y Bas, 2015: 499).

Sí que hay referencias a ésta en la Recomendación CM/Rec (2012)1, que directamente se refiere a la necesidad de una apertura basada en la participación y el compromiso (art. 42). También lo hace EBU (2014b) al señalar la necesidad de mecanismos que escuchen a las audiencias y de instrumentos de participación de la sociedad y de los periodistas.

\section{b. Responsabilidad y rendición de cuentas}

Las políticas europeas sobre responsabilidad social corporativa responden a una dinámica de políticas blandas sin carácter vinculante. "La UE es abundante en comunicaciones sobre RSC y cuestiones relacionadas, si bien no consigue la plasmación de las directrices en las empresas, puesto que no dejan de ser recomendaciones de tipo voluntario que las compañías no están obligadas a asumir ni los Estados miembros a imponer” (Fernández y Campos, 2013: 151).

En lo referente a la rendición de cuentas es destacable la Comunicación de Radiodifusión de 2009. Entre sus novedades se encuentra la introducción de una evaluación previa de los nuevos servicios significativos a través de dos fases: una evaluación del valor público y una evaluación del impacto de mercado (Michallis, 2011: 43). Se trata en concreto del Test del Valor Público que ya están ensayando diversos Estados miembros, en especial Reino Unido y Alemania.

En términos generales la Recomendación CM/Rec (2012)1 señala la necesidad de que se promueva una cultura de responsabilidad y rendición de cuentas en los medios de comunicación públicos, con códigos claros y accesibles a los públicos, con controles editoriales internos a través de mecanismos de representación del personal que no deben limitarse sin más a la conducta del periodista, sino que deben abarcar cuestiones más amplias de rendición de cuentas, transparencia y participación ciudadana (art. 49), como los efectos sobre el empleo, las industrias creativas, la diversidad de las expresiones culturales, el pluralismo, la ciudadanía informada, la alfabetización mediática, la salud pública y el medio ambiente (Wagner y Berg, 2015: 32). 


\section{Breve aproximación al modelo de gobernanza de la radiotelevisión pública en España}

En España junto con la radiotelevisión pública estatal (CRTVE) existen medios audiovisuales de titularidad pública en prácticamente casi todas las comunidades autónomas. Desde su nacimiento cada región ha tenido una estrategia propia en el desarrollo de su radiotelevisión pública. Sin embargo, y en términos generales "la heterogeneidad del modelo encaja en la clasificación propuesta por Hallin y Mancini (2004) a la hora de comparar los sistemas mediáticos. En concreto, la televisión autonómica española responde a un modelo de pluralismo externo" (Manfredi, 2011: 57).

Para hacer una primera aproximación al modelo de gobernanza de la radiotelevisión pública en nuestro país es, por lo tanto, necesario analizar junto con la corporación estatal las radios y televisiones regionales y comprobar si se adaptan al marco diseñado en Europa o si por el contrario, responden a un patrón desfasado, en función de los indicadores ya estudiados.

\subsection{Estructura: independencia y accountability}

En España, la autonomía político-partidista de la radiotelevisión pública se encuentra regulada a nivel estatal por la Ley 17/2006, de 5 de junio, de la radio y la televisión de titularidad estatal. Esta norma significó "una auténtica independencia de la nueva Corporación RTVE, plasmada en la elección parlamentaria por amplio consenso de su presidente y su Consejo de Administración y una autonomía financiera creciente" (Bustamante, 2008:24). Esta política fue seguida por algunas Comunidades Autónomas que decidieron modificar sus normativas audiovisuales de origen. Es el caso de Cataluña, Andalucía, y con posterioridad, Baleares y Galicia. Lo han hecho recientemente Canarias (Zallo, 2015) y Asturias.

Todas estas leyes plantean, con mayor o menor intensidad, una serie de medidas que garantizan la autonomía política de los principales órganos de gestión y/o control: entre ellas destaca que el director/presidente y el Consejo de Administración pasan a ser 
nombrados en general por el Parlamento por mayorías reforzadas y por períodos superiores a la legislatura. Se han aumentado también las incompatibilidades y las exigencias de profesionalidad en comparativa con las antiguas normas.

Sin embargo, estos cambios no han sido del todo suficientes. Por un lado, la Ley 17/2006 fue reformada por el R.D- Ley 12/2012 que vuelve en varios aspectos al modelo gubernamental anterior. Por otra parte, muchas radiotelevisiones autonómicas continúan en un modelo anclado en el pasado con órganos de gestión y/o control elegidos directamente por el Gobierno o por cuotas partidistas y por mandatos que coinciden con la legislatura. En aquellas radios y televisiones públicas en donde sí se ha modificado la normativa de origen siguiendo el patrón de la Ley 17/2006 (Cataluña, Andalucía, Galicia, Baleares, Canarias y Asturias) sí se evidencian mejoras, pero sigue habiendo una necesidad de cambio (López Cepeda, 2012 y 2015).

En lo referente a los órganos de gestión/control y responsabilidad o rendición de cuentas (accountability) en la radiotelevisión pública en España domina un modelo con una supervisión en torno a tres mecanismos: director y consejo de administración en el ámbito interno y comisiones de control parlamentario en el externo. A nivel estatal y en las comunidades de Cataluña y Andalucía este patrón se completa con autoridades audiovisuales.

Las deficiencias, sin embargo, son plausibles. Para empezar entre los directores y consejos de administración se encuentran los problemas de dependencia político-partidista explicados con anterioridad y que se reproducen a la hora de tomar decisiones. Es necesario que se aprueben mandatos-marco y contratos-programas, ya previstos a nivel estatal en la Ley 17/2006. Pero "el contrato-programa nunca ha sido formalizado ni con el Gobierno ni con el Parlamento" (Informe Teledetodos, 2015: 23). Por su parte a nivel autonómico son escasas las radios y televisiones públicas que cuentan con estos mecanismos.

A esto hay que añadir que solamente dos comunidades autónomas (Cataluña y Andalucía) tienen autoridades audiovisuales indepen- 
dientes $^{3}$, mientras que a nivel estatal la previsión del Consejo Estatal de Medios Audiovisuales (CEMA) por la Ley 7/2010, de 31 de marzo, General de la Comunicación Audiovisual, se ha traducido en la creación de la Comisión Nacional del Mercado y la Competencia (CNMC) en 2013, como superregulador que aglutina entre otras competencias las del CEMA.

Entre los mecanismos que deben completar los órganos de responsabilidad principales, Wagner y Berg (2015) señalan la necesidad de mecanismos de responsabilidad financiera, regional, ante las audiencias y de carácter profesional.

En España, la necesidad de una fiscalización financiera podría ejercerse por las propias Comisiones de Control Parlamentario que deberían abandonar su debate político, así como por los Tribunales de Cuentas. Esta fiscalización debe ser completada por consejos regionales en la radiotelevisión pública.

En lo referente al ombudsman o defensores de la audiencia, la empresa pública pionera ha sido Canal Sur en Andalucía, seguida de CRTVE y de la Corporació Catalana de Mitjans Audiovisuals.

Las directrices editoriales y órganos de representación personal son básicos para mejorar la calidad y la rendición de cuentas del servicio público audiovisual. En CRTVE la Ley 17/2006 previó la creación de Consejos de Informativos, pero tal y como se señala en el Informe Teledetodos (2015:77) es preciso recuperar la idea central de este órgano "como instrumento esencial de la independencia informativa del servicio público", rescatando su carácter vinculante.

En el resto de las radios y televisiones públicas autonómicas solo existen órganos de representación profesional en Cataluña, Andalucía y País Vasco (Sánchez de la Nieta, Monfort y Fuente, 2015).

\footnotetext{
${ }^{3}$ En otras comunidades, como Canarias, Castilla y León, Baleares o Galicia, se han aprobado normas o proyectos de ley que prevén la creación de autoridades audiovisuales independientes en cada una de estos territorios.
} 


\subsection{Gestión eficaz y Cultura}

Una estructura eficaz capaz de afrontar la innovación en los medios públicos es básica para poder integrarse en el cambio. En España todas las radios y televisiones públicas cuentan con una web pero una gestión eficaz no se puede quedar ahí, sino que hay que abrir espacios de innovación con nuevos formatos que conecten con las audiencias (Zankova, 2013). En Europa, se ha pasado del concepto de public broadcasting al de public service media, y algunos autores apuntan a su necesaria migración al public service commons o servicio de comunicación público. Sus principales características radicarían en la posición importante de la audiencia tanto a nivel institucional, como en el diseño de plataformas (Azurmendi, Llorens, López y Bas, 2015).

Esta idea se relaciona directamente con la definición de Cultura de los medios de comunicación públicos dada en la Recomendación CM/Rec (2012)1, que atañe a la participación y transparencia, responsabilidad y rendición de cuentas.

La participación o apertura de la radiotelevisión pública en España es bastante deficiente, tal y como lo demuestran varias investigaciones en los últimos años: Las referencias a ésta en los medios audiovisuales públicos no son muy abundantes en la normativa española ni estatal (art. 9 de la Ley General de la Comunicación Audiovisual) ni en la autonómica. Los textos regionales mencionan la contribución democrática de las televisiones autonómicas públicas, la finalidad de atender a las necesidades de información, de oferta plural, de acceso a la cultura y a la educación, a las creaciones culturales, pero estos principios no se encuentran desarrollados (Azurmendi, Llorens, López y Bas, 2015).

En la práctica la participación de las audiencias es más bien individual, periférica y escasa (Azurmendi, Llorens, López y Bas, 2015).

En lo referente a la transparencia, la preocupación por su regulación en el sector público ha sido mayor. Existe una ley estatal y leyes autonómicas en prácticamente todas las comunidades autónomas. Sin embargo, la entrada en vigor de la norma estatal (Ley 19/2013, de 9 de 
diciembre, de transparencia, acceso a la información pública y buen gobierno) a nivel autonómico y local es muy reciente para verificar su cumplimiento. En materia de medios audiovisuales propiamente dichos la transparencia se regula en la Ley 7/2010 General de la Comunicación Audiovisual.

La Responsabilidad Social Corporativa se concibe como una prerrogativa voluntaria que asumen las empresas públicas. Un amplio estudio de Tania Fernández (2015) evidenció que no todas las radios y televisiones públicas en España publicaban en sus webs memorias de RSC.

Finalmente, y en lo que concierne a la rendición de cuentas queda mucho por hacer. Mientras que en países como Reino Unido o Alemania se están ensayando el Test de Valor Público, en España se debería estudiar esta posibilidad a través de las autoridades audiovisuales independientes.

\section{Conclusiones}

La Unión Europea ha diseñado un modelo de gobernanza de los medios de titularidad pública centrado en la independencia, responsabilidad, innovación, transparencia, apertura y rendición de cuentas. No se trata de una cuestión baladí, debido a que la radiotelevisión pública en Europa debe afrontar grandes retos, y es necesaria una reforma urgente. No hay que olvidar además que "el servicio público de radiotelevisión es un mandato imperativo de nuestro modelo social europeo, por mucho que cada Estado miembro tenga la capacidad de adecuarlo a las situaciones nacionales" (Informe Teledetodos, 2015: 11). Las recomendaciones europeas no tienen carácter obligatorio para los Estados miembros pero se hace necesario que estos reformen lo antes posible el modelo de gobernanza de la radiotelevisión pública para seguir manteniéndola en el escenario digital.

Siguiendo a Wagner y Berg (2015), mientras que la buena gobernanza es crucial para una percepción positiva del servicio público y su aceptación por parte de la sociedad, la mala gobernanza (caracterizada 
por las interferencias políticas, la falta de imparcialidad y profesionalidad, falta de respuesta a las necesidades del público junto con una incapacidad para reformularse a sí mismos) conducirá a una disminución del servicio público en todos los aspectos, en cuanto a calidad del programa, cuotas de audiencia, reputación y legitimación.

La escasa percepción de la gobernanza y una superposición en ocasiones de los intereses institucionales por encima de la sociedad han generado que en España el modelo de gobernanza de la radiotelevisión pública no sea siempre positivo, acorde con los parámetros recomendados por la UE.

\section{Bibliografía}

Azurmendi, A., Llorens, C. López, N. y Bas, J.J. (2015). “La participación del público como valor añadido de servicio público para la televisión de proximidad. Estudio de caso de $\mathrm{La}$ noche de..., en ETB 2". Revista Latina de Comunicación Social, 70, pp. 490 a 518.

Beceiro, S. (2012). "Evolución de la legislación audiovisual en la UE en el entorno digital: Los contenidos se independizan del soporte", en Congreso AE-IC, 2012, Tarragona.

Bonet, M., Arboledas, L. y Fernández-Quijada, D. (2013).

"Innovación tecnológica y servicio público: el abismo entre políticas y realidad", Derecom, 14, pp. 40-57.

Bustamante, E. (2008). La Televisión digital terrestre en España: por un sistema televisivo de futuro acorde con una democracia de calidad. Madrid: Fundación Aternativas.

Campos, F. (2015a). "Prólogo: Nuevos medios audiovisuales públicos para la era digital". En López Cepeda, Ana M. Nuevos y viejos paradigmas de la televisión pública. Alternativas a su gobierno y (des) control. Salamanca: Comunicación Social.

Campos, F. (2015b). "Financiación e indicadores de gobernanza de la radiotelevisión pública en Europa”, En Marzal, J., Izquierda, J. y Casero, A. (eds.). La crisis de la televisión pública. El caso de RTVV y los retos de una nueva gobernanza. Bellaterra: UAB, Serveis de Publicaions; Castelló de la Plana: Publicacions de la Universitat 
Jaume I; Barcelona: Universitat Pompeu Fabra; Valencia:

Publicacions de la Universitat de Valencia, pp. 189-216.

Casado, L. (2008). "La configuración de la televisión de titularidad del Estado como servicio público en la Ley 17/2006", RVAP, 80, pp. 55-109.

Council of Europe Recommendation CM/Rec (1996) 10 of the Committee of Ministers to Member States on the guarantee of the independence of public service broadcasting

Council of Europe Declaration (2006) of the Committee of Ministers on the guarantee of the independence of public service broadcasting in the Member States

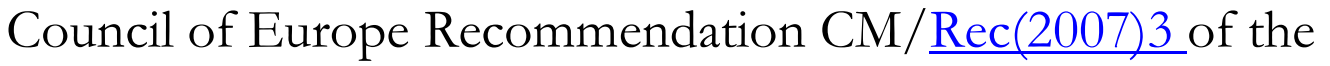
Committee of Ministers to member states on the remit of public service media in the information society

Council of Europe Recommendation CM/Rec(2012)1 of the Committee of Ministers to Member States on public service media governance.

Declaration of the Committee of Ministers (2012) on public service media governance.

Directiva 1989/552/CEE del Consejo, de 3 de octubre de 1989 sobre la coordinación de determinadas disposiciones legales, reglamentarias y administrativas de los Estados miembros relativas al ejercicio de actividades de radiodifusión televisiva.

Directiva 2007/65/CE del Parlamento Europeo y del Consejo, de 11 de diciembre de 2007 por la que se modifica la Directiva 89/552/CEE del Consejo sobre la coordinación de determinadas disposiciones legales, reglamentarias y administrativas de los Estados miembros relativas al ejercicio de actividades de radiodifusión televisiva.

Directiva 2010/13/UE del Parlamento Europeo y del Consejo, de 10 de marzo de 2010 sobre la coordinación de determinadas disposiciones legales, reglamentarias y administrativas de los Estados miembros relativas a la prestación de servicios de comunicación audiovisual.

European Broadcasting Union (2014a). Vision 2020 Connecting to a networked society.

European Broadcasting Union (2014b). PSM V alues Review. The Tool. 
Fernández, T. y Campos, F. (2013). "La responsabilidad social corporativa en la radio-televisiones públicas de Europa". Cuadernos.info, 33, pp. 145-157.

Fernández, T. (2015). "A responsabilidade social corporativa nas radiotelevisiósn públicas da Unión Europea”, Tesis doctoral. Universidad de Santiago de Compostela.

Ferrell, G. (2016). "PSM in the 21st century: What value and which values". European Broadcasting Union. Recuperado el 10 de marzo de 2016, de https://www3.ebu.ch/files/live/sites/ebu/files/Publications/ EBU-MIS\%20\%20PSM $\% 20$ in $\% 20$ the $\% 2021$ st $\% 20$ Century $\% 20$ $\% 20$ What $\% 20$ Value $\% 20$ and $\% 20$ Which $\% 20$ Values.pdf

Informe Teledetodos (2015). Un nuevo modelo para un tiempo nuevo. Recuperado el 10 de marzo de 2016, de http://teledetodos.es/index.php/blogs/item/1192-un-nuevomodelo-para-un-tiempo-nuevo-espana-2015-diagnostico-delservicio-publico-de-radio-television-y-servicios-interactivospropuestas-para-una-ciudadania-democratica

López Cepeda, AM. (2012). "Modelos audiovisuales públicos en

España. Perfil profesional, empresarial y político de sus principales órganos internos de gestión", Comunicación y Sociedad, 25(1), pp. 399-427.

López Cepeda, AM. (2015). Nuevos y viejos paradigmas de la televisión pública. Alternativas a su gobierno y (des) control. Salamanca: Comunicación Social.

Manfredi, J.L. (2011). "Algunas cuestiones pendientes en la regulación del audiovisual”, El Cronista del Estado Socialy

Democrático de Derecho, 24, pp. 54-59.

Michalis, M. (2011). "La política europea de comunicación y su impacto en los medios de radiodifusión". En Campos (Coord.) El nuevo escenario mediático. Salamanca: Comunicación Social, pp. 29-47.

Michalis, M. (2014). "Focal points of European Media. Policy from Inception till Present: Plus ça change?”. En Donders, Pauwels y Loisen (eds.). The Palgrave Handbook of European Media Policy. Londres: Palgrave Macmillan, pp. 128-142. 
Resolución del Parlamento de Europa, de 25 de noviembre de 2010, sobre el servicio público de radiodifusión en la era digital: el futuro del sistema dual.

Sánchez de la Nieta, M.A., Monfort, A. y Fuente C. (2015).

"Estatutos de redacción y comités profesionales en las empresas periodísticas: una aproximación desde la RSC", Comunicación y Sociedad, 28(2), pp. 55-72.

Wagner, M. y Berg, A-C. (2015). "Legal Focus Governance

pronciples for Public Service Media". European Broadcasting

Union. Recuperado el 10 de marzo de 2016, de

https://www3.ebu.ch/publications/principes-de-gouvernancepour-le

Zallo, R. (2015). “Análisis de la nueva Ley de Radio y Televisión

Pública de Canarias", Revista Latina de Comunicación Social, 70, pp. 322-346.

Zankova, S. (2013). "Públic Service Media Journalism and

Democracy in the Digital Age", Journalism and Mass

Communication, 3(10), pp. 679-689.

Zankova, S. (2014). "Governance, accountability and transparency of public service media in contemporary medialized world: The case of Bulgaria". en M. Głowacki \& L. Jackson (Eds.), Public media management for the twenty-first century: Creativity, innovation, and interaction. London, New York: Routledge

Reconocimientos: Los resultados de este artículo forman parte de las actividades de difusión del proyecto del Programa estatal de Fomento de la Investigación Científica y Técnica de Excelencia, subprograma estatal de Generación de Conocimiento del Ministerio de Economía y Competitividad de España sobre "Indicadores de gobernanza, financiación, rendición de cuentas, innovación, calidad y servicio público de las RTV europeas aplicables a España en el contexto digital" (Referencia CSO2015-66543- P. 


\title{
Public Value Test. La adaptación de la gobernanza a los nuevos medios
}

\author{
Marta Rodríguez-Castro \\ Universidade de Santiago de Compostela
}

Cómo citar: Rodríguez-Castro, M. (2017). Public Value Test. La adaptación de la gobernanza a los nuevos medios. En Túñez López, M.; Campos-Freire, F. y Silva Rodríguez A. (Eds.). Estudios sobre financiación, legislación e innovación en la Televisión Pública. Cuadernos Artesanos de Comunicación, cac126, pp 59-74. La Laguna (Tenerife): Latina.

DOI: $10.4185 / \operatorname{cac} 126$

L

A EXPANSIÓN de las actividades de las radiotelevisiones públicas europeas en los nuevos medios no ha estado exenta de reproches de los medios privados. La necesidad de gestionar mejor esta evolución mediática ha derivado en nuevas formas de gobernanza, entre las que se encuentran las denominadas pruebas de valor público. Desde que el Reino Unido desarrollase el Public Value Test en 2007 y la Comisión Europea recomendase la implantación de un mecanismo de evaluación previo similar, diez Estados miembros y otros dos no comunitarios han adoptado este procedimiento. En este capítulo se traza una panorámica sobre estas pruebas de valor público para entender su funcionamiento en un contexto marcado por la inestabilidad, el desarrollo tecnológico y la necesidad de políticas de transparencia.

Palabras clave: pruebas de valor público; gobernanza; Public Service Media; transparencia; televisión pública. 
La entrada en el siglo XXI ha estado marcada, en lo que a medios de comunicación públicos se refiere, por una notable tensión entre éstos y el sector privado, lo que ha derivado en un conjunto de medidas de gobernanza, control e intento de legitimación de los medios públicos a nivel europeo.

Entre estas medidas encontramos las denominadas pruebas de valor público o pruebas de evaluación previa, que se instalaron por primera vez en el Reino Unido en 2007 para que, dos años después, la Comisión Europea recomendase su adaptación a los distintos Estados miembros a través de la Comunicación de 2009. Las pruebas de valor público han sido objeto de un debate en torno a su pertinencia, su utilidad y, especialmente, su ambivalencia, ya que pueden usarse tanto a favor como en contra de los organismos de radiodifusión públicos.

Dicho debate ha marcado la paulatina introducción de la prueba en distintos contextos europeos. En la actualidad, 10 Estados miembros de la Unión Europea y otros 2 extracomunitarios pero enmarcados en el Espacio Económico Europeo (EEE) han optado por incluir este procedimiento como parte de sus políticas de gobernanza. Estos procesos de adaptación del test, sumados a la situación de stand-by en la que se encuentra la prueba en el caso español, hacen necesaria la revisión de lo que está sucediendo en Europa con las pruebas de valor público.

\section{La conversión digital de los medios públicos: hacia el Public Service Media}

El desarrollo de los medios de comunicación siempre estuvo marcado por los avances tecnológicos. El origen de las pruebas de evaluación previa se encuentra en la transición de las radiotelevisiones públicas al nuevo entorno digital, caracterizado por su carácter multimedia, la interconectividad y la interactividad.

Los medios de comunicación públicos intentaron beneficiarse de las ventajas que traen consigo las nuevas plataformas y el nuevo entorno digital a la hora de desarrollar su misión de servicio público. En los últimos años, por lo tanto, se ha pasado del denominado Public Service Broadcasting (PSB, radio y televisión públicas) al Public Service Media 
(PSM), un concepto mucho más amplio que engloba estas nuevas actividades de servicio público que no están limitadas a los medios de difusión tradicionales.

La transición hacia el PSM ha sido altamente cuestionada por el sector privado, que durante años presentó quejas ante la Comisión Europea en relación a la expansión de las actividades de las entidades públicas hacia los nuevos medios, alegando conflictos con respecto a su financiación pública o su escasa relación con la misión de servicio público establecida.

Esta situación puso de manifiesto la necesidad de una regulación adecuada al entorno digital, en la cual el Consejo de Europa jugó un rol fundamental con la publicación de la Recomendación del año 2007 con respecto a la misión de los PSM en la sociedad de la información (Comité de Ministros, 2007). Este documento recoge los principales cambios que experimentaba el mundo de las comunicaciones, como la integración internacional, la concentración horizontal y vertical de los medios privados o la migración de audiencias de los medios tradicionales a los nuevos medios.

El Comité de Ministros, por lo tanto, insta a los Estados miembros a que adapten la regulación de sus organismos de PSB para convertirlos progresivamente en PSM, legitimando el uso de los nuevos medios por parte de las entidades públicas y atendiendo a las necesidades de una necesidad cada vez más digital e interconectada.

La legitimación política, sumado al innegable apoyo de la audiencia hacia nuevas formas de consumo, son dos de los pilares básicos sobre los que se sustenta el desarrollo de los PSM. Según Bardoel y Ferrell Lowe (2007), se pueden establecer tres criterios fundamentales empleados por la Comisión Europea para determinar una financiación correcta del PSM:

“1. ¿Cuenta con una definición clara y precisa y una vinculación con la misión de servicio público, especialmente en lo relativo a las nuevas actividades mediáticas? 
2. ¿Cuenta con una definición apropiada y transparente de las actividades comerciales y de servicio público?

3. ¿Cuenta con una financiación proporcionada para las actividades de radiodifusión pública (PSB) que evite la sobrecompensación y las subvenciones cruzadas?" (Bardoel y Ferrell Lowe, 2007).

La adaptación de la misión de servicio público es uno de los pasos más importantes a dar en el proceso de transformación hacia el PSM. Este cambio no se puede producir sin repensar y reafirmar la necesidad del concepto servicio (Jakubowicz, 2007). El entorno mediático actual hace que los PSM sean más necesarios que nunca.

La tendencia en los medios digitales es la migración de usuarios hacia servicios de pago o suscripción, en contraposición a la idea de acceso universal que se encuentra en la misión de servicio público de cualquier medio público. La segmentación de audiencias y la creación de contenidos nicho también ponen de manifiesto la necesidad de un servicio público dirigido a audiencias amplias, al mismo tiempo que mientras la tendencia de globalización de las empresas mediáticas se consolida, los PSM pueden proporcionar el contrapunto más local, regional y nacional que todo ecosistema mediático necesita para mantener la cohesión social.

\section{E1 proceso de adaptación de las pruebas en Europa}

Esta adaptación de las radiotelevisiones públicas hacia el ecosistema digital estuvo rodeada de protestas por parte de los medios de comunicación privados, tanto los tradicionales como los que emergieron en torno al mundo digital. Éstos consideraban que el hecho de contar con fondos públicos y de no estar sometidos a la necesidad de obtener beneficios económicos concedía a los medios públicos una ventaja competitiva que mermaba las posibilidades de que las iniciativas privadas fuesen bien acogidas y consiguiesen consolidarse en un mercado todavía incipiente e inestable.

Las protestas de los medios de comunicación privados surgen en el marco nacional, pero pronto se elevan hasta la Comisión Europea, ante 
la que se alegan fallos de mercado fruto de una doble provisión de servicios y se denuncia la posible doble financiación de las radiotelevisiones públicas. A todo esto también hay que sumar numerosas quejas por falta de transparencia en los procesos de negociación y desarrollo de las políticas de comunicación.

De esta forma se detonaron una serie de investigaciones llevadas a cabo por la Dirección General de Competencia de la Comisión Europea en torno a la financiación de las televisiones públicas. Estas investigaciones desembocaron en la negociación de la Comisión Europea con los Estados miembros para que éstos elaborasen una mejor definición de su misión de servicio público, así como para que ejerciesen un mayor control sobre su financiación e inversión de recursos en los nuevos medios. El debate generado alrededor de esta situación tendrá repercusiones a nivel europeo a raíz de la revisión de la Comunicación de 2001, relevada por la Comunicación de 2009.

La «Comunicación de la Comisión sobre la aplicación de la Comisión sobre la aplicación de las normas en materia de ayudas estatales a los servicios públicos de radiodifusión» (Comisión Europea, 2009) constituye el primer texto legal europeo que recoge la sugerencia de implantar una prueba de evaluación previa orientada a la aprobación de las actividades de las radiotelevisiones públicas en los nuevos medios.

La definición de prueba que se propone en dicha Comunicación es básica y no entra a detallar el proceso en profundidad, dejando libertad para adaptar este instrumento a los países que opten por incorporarlo a su contexto nacional. El párrafo 84 de la Comunicación de 2009 recoge la idea esencial de la prueba:

"Como se ha indicado anteriormente, la ayuda estatal a los organismos públicos de radiodifusión puede utilizarse para distribuir servicios audiovisuales en todas las plataformas siempre que se cumplan los requisitos materiales del Protocolo de Ámsterdam. Para ello, los Estados miembros deberán examinar, mediante un procedimiento de evaluación previa basado en una consulta pública abierta, si los nuevos servicios audiovisuales previstos por los organismos públicos de 
radiodifusión cumplen los requisitos del Protocolo de Ámsterdam, es decir, si satisfacen las necesidades democráticas, sociales y culturales de la sociedad, teniendo también en cuenta debidamente sus efectos potenciales en las condiciones comerciales y en la competencia." (Comisión Europea, 2009: 22 \$84). Así, la prueba propuesta por la Comisión Europea (también denominada prueba de Ámsterdam debido a su vinculación con el protocolo homónimo) recoge tres partes fundamentales a la hora de evaluar ex ante un nuevo servicio: el análisis de su valor público, el de su impacto de mercado, y la realización de una consulta pública abierta.

Para la Comisión, el valor público de la propuesta debe medirse a partir de la «satisfacción de los valores sociales, democráticos y culturales de la sociedad» (Comisión Europea, 2009, \$87), mientras que el impacto de mercado se debería determinar en función de elementos como «la existencia de ofertas similares o sustituibles, la competencia editorial, la estructura del mercado, la posición de mercado del organismo público de radiodifusión, el nivel de competencia, y el posible impacto sobre las iniciativas privadas» (Comisión Europea, 2009, \$87).

A pesar de que la Comisión Europea reconoce la competencia de los Estados miembros en materia de radiodifusión, dejándoles margen para la adaptación de la prueba en función de las características de cada contexto nacional, en algún otro aspecto se muestra menos flexible. Es el caso de, por ejemplo, la necesidad de que el organismo que lleve a cabo la evaluación sea independiente de la dirección del organismo público de radiodifusión (Comisión Europea, 2009, \$86) o de que se incluya un proceso de consulta abierta en la que los distintos grupos de interés puedan expresar sus opiniones sobre la propuesta de nuevo servicio (Comisión Europea, 2009, §87).

La resolución de la prueba se debe basar en la contraposición de las dos evaluaciones que la componen, considerando también los resultados de la consulta. Según la Comunicación de 2009, "si los efectos en el mercado son predominantemente negativos, la financiación estatal de los servicios audiovisuales parecerá proporcional únicamente si se justifica por el valor añadido de los valores sociales, democráticos y culturales de la sociedad, teniendo en 
cuenta también la oferta general de servicio público existente." (Comisión Europea, 2009:22, §88)

Desde la publicación de la Comunicación de 2009, un total de 10 países de la Unión Europea -Reino Unido, Alemania, la región belga de Flandes, Irlanda, Austria, los Países Bajos, Dinamarca, Suecia, Finlandia y Croacia- y otros 2 pertenecientes al Espacio Económico Común -Islandia y Noruega- han adoptado y adaptado este procedimiento ex ante, tal y como se representa en la imagen del mapa.

\section{Imagen 1: Inversión publicitaria}

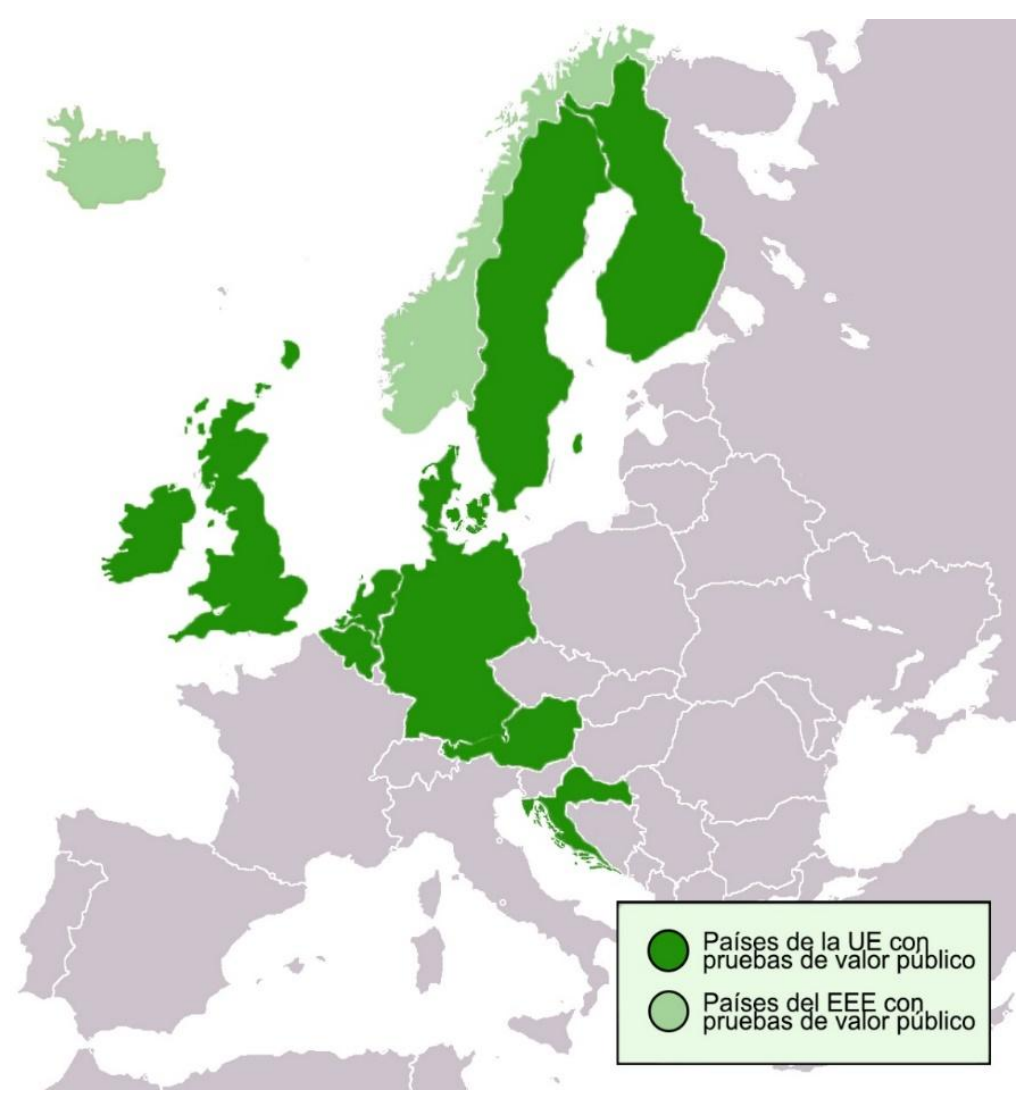

Fuente: Elaboración propia

El caso de Reino Unido es especial, ya que las pruebas de evaluación previa se utilizaron por primera vez para la aprobación de los nuevos servicios de la BBC en el año 2007, es decir, con anterioridad a la recomendación de la Comisión Europea. De hecho, ha sido el Public $V$ alue Test británico el que ha servido de modelo a Bruselas a la hora 
de recomendar su mecanismo ex ante. Debido a este carácter pionero, a continuación entraremos en detalle en su desarrollo, que servirá para entender un poco mejor el concepto y el funcionamiento general de las pruebas.

\section{La primera prueba de valor público: el Public Value Test británico}

La prueba de valor público británica es, debido a su carácter iniciático, la más popular de entre los mecanismos ex ante europeos. Se implantó en el año 2007 a raíz de la modificación de la BBC Charter, y desde entonces se han llevado a cabo un total de 5 pruebas que tuvieron como objeto de análisis las siguientes propuestas: un servicio de televisión bajo demanda, otro de televisión en alta definición, un canal de televisión digital orientado a la comunidad gaélica, un servicio de vídeo local y un paquete de cambios relativos a los servicios televisivos y online de la BBC. De las cinco propuestas anteriores, cuatro fueron aprobadas y tan sólo la relativa al servicio de vídeo local suspendió la prueba y no pudo llevarse a cabo.

Este mecanismo se entiende como un procedimiento dinámico frente al estatismo de la BBC Charter, lo que facilita una mejor adaptación a las transformaciones tecnológicas, culturales, de las expectativas del público y de las condiciones de mercado (BBC Agreement, 2006, art. 23(1)). El BBC Agreement establece la base legal del Public Value Test en los artículos 23 a 33, por lo que las cinco pruebas se han desarrollado de forma similar bajo estos parámetros.

El proceso se inicia cuando la BBC Executive presenta una solicitud de nuevo servicio ante el BBC Trust, acompañada de un informe que recoge toda la información relativa a su puesta en marcha $\mathrm{y}$ funcionamiento -como un presupuesto estimativo, objetivos a superar, escala potencial o incluso pilotos y pruebas-. El BBC Trust debe entonces valorar la necesidad de iniciar o no la prueba de valor público, en función de cuatro parámetros: el impacto potencial del servicio, sus implicaciones financieras, su innovación y su duración. Si el BBC Trust considera que la propuesta tiene un peso significativo dará paso a la 
apertura oficial de proceso, que deberá completarse en un plazo máximo de 6 meses.

El Public Value Test consiste en dos evaluaciones distintas que se desarrollan de forma simultánea en un plazo de 3 meses: la evaluación del valor público (PVA), llevada a cabo por el BBC Trust, y el estudio del impacto de mercado (MIA), a cargo de la Ofcom. Estos dos análisis, como ya se mencionó arriba, son parte esencial de la prueba recomendada por la Comisión Europea y están presentes en la gran mayoría de los mecanismos ex ante europeos ${ }^{4}$.

El PVA tiene como objeto de análisis un concepto, el de «valor público», complejo y muy difícil de definir y cuantificar. Para facilitar la tarea del BBC Trust durante la evaluación del valor público, en el BBC Agreement se desglosan tres concepciones a partir de las que abordarlo (BBC Agreement, art. 28(2)):

- El valor que cada ciudadano que abone el canon pueda ver en el cambio propuesto de forma individual.

- El valor que el cambio propuesto aporte a la sociedad como conjunto, es decir, en relación a los Public Purposes de la BBC y su misión de servicio público.

- La relación de calidad y precio de la propuesta y sus costes potenciales.

Teniendo esto en cuenta, junto con otros criterios como la calidad de los resultados o el impacto individual y social, el BBC Trust evaluará el valor público de la propuesta. Para ello, podrá contar con recursos como predicciones de demanda, resultados de pruebas piloto, opiniones de expertos y estudios de mercado. Sin embargo, una de las fuentes fundamentales para este apartado la constituyen los resultados de la consulta pública abierta, realizada durante un periodo de 28 días durante los cuales los ciudadanos británicos y los distintos grupos de

\footnotetext{
${ }^{4}$ La única prueba de evaluación previa que no cuenta con ambas evaluaciones es la de los Países Bajos. El mecanismo ex ante opta por suprimir el análisis del impacto de mercado, centrándose tan solo en la evaluación del valor público del servicio propuesto.
} 
interés pueden manifestar sus opiniones y visiones con respecto al nuevo servicio propuesto.

De forma paralela al PVA, y en estrecha relación con el BBC Trust, la Ofcom desarrolla el MIA. La evaluación del impacto de mercado combina pruebas empíricas con consultas a expertos, con el objetivo de valorar el impacto directo que la implantación del servicio pudiese tener tanto en los consumidores como en los productores de servicios similares, así como su influencia, positiva o negativa, en la competencia y en el desarrollo del mercado.

La Ofcom y el BBC Trust intentarán publicar los resultados de sus respectivas evaluaciones de forma simultánea. Una semana más tarde, el BBC Trust deberá anunciar sus conclusiones provisionales fruto de la confrontación de ambos informes. Se abrirá entonces una consulta pública de 28 días orientada a la recopilación de comentarios sobre este resultado, tras la cual se publicará la decisión final: aprobar el cambio, aprobarlo sujeto a condiciones, o rechazarlo.

La conclusión de la prueba debe ser comunicada a la Secretaría de Estado de Cultura, Medios de Comunicación y Deporte, que podría ejercer su derecho de veto, no en función de los méritos de la propuesta, sino de la corrección con la que se haya desarrollado la prueba.

\section{E1 Drei-Stufen-Test, una prueba regional}

Alemania fue el primer país en implantar de forma estable una prueba de evaluación previa tras la Comunicación de 2009, después de años de negociaciones entre el gobierno alemán y la Comisión Europea en torno a la financiación de su sistema público de radiodifusión, que concluyeron con la recomendación de la Comisión de implantar un mecanismo de evaluación ex ante que regulase la aprobación de nuevos servicios. De esta forma, el Drei-Stufen-Test (prueba de los tres pasos) se materializaba en el año 2009 con la modificación del Rundfunkstaatsvertrag, la ley alemana de radiodifusión acordada por consenso de los Länder. 
El Drei-Stufen-Test se recoge en este artículo por contar con ciertas particularidades que detallaremos a continuación, pero también por ser la prueba europea que más veces se ha llevado a cabo: hasta el momento, un total de 45 servicios han sido aprobados mediante este procedimiento. Esta situación excepcional se debe, por una parte, a que su alcance no está limitado a la evaluación de nuevos servicios o modificaciones significativas, sino que los servicios vinculados a los nuevos medios que estuviesen activos antes de 2009 también tuvieron que superar la prueba para garantizar su continuación; por otro lado, ese elevado número de pruebas está vinculado con la estructura regional de la radiodifusión alemana, ya que tanto las emisoras que emiten a nivel nacional (ARD y ZDF) como las 9 emisoras regionales deben aplicar el procedimiento.

El desarrollo del Drei-Stufen-Test está ligado a los tres pasos o aspectos de los servicios propuestos que se deben analizar: la relación del servicio con las necesidades democráticas, sociales y culturales de la sociedad, la contribución de la propuesta a la competencia editorial, y el gasto financiero necesario para llevar a cabo la propuesta

El proceso del Drei-Stufen-Test se desarrolla en cinco fases que, en conjunto, no deben superar los seis meses de duración. La primera de estas fases sería el examen preliminar, que se inicia con la elaboración por parte de la emisora pública de un concepto de la propuesta, con información relativa a su contenido, target o futura organización. El director de la emisora entregará este informe al Consejo de Radiodifusión correspondiente (Rundfunkrat), que valorará la pertinencia de abrir o no el procedimiento oficial, pudiendo rechazar directamente en esta fase la propuesta en caso de que ésta no se adapte a las restricciones legales ${ }^{5}$.

En caso de que el Rundfunkrat considere necesario iniciar el Drei-StufenTest se procederá a la apertura formal del procedimiento. En esta segunda fase se marcará el calendario de la prueba, con una duración máxima de seis meses, y se asignarán las distintas tareas a los órganos

\footnotetext{
${ }^{5}$ La legislación alemana en materia de radiodifusión incluye una lista negativa en la que se detallan todos los servicios vetados a los medios de comunicación públicos, en función de su escasez de valor democrático, cultural o social (Dörr, 2011:78)
} 
pertinentes. Al mismo tiempo, es en esta segunda fase cuando se abre la consulta pública de seis semanas a través de la que los terceros interesados podrán expresar su opinión sobre la propuesta.

La tercera etapa del Drei-Stufen-Test consiste en la recopilación de toda la información necesaria para la evaluación y posterior toma de decisiones. El informe de mercado es encargado a una consultora externa elegida por concurso público, que dispondrá de dos meses para la elaboración del informe. Para ello, podrá recurrir a fuentes diversas, entre las que pueden incluirse las opiniones recabadas durante la consulta pública.

Tras esta fase de recopilación de información, el Rundfunkrat deberá aplicar los tres criterios que vertebran el Drei-Stufen-Test y decidir si aprobar o no la propuesta analizada. Esta fase de toma de decisiones se produce en un pleno del Rundfunkrat donde el resultado debe ser aprobado por mayoría de dos tercios. Tras la pronunciación del Rundfunkrat se procede a la etapa final del proceso, su cierre oficial, publicándose toda la documentación relevante empleada durante el transcurso de la prueba, así como la justificación de la decisión final.

\section{Otras experiencias europeas en torno a las pruebas de evaluación previa}

Como ya se apuntó antes, un total de 12 países europeos han optado por adaptar un mecanismo ex ante para aprobar los nuevos servicios de sus radiotelevisiones públicas. En este artículo nos hemos centrado en el funcionamiento de dos de los principales paradigmas de prueba, el británico y el alemán, pero en este apartado se trazará un pequeño panorama general alrededor de las pruebas europeas, de tal manera que quede mejor perfilada una idea global sobre su funcionamiento y utilidad.

La estructura global de las pruebas europeas consiste en la evaluación del valor público y del impacto de mercado, siguiendo de forma bastante directa la recomendación de la Comisión Europea. El único mecanismo ex ante que rompe con esta regla es el de los Países Bajos, que no incluye la evaluación del impacto de mercado y se basa 
únicamente en el criterio del valor público. Otro aspecto en el que sí coinciden todas las pruebas es en la inclusión de la consulta pública abierta en la que los terceros interesados puedan expresar su punto de vista sobre la propuesta analizada. El período durante el que se desarrolla esta consulta oscila entre las 3 y las 6 semanas.

La duración de las pruebas de valor público europeas oscila entre los 3 y los 6 meses. La mayor o menor duración de la prueba tiene consecuencias directas en su presupuesto. Países como Reino Unido y Alemania apuestan por mecanismos que se extienden hasta los 6 meses y que requieren un gran desembolso económico (entre 500.000 y 1.000.000€). Otros como Noruega o Suecia fijan la duración de sus pruebas en 3 meses, lo que aporta dinamismo y rapidez a la toma de decisiones.

Uno de los aspectos de las pruebas que presenta mayor diversidad tiene que ver con los agentes encargados del desarrollo de la prueba y de la toma de decisiones. Mientras que en algunos casos se opta por organismos independientes, tanto del sector político como de la propia dirección de la radiotelevisión pública (el BBC Trust, en Reino Unido o los Rundfunkrat alemanes), en otros contextos la prueba corre a cargo de un agente político o éste cuenta con un peso importante en la toma de decisiones.

Así sucede en Noruega, donde la influencia del agente político se sitúa en el extremo: la aprobación o no de la propuesta de la NRK reside en el Kongen i statsråd, que además puede desestimar la recomendación a la que la Autoridad de Medios haya llegado después de la evaluación. La independencia supone una característica muy deseable a la hora de diseñar y desarrollar una prueba de valor público, ya que sólo a través de este camino se podrán alcanzar resultados justos que contribuyan a la legitimación del papel de la radiotelevisión pública y a su avance en los nuevos medios.

En cuanto al contexto español, la prueba de valor público no ha llegado a desarrollarse, a pesar de que la Ley de la Comunicación Audiovisual de 2010 aprobada durante la segunda legislatura de José Luis Rodríguez 
Zapatero recoge en su artículo 41(3) la definición de este procedimiento:

En particular, las autoridades audiovisuales competentes deberán evaluar si los nuevos servicios significativos que se pretendan incluir se ajustan a la misión de servicio público encomendada y si alteran la competencia en el mercado audiovisual. Durante la evaluación se deberá otorgar audiencia a los distintos interesados, y sus resultados deberán publicarse. (Ley de la Comunicación Audiovisual, 2010, art.41(3).

Sin embargo, la prueba de evaluación previa española nunca superó esta dimensión teórica y su introducción, a día de hoy, no se ha hecho efectiva. El principal motivo de este estancamiento se encuentra en que el Consejo Estatal de Medios Audiovisuales (CEMA), incluido en el Título V de la misma ley, tampoco llegó a crearse nunca. Con la llegada del Gobierno de Mariano Rajoy se optó por la derogación del CEMA, siendo absorbidas sus competencias por la Comisión Nacional de los Mercados y la Competencia (CNMC). En la actualidad, y a pesar de que el artículo 41 no ha sido suprimido ni modificado, la prueba de valor público española sigue sin ser una realidad.

De forma general, el estudio de las pruebas de valor público en Europa deja entrever que donde mejor acogida ha tenido este procedimiento ha sido en los países que ya contaban con un sistema de medios públicos fuerte y consolidado en su mercado.

\section{Conclusiones: adaptando la gobernanza a los nuevos medio}

Las pruebas de valor público, tal y como se ha intentado perfilar en este artículo, constituyen una reacción institucionalizada a la urgente necesidad de adaptar la gobernanza de las radiotelevisiones públicas al desarrollo de sus actividades en los nuevos medios. En un contexto de tecnología y medios en constante cambio, la gobernanza debe ser capaz de lidiar con la oposición del sector privado al mismo tiempo que asegura el desarrollo óptimo de la misión de servicio público de los medios de comunicación estatales. 
Una aproximación crítica a las pruebas obliga a entenderlas como un arma de doble filo. Si bien existe un cierto consenso en torno a los aspectos positivos de los procedimientos de evaluación ex ante legitimación de las actividades del sector público en los nuevos medios (Thoresen y Bolstad, 2011), freno de las críticas del sector comercial (Wormbs, 2011), uso como herramienta de transparencia y escrutinio público o incluso el uso de los nuevos medios de forma más selectiva y efectiva (Bardoel y Vochteloo, 2011)-; también son muchas las sombras que se han generado alrededor de estas pruebas.

Entre estas cualidades negativas se incluye la reducción de estrategias de colaboración con terceros, al minarse el atractivo de la emisora pública (Thoresen y Bolstad, 2011), y con el propio público, o el hecho de que las pruebas de valor público sigan constituyendo un complejo proceso administrativo que pone trabas a la agilidad y adaptación de los medios públicos a los cambios frenéticos que se producen en su entorno. De esta forma, hay quien considera que las pruebas de valor público suponen una nueva forma de escrutinio de los servicios de radiodifusión pública, y que no deberían ser un sustitutivo de políticas de comunicación claras y que defiendan el papel de los medios públicos dentro de la sociedad.

Las diferentes formas en las que la prueba se ha extrapolado a los distintos contextos nacionales de los 12 países que la han adoptado deja espacio para que los que todavía no lo han hecho pueden plantearse un diseño óptimo para esta adaptación de la gobernanza, en función de las necesidades de su sistema de radiodifusión pública, y conjugando las luces y sombras presentes en estos procedimientos.

\section{Bibliografía}

Bardoel J.L.H. \& Lowe, G. F. (2007). From public service broadcasting to public service media: The core challenge. En Lowe, G. F. \& Bardoel, J.L.H., From public service broadcasting to public service media (pp. 9-26). Göteborg: Nordicom.

Bardoel J.L.H. \& Vochteloo, M. (2011). Dutch Public Service Broadcasting Between Bureaucratic Burden and Political Choice. Implementing the Amsterdam Test in the Netherlands. En Donders, K. \& Moe, H. (eds.), Exporting the Public Value Test: The 
Regulation of Public Broadcasters's New Media Services Across Europe (pp. 135-144). Gotemburgo: Nordicom.

BBC Trust (2012). BBC Trust assessment processes. Guidance document www.bbc.co.uk

Comisión Europea (2009). Comunicación de la Comisión sobre la aplicación de las normas en materia de ayudas estatales a los servicios públicos de radiodifusión. Bruselas: Comisión Europea.

Comité de Ministros (2007). Recommendation CM/Rec (2007)3 of the Committee of Ministers to member's states on the remit of public service media in the information society. Estrasburgo: Consejo de Europa

Department for Culture, Media and Sport (2006). Broadcasting Agreement.

Die Medienanstalten (2009). Staatsvertrag für Rundfunk und Telemedien.

Donders, K. (2011). The Public Value Test. A Reasoned Response or Panic Reaction? En Donders, K. \& Moe, H. (eds.), Exporting the Public V alue Test: The Regulation of Public Broadcasters's New Media Services Across Europe (pp. 29-38). Gotemburgo: Nordicom.

Gobierno de España. Ley 7/2010, de 31 de marzo, General de la Comunicación Audiovisual.

Hilden, J. (2013). European Public Service Broadcasting Online. Helsinki: University of Helsinki.

Jakubowicz, K. (2007). Public service broadcasting: a new beginning, or the beginning of the end? Londres: Knowledge Politics.

Thoresen, H. \& Bolstad, E. (2011). Ex Ante Limits Public Broadcasting and Gives the Public Less Attractive Services. En Donders, K. \& Moe, H. (eds.), Exporting the Public V alue Test: The Regulation of Public Broadcasters's New Media Services Across Europe (pp. 107-116). Gotemburgo: Nordicom.

Wormbs, N. (2011). Swedish Pre-Screening of New Services. Treading Lightly. En Donders, K. \& Moe, H. (eds.), Exporting the Public $V$ alue Test: The Regulation of Public Broadcasters's New Media Services Across Europe (pp. 127-134). Gotemburgo: Nordicom. 


\title{
Competitividad de la televisión pública en la distribución de contenidos
}

\author{
Verónica Crespo Pereira \\ Universidade de Vigo
}

Cómo citar: Crespo-Pereira, V. (2017). Competitividad de la televisión pública en la distribución de contenidos. En Túñez López M.; Campos-Freire, F. y Silva Rodríguez A. (Eds.). Estudios sobre financiación, legislación e innovación en la Televisión Pública. Cuadernos Artesanos de Comunicación, cac126, pp 75-87. La Laguna (Tenerife): Latina. DOI: $10.4185 /$ cac126

\begin{abstract}
T A IRRUPCIÓN de las nuevas tecnologías y el nuevo escenario $\mathcal{L}$ competitivo mediático son elementos que define la producción y distribución de contenidos audiovisuales en la actualidad. La democratización de la banda ancha y de nuevos dispositivos favorecen la explotación de multiplicidad de plataformas para la emisión de contenidos a la par que incrementan las oportunidades de atraer nuevas audiencias nacionales e internacionales. En este contexto, los broadcasters luchan por abrir nuevas vías de negocio y optimizar al máximo las posibilidades de los soportes. En este capítulo se analiza el papel de las que desempeñan las plataformas digitales como motor para la innovación en la distribución y se revisan, también, las tendencias advertidas en dicho campo entre las televisiones públicas europeas.
\end{abstract}

Palabras clave: televisión pública; innovación; distribución; contenidos; PSM. 
El sector audiovisual se encuentra en una fase de transición hacia la distribución híbrida digital. La democratización de internet y la banda ancha facilita la aparición nuevos competidores que abocan a la redefinición de estructuras y modelos de negocio de unos broadcasters acostumbrados a reunir grandes audiencias entorno a la televisión lineal.

En la era de lo digital, el nuevo modelo de televisión pública se enfrenta a una serie de retos vinculados a distintas áreas, entre las que se halla la distribución. Algunos de los elementos de mayor relevancia para la estabilidad y competitividad de los PSM en este campo se encuentran la revisión de las políticas de distribución de la señal (ya sea terrestre, cable, satélite y nuevas redes), el desarrollo de nuevos servicios de comunicación, y la presencia universal, gratuita y obligatoria de los servicios públicos las ofertas multicanal de terceros operadores (Moragas y Prado, 2001).

Resultado de esta redefinición se produce un incremento de la competitividad que exige planteamientos estratégicos eficientes entorno al concepto de servicio audiovisual otorgado a la televisión contemporánea (Campos-Freire, 2013). Un cambio de paradigma que lleva a la recuperación y fortalecimiento de la noción de televisión pública como ente que aboga por los servicios a la ciudadanía.

En este contexto, los radiodifusores públicos deben adaptarse al actual panorama digital como síntoma de su compromiso, cumplimiento y refuerzo con su misión. De acuerdo a su definición fundacional, los PSM europeos están especialmente abocados a abrir camino hacia la accesibilidad y universalidad de sus servicios.

Ya en 2000, el libro blanco A New Future for Communications, del Department of Trade and Industry y el Department of Culture, Media and Sport (2000) británicos, apunta la necesidad garantizar un servicio público que atienda al nuevo marco de la televisión digital y al dinámico mercado y establece como principales objetivos la universalidad del acceso a servicios de calidad. Es por ello que la innovación en el campo de la distribución se alinea como pieza clave para garantizar la 
universalidad de los servicios y la viabilidad y sostenibilidad de los radiodifusores de carácter público en el actual panorama mediático.

Las nuevas tecnologías se postulan como herramientas de utilidad para la legitimación social de lo público y la consecución de un posicionamiento competitivo dado el actual escenario mediático. La diversificación de dispositivos y explotación de nuevos canales son algunas de las últimas fórmulas incorporadas por las televisiones públicas europeas en su carrera hacia la adaptación al contexto digital y expansión y satisfacción de nuevos mercados.

La multiplataforma es la última de las estrategias online adoptadas por broadcasters de todo el mundo al generar especial valor añadido y ofrecer un mejor cumplimiento de los imperativos fundacionales en el caso de los entes públicos (Suárez Candel, 2010).

Un nuevo paradigma caracterizado por, entre otros elementos, la no linealidad de los contenidos, el visionado bajo demanda, la movilidad y ubicuidad de los servicios, la hibridación de contenidos y servicios, la interactividad y conectividad, la participación y la versatilidad de servicios o personalización de los mismos.

Sin embargo, y hasta alcanzar dicho nivel de explotación tecnológica, la estrategias online han evolucionado paulatinamente. Así pues y de acuerdo a Suárez Candel (2012), la adopción de políticas online se realizó en seis olas o fases compuestas por: la Web 1.0; la Web 1.0 extendida; la Web 2.0 y bibliotecas de medios; introducción del móvil; televisión híbrida y conectada y la conectividad entre dispositivos.

Con el desarrollo tecnológico también llegaron los cambios en el consumo audiovisual. El usuario hoy dispone de completo poder y control sobre el visionado. Como resultado de este empoderamiento, las audiencias se fragmentan y los grupos nicho comienzan a ser el objetivo de unas corporaciones públicas que apuestan por la segmentación y personalización de servicios y políticas de distribución adaptadas a las demandas de unos espectadores exigentes y dispersos. 


\section{Antecedentes y metodología}

Esta investigación revela, mediante el método analítico y sintético, las tendencias en el campo de la distribución en el escenario audiovisual. De forma específica, este capítulo se centra en las principales tendencias observadas en el campo de la distribución de contenidos por parte de PSM europeos. Para ello, se llevó a cabo un análisis de las webs de los 28 radiodifusores públicos europeos que se detallan en la tabla 1.

De forma complementaria, se realizó una investigación secundaria a partir de las principales bases de datos sobre televisión europea (MAVISE) e informes del OBS y cadenas públicas.

\section{Resultados}

A continuación se muestran las principales tendencias halladas en el área de innovación en la distribución entre los PSM europeos. Dada la amplia muestra de cadenas analizadas se ha optado por facilitar ideas generales acerca de aquellos elementos más destacables en la distribución.

\subsection{Tendencia a la digitalización de la señal}

Cifras del Observatorio Audiovisual Europeo señalan que en 2014 el $87,8 \%$ de los hogares de la Unión Europea tiene acceso a la televisión digital en sus diversas plataformas (TDT, satélite digital, cable digital y IPTV) (OBS, 2015). A pesar de estas cifras, la instauración de la TDT con el objetivo 2020 es desigual entre los países de la U.E.

Mientras algunos países europeos todavía luchan por la normalización de la televisión digital terrestre, otros más avanzados ya han saltado a la emisión en Alta Definición como síntoma de compromiso hacia los servicios de calidad por parte de los PSM.

Es el caso de la televisión francesa que, desde el 5 de abril de 2016, emite íntegramente en HD impulsando que France Télévisions y sus canales secundarios (France 3, France 4, France 5, France ô, Gulli, 
Public sénat, LCP) se adapten a la norma. En esta línea, broadcasters públicos como la alemana ARD, la finlandesa Yle o la italiana Rai ya han iniciado la adopción del full HD en sus emisiones.

Tabla 1. Listado de PSM analizados por países

\begin{tabular}{|c|c|}
\hline País & PSM \\
\hline Alemania & $\begin{array}{l}\text { Arbeitsgemeinschaft Rundfunkanstalten der Bundesrepublik } \\
\text { Deutschland (ARD), Zweites Deutsches Fernsehen (ZDF), } \\
\text { Deutsche Welle, Deutschlanradio }\end{array}$ \\
\hline Austria & Österreichischer Rundfunk (ORF) \\
\hline Bélgica & $\begin{array}{l}\text { Vlaamse Radio- en Televisieomroep (VRT), Radio Télévision } \\
\text { Belge de la Communauté Française (RTBF), BRF }\end{array}$ \\
\hline Bulgaria & Balgarska Nationalna Televizija (BNT), BNR \\
\hline Chipre & $\mathrm{CyBC}$ \\
\hline Croacia & Hrvatska Radiotelevizija (HRT) \\
\hline Dinamarca & Danmarks Radio (DR), TV2/Danmark (DK/TV2) \\
\hline Eslovaquia & Rozhlas a televízia Slovenska (RTS) \\
\hline Eslovenia & Radiotelevizija Slovenija (RTVSLO) \\
\hline España & Radio Televisión Española (RTVE) \\
\hline Estonia & Eesti Rahvusringhääling (ERR) \\
\hline Finlandia & Yleisradio Oy (YLE) \\
\hline Francia & $\begin{array}{l}\text { France Televisions, Arte France, France Médias Monde, } \\
\text { Chaine Parlamentaire, Radio France, TV5 Monde }\end{array}$ \\
\hline Reino Unido & $\begin{array}{l}\text { British Broadcasting Corporation (BBC), Channel } 4 \text { Group, } \\
\text { S4C, Services Sound and Vision Corporation }\end{array}$ \\
\hline Grecia & Ellinikí Radiofonía Tileórasi (ERT) (antes NERIT) \\
\hline Hungría & MTVA \\
\hline Irlanda & Radio Telefís Éireann (RTE), TG4 \\
\hline Italia & Radiotelevisione Italiana (RAI) \\
\hline Letonia & Latvijas Radio (LR), Latvijas Televizija (LTV) \\
\hline Lituania & Lietuvos nacionalinis radijas ir televizija (LRT) \\
\hline Luxemburgo & Chaine Parlementaire \\
\hline Malta & Public Broadcasting Services (PBS) \\
\hline Países Bajos & Nederlandse Publieke Omroep (NPO) \\
\hline Polonia & Polskie Radio (PR), Telewizja Polska (TVP) \\
\hline Portugal & Rádio e Televisão de Portugal (RTP) \\
\hline Rep. Checa & Český rozhlas (CR), Česká televize (CT) \\
\hline Rumanía & $\begin{array}{l}\text { Societatea Română de Radiodifuziune (SRR), Societatea } \\
\text { Română de Televiziune (TVR) }\end{array}$ \\
\hline Suecia & $\begin{array}{l}\text { Sveriges Radio (SR), Sveriges Television (SVT), } \\
\text { Utbildningsradio (UR) }\end{array}$ \\
\hline
\end{tabular}

Fuente: Elaboración propia 
Tabla 2. Cobertura de la TV digital en Europa

\begin{tabular}{|c|c|c|c|c|c|c|c|}
\hline & \multicolumn{4}{|c|}{ Miles de hogares con $T_{v}$ digital } & \multicolumn{3}{|c|}{ Total hogares con $\mathrm{Tv}$} \\
\hline País & Cable & DTH/Sat & TDT & IPTV & Digital & Tv & TV, $\%$ \\
\hline AL & n.a. & 350 & 150 & n.a. & 500 & 701 & $71,3 \%$ \\
\hline AT & 662 & 1.813 & 210 & 255 & 2.949 & 3.613 & $81,4 \%$ \\
\hline BE & 2.154 & 273 & 48 & 1.231 & 3.706 & 4.679 & $79,2 \%$ \\
\hline BG & 601 & 1.097 & 776 & 150 & 2.624 & 2.873 & $91,3 \%$ \\
\hline $\mathrm{CH}$ & 1.198 & 261 & 66 & 948 & 2.473 & 2.583 & $95,7 \%$ \\
\hline CY & 23 & 13 & 188 & 61 & 285 & 302 & $94,4 \%$ \\
\hline $\mathrm{CZ}$ & 498 & 2.040 & 1.430 & 227 & 4.195 & 4.437 & $94,5 \%$ \\
\hline DE & 6.010 & 17.872 & 1.913 & 2.077 & 27.872 & 38.649 & $72,1 \%$ \\
\hline DK & 939 & 240 & 326 & 389 & 1.894 & 2.335 & $81,1 \%$ \\
\hline EE & 85 & 76 & 114 & 169 & 444 & 550 & $80,7 \%$ \\
\hline ES & 089 & 224 & 3.271 & 749 & 7.333 & 7.487 & $99,1 \%$ \\
\hline FI & 146 & 114 & 669 & 261 & 2.490 & 2.416 & $103,1 \%$ \\
\hline FR & 1.082 & 9.374 & 4.419 & 10.814 & 25.689 & 27.165 & $94,6 \%$ \\
\hline GB & 3.759 & 1.848 & 11.047 & 1.478 & 28.132 & 28.183 & $99,8 \%$ \\
\hline GR & 0 & 928 & 2.660 & 65 & 3.653 & 4.405 & $82,9 \%$ \\
\hline HR & 83 & 226 & 904 & 366 & 1.579 & 1.637 & $96,5 \%$ \\
\hline HU & 724 & 1.048 & 351 & 440 & 2.563 & 3.700 & $69,3 \%$ \\
\hline IE & 377 & 918 & 239 & 36 & 1.570 & 1.621 & $96,9 \%$ \\
\hline IS & n.a. & 10 & 157 & 37 & 204 & 119 & $171,4 \%$ \\
\hline IT & 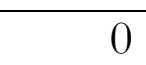 & .735 & 18.260 & 121 & 25.116 & 25.157 & $99,8 \%$ \\
\hline LT & 147 & 127 & 659 & 119 & 1.052 & 1.333 & $78,9 \%$ \\
\hline LU & 107 & 44 & 26 & 34 & 211 & 212 & $99,5 \%$ \\
\hline LV & 122 & 106 & 256 & 162 & 646 & 824 & $78,4 \%$ \\
\hline ME & n.a. & 43 & n.a. & 62 & 103 & 195 & $52,8 \%$ \\
\hline MK & 20 & 19 & 248 & 88 & 375 & 534 & $70,2 \%$ \\
\hline MT & 59 & 3 & 68 & 6 & 136 & 142 & $95,8 \%$ \\
\hline NL & 3.524 & 716 & 600 & 1.514 & 6.354 & 7.381 & $86,1 \%$ \\
\hline NO & 663 & 771 & 309 & 318 & 2.061 & 2.215 & $93 \%$ \\
\hline PL & 2.376 & 7.758 & 905 & 263 & 11.302 & 13.449 & $84 \%$ \\
\hline PT & 1.286 & 710 & 791 & 985 & 3.772 & 3.887 & $97 \%$ \\
\hline RO & 1.646 & 2.404 & 0 & 53 & 4.103 & 7.167 & $57,2 \%$ \\
\hline RU & 2.676 & 17.267 & 7.617 & 3.473 & 31.033 & 51.156 & $60,7 \%$ \\
\hline SE & 785 & 797 & 1.067 & 659 & 3.308 & 4.537 & $72,9 \%$ \\
\hline SI & 231 & 54 & 267 & 239 & 791 & 824 & $96 \%$ \\
\hline SK & 219 & 830 & 34 & 199 & 1.282 & 1.797 & $71,3 \%$ \\
\hline TR & 592 & 10.390 & 7 & 286 & 11.275 & 19.948 & $56,5 \%$ \\
\hline EUR 28 & 30.034 & 70.388 & 60.722 & 23.122 & 185.042 & 210.762 & $87,8 \%$ \\
\hline EUR 36 & 35.183 & 99.499 & 70.552 & 28.334 & 233.066 & 288.213 & $80,9 \%$ \\
\hline
\end{tabular}

Fuente: Observatorio Audiovisual Europeo (2016b). Elaboración propia. 
En un contexto de convergencia e hibridación, parece paradójico el registro de un fuerte incremento de los canales lineales de televisión. En un periodo de siete años las licencias en Europa han aumentado en 1.659 unidades hasta llegar a la cifra de 5.274 canales en 2015. De tal manera que actualmente, en la mitad de los 28 países de la Unión Europea se puede acceder a más de 400 canales de televisión (Observatorio Audiovisual Europeo, 2016).

Tras este aumento de cifras tan significativo se halla en la generalización del lanzamiento de canales en Alta Definición, principal motor del aumento de canales entre el periodo 2009 y 2015. Un incremento de soportes que no necesariamente diversifica la oferta de la programación pues se dedican principalmente a la emisión en simultáneo de canales preexistentes (Observatorio Audiovisual Europeo, 2016).

En paralelo a la cobertura digital de la señal, la TDT amplía los servicios de la ciudadanía adaptándose a las necesidades de las audiencias más jóvenes y desligadas de la linealidad televisiva. La creación de plataformas híbridas es una tendencia entre los broadcasters públicos de mayor envergadura. En conjunción con compañías de telecomunicación y televisiones privadas y públicas, la BBC lanza el servicio Youview un servicio de TDT (con estándar DVB-T y DVBT2) con servicio bajo demanda y catch-up TV que, operativo también mediante Internet, ofrece contenidos de un gran número de operadores públicos y privados (Kenny, Foster y Suter, 2014).

La emisión en $4 \mathrm{~K}$ será el siguiente paso que complete la digitalización de la señal. A pesar que se espera una lenta adopción, actualmente corporaciones como la BBC han comenzado a valorar la viabilidad técnica y comercial del Ultra HD iniciando el camino a la emisión en plataformas Premium (BBC iPlayer) y UHD Blu-ray de contenidos deportivos y documentales (BBC Academy, 2016). France Télévisions también ha incorporado el $4 \mathrm{~K}$ a sus emisiones. En concreto, en la competición deportiva Roland Garrós de 2015 ha podido verse a través de la TDT para televisiones que soporten $4 \mathrm{~K}$, además de a través de señal satélite e IP networks. 


\subsection{Omnipresencia de los operadores públicos}

En respuesta a la introducción de nuevos operadores y al incremento de la presencia de los tradicionales, los PSM europeos están abocados a incrementar sus cuotas de mercado y al mantenimiento de un crecimiento constante. Como consecuencia, la solución a dichos requerimientos el incremento de la variedad de canales, de plataformas y mercados para la distribución dan lugar a la omnipresencia de los operadores públicos.

El espacio de la Unión Europea se caracteriza por una fuerte concentración de canales. Reino Unido, Francia y Alemania acumulan el 46\% de las licencias en la U.E. en 2015. Reino Unido en solitario acumula 1.556 canales de televisión lineal. De estas cifras, las dos terceras partes se destinan a emitir en territorio extranjero. La fortaleza en la producción audiovisual de estos países junto con su interés por incrementar presencia en el mercado foráneo, hace entrever una presencia internacional cada vez más pujante entre las corporaciones públicas y privadas de mayor envergadura (Observatorio Audiovisual Europeo, 2016).

La estrategia de dirigirse a mercados extranjeros es una tendencia al alza entre televisiones públicas y privadas de los países europeos. En un periodo de siete años el número de canales ha crecido exponencialmente. Los datos apuntan que en Reino Unido, país que cuenta con el que mayor número de canales en Europa, destina dos tercios de su oferta a emitir en terceros países, a la vez que un tercio de los canales establecidos en Francia lo hacen fuera de territorio nacional. De acuerdo al Observatorio Audiovisual Europeo (2016), se estima que cerca de un $66 \%$ de los países europeos recibe más de 50 canales extranjeros. Austria, Polonia, Italia y Hungría sobrepasan la media con 152, 140, 109 y 107 canales extranjeros en sus territorios respectivamente.

\subsection{La IPTV y el desarrollo de nuevos dispositivos}

Uno de los grandes retos a los que se enfrentan la radiotelevisiones públicas es la adaptación a las demandas de la sociedad y la 
reformulación de la televisión digital conectada y semántica (WebTV 3.0) (Campos-Freire, 2013). En la era de la convergencia mediática, las plataformas para la distribución se incrementan exponencialmente. Nuevas formas de recepción de la señal, como la IPTV, se convierten hoy en fórmulas para alcanzar a audiencias globales a bajo coste. Tal es su democratización que hoy prácticamente todo PSM europeo ofrece en su web la posibilidad de consumir el contenido bajo demanda y en directo a través de diversos soportes.

En consecuencia, la orientación a la multipantalla es complementaria a la aparición de la IPTV. La introducción de nuevas fórmulas para la difusión de contenido es una constante en auge en la televisión. Además de los dispositivos ya consolidados, como el PC, la Tablet o los Smartphones, los operadores públicos europeos han comenzado a explorar alternativas. Las consolas, y en especial la Xbox One y Playstation 3, ya forman parte del catálogo de plataformas para la distribución de cadenas como la belga RTBF y la española RTVE (rtbf.be, 2016).

Los accesorios conectados a internet o wereables conformarán el siguiente paso en el avance en el campo de la distribución. En su objetivo de ofrecer nuevas y enriquecidas experiencias a las audiencias, la televisión pública belga (RTBF) ha apostado por invertir en proyectos innovadores que aborden nuevas fórmulas para la distribución. En proceso de experimentación como plataformas para la distribución se encuentran las Google Glass y Vuzix M100 (rtbf.be interactive, n.d.).

\subsection{El auge de la Smart TV y el HbbTV}

El desarrollo de la televisión inteligente (SmartTV) y la televisión híbrida (HbbTV) es otra tendencia que está cobrando presencia en el panorama de los PSM como vía hacia el servicio de valor añadido y el enriquecimiento de la experiencia para el consumidor. Paralelamente a la apertura de nuevas vías a la difusión se crean contenidos ex profeso a dichas ventanas, bajo fórmulas interactivas, on demand $y$ personalizadas. 
Corporaciones públicas como RTVE y la Rai ya han comenzado a incorporar el estándar HbbTV mientras que corporaciones como la BBC han comenzado a acelerar el proceso de adopción del estándar HbbTV 2.0.1. en el mercado británico junto a Freeview, Digital UK y DTG (BBC Media Centre, 2016b).

Al hilo de esta democratización tecnológica, tiene lugar el desarrollo de proyectos digitales punteros tales como el Botón Rojo para televisiones con estándar HbbTV. El proyecto adoptado por entes públicos como RTVE o la BBC incorporan dichas novedades en su camino hacia los servicios interactivos, enriquecedores y complementarios a la oferta lineal.

\subsection{La distribución en redes sociales y aplicaciones}

Las redes sociales se anuncian como la fórmula definitiva hacia una convergencia que se alinea directamente con la función de misión pública de las televisiones europeas. Dada la versatilidad del social media, la mayoría de los PSM europeos las han incorporado como herramienta estratégica en el campo de la distribución. La capacidad para abrir nuevos canales de difusión de contenidos a bajo coste y alcanzar audiencias mundiales es una de las principales ventajas de estos medios. La interactividad y la personalización complementan este escenario que es aprovechado para emitir contenidos innovadores y obtener feedback de sus seguidores.

Paralelamente, algunas PSM han comenzado a experimentar con nuevas ventanas del entorno digital para la distribución de contenidos. La explotación de aplicaciones es la última tendencia entre las corporaciones públicas de mayor envergadura. El uso de redes globales, accesibles desde dispositivos móviles, como Telegram y WhattsApp se convierten en vehículo para la difusión de contenidos informativos de forma personalizada para entes como la BBC News. Así mismo, y con el objeto de incrementar la presencia en mercados internacionales y conectar con otros públicos, la división ha comenzado a emplear redes sociales nacionales, como Yik Yak para el mercado canadiense y VKontakte para el ruso (BBC Media Centre, 2016; Burrell, 2016). 
En línea con esta explotación se encuentra la irrupción de departamentos especializados denominados "MediaLabs" que tienden puentes hacia la innovación en la comunicación con los públicos (Valencia-Bermúdez y Campos-Freire, 2015).

\subsection{Conclusiones}

De acuerdo al análisis realizado se ha podido detectar una serie de tendencias generales en respuesta al nuevo contexto mediático. De forma resumida los siguientes puntos concentran las ideas principales:

- Tendencia a la televisión digital: la digitalización de la señal en sus diversas modalidades es un proceso imparable en el contexto europeo. Cifras del Observatorio Audiovisual Europeo señalan una penetración de la televisión digital próximo a porcentajes del 90 por cien. Por su parte, la introducción del HD es una tendencia en auge entre aquellas corporaciones públicas de mayor envergadura. Como consecuencia de la adopción del HD, se han originado una amplia oferta de canales en Alta Definición que, si bien han incrementado el volumen de canales lineales en el conjunto de la Unión Europea, no tienen un reflejo directo en la oferta de contenidos, pues principalmente dichos canales se destinan a duplicar la oferta de canales preexistentes.

- La omnipresencia de los operadores públicos: consecuencia de la extrema competencia en el sector mediático, los operadores tradicionales abogan por incrementar las ventanas de distribución así como la oferta en la programación. El reto consiste en ganar visibilidad en mercados internacionales a la vez que se mantienen los nacionales.

- Orientación a la IPTV y multipantalla: con la democratización de internet y de la banda ancha, los PSM no han permanecido al margen de aquellas tendencias que apuntan a la prestación de servicios y contenidos mediante el Internet Protocol Television y a la prestación de servicios mediante las diversas pantallas. La multipantalla, última estrategia online adoptada por los opera- 
dores públicos y privados, permite alcanzar audiencias mundiales y otorga el poder del visionado a los espectadores. Además de las ya tradicionales pantallas, las corporaciones públicas han comenzado a explotar nuevos dispositivos con conectividad, tales como los wereables y consolas, abiertos a la personalización e interacción con las audiencias más jóvenes y tecnológicas.

- El auge de la SmartTV y HbbTV: mejorando las prestaciones de la televisión, los estándares HbbTV y la SmartTV vienen a introducir la conectividad del usuario con los servicios y contenidos prestados por los PSM. El Botón Rojo, iniciativa ya adoptada por PSM europeas, vienen a enriquecer y complementar la experiencia de la televisión lineal.

- La distribución en redes sociales y aplicaciones: la explotación de plataformas sociales y apps apuntan a estrategias para conseguir nuevas las ventanas de distribución segmentadas y personalizadas ante públicos juveniles principalmente.

\section{Bibliografía}

BBC Academy (2016). 4K and UHF: Why does it matter? http://www.bbc.co./academy/technology/article/art20160119 144803706

BBC Media Centre (2016). First BBC 'newsbot' brings more Uzbek content to Telegram.

http://www.bbc.co.uk/mediacentre/latestnews/2016/bbcuzbeck-newsbot

BBC Media Centre (2016b). BBC statements on the future adoption of HbbTV standards.

http://www.bbc.co.uk/mediacentre/statements/hbb-tvstandards

Burrell, I. (2016). BBC News courts millenials to save its future. http:/ /www.thedrum.com/opinion/2016/07/14/bbc-newscourts-millennials-save-its-future

Campos-Freire, F. (2013). El futuro de la TV europea es híbrido, convergente y cada vez menos público. Revista Latina de 
Comunicación Social, 68, 088-118.

https://doi.org/10.4185/RLCS-2013-970

Duval, G. (2015). En 2016, la TNT devient HD, faudra t-il tout changer? http:/ / france3-regions.francetvinfo.fr/limousin/en2016-la-tnt-devient-hd-faudra-t-il-tout-changer-893263.html

Kenny, R., Foster, R. \& Suter, T. (2014). The value of DTT in an era of increasing demand for spectrum. Reino Unido:

Communications Chambers.

Moragas, M. \& Prado, E. (2001). Repensar la televisión pública en el contexto digital.

www.portalcomunicacion.com/both/opc/tvp.pdf

Observatorio Audiovisual Europeo. (2016). Mavise Extra: Linear and on-demand audiovisual media services in Europe 2015.

Estrasburgo: European Audiovisual Observatory.

Observatorio Audiovisual Europeo. (2016b). Yearbook 2015. Key

Trends. Television, cinema, video and On-Demand Audiovisual

Services. Estrasburgo: European Audiovisual Observatory.

Rtbf.be Interactive. (2016). Retrouvez tous vos programmes RTBF préférés sur consoles! https://www.rtbf.be/interactive/console Rtbf.be interactive. (n.d.). La RTBF teste les lunettes intelligentes pour vous! https://www.rtbf.be/interactive/smartglasses Suárez-Candel, R. (2010). Digitalizing terrestrial broadcasting: public policy and public service issues. Communication, Politics \& Culture, 43 (2), 99-117.

http:/ / search.informit.com.au/documentSummary;dn=673340 663971594;res=IELAPA

Suárez-Candel. R. (2012). Adapting Public Service to the

Multiplatform Scenario: Challenges, Opportunities and Risks.

Hamburgo: Hans-Bredow-Institut.

Valencia-Bermúdez, A. \& Campos-Freire, F. (2015). La innovación como motor del nuevo servicio público audiovisual: análisis comparado de las corporaciones estatales de Francia, España e Irlanda. Revista Latina de Comunicación Social, 90. https://doi.org/10.4185/cac90 



\section{Programación de contenidos en las televisiones públicas y privadas europeas}

Finocha Formoso Barro

Universidade da Coruña

Cómo citar: Formoso, F. (2017). Programación de contenidos en las televisiones públicas y privadas europeas. En Túñez López, M.; Campos-Freire, F. y Silva Rodríguez A. (Eds.). Estudios sobre financiación, legislación e innovación en la Televisión Pública. Cuadernos Artesanos de Comunicación, cac126, pp 89-100. La Laguna (Tenerife): Latina. DOI: $10.4185 /$ cac126

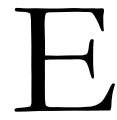

L NACIMIENTO de nuevas cadenas de televisión que originó la digitalización debería haber favorecido, en principio, la evolución de los contenidos. Esta teoría, también la apoya el aumento de la movilidad que se ha originado gracias a la evolución tecnológica y al uso de los terminales móviles. Sin embargo la multiplicidad de canales no ha traído consigo un avance de los contenidos. En este capítulo se analiza la programación de los países europeos con más audiencia: Alemania, Inglaterra, Francia, Italia y Holanda. El análisis permite observar como los canales se limitan a distribuir repeticiones y a emitir producción más barata. En Europa se han mantenido líderes de audiencia los mismos canales que en la era analógica. Los contenidos se adaptan a la idiosincrasia de cada país aunque se emiten programas similares tanto en formatos de entretenimiento como en ficción.

Palabras clave: programación televisiva; televisión; formatos; audiencia. 
Los nuevos canales de televisión que han aparecido en Europa tras la digitalización han generado un momento álgido en la producción de contenidos audiovisuales. En el continente europeo los operadores públicos son los responsables máximos de la transformación digital frente a otros países, como Estados Unidos, donde las televisiones privadas son los principales actores.

El incremento de operadores ha ocasionado una fragmentación de las audiencias y ha ocasionado una gran competitividad entre los canales que ven en los contenidos, los auténticos motores de las empresas audiovisuales para generar diferenciación (Formoso, 2015: 43). Hay que considerar también que los espectadores se transforman en fans que utilizan dispositivos en vez de televisores y consumen televisión bajo demanda, además de televisión lineal. Estos cambios han generado variaciones en el modelo de negocio, en los tipos de distribución así como en la transmisión y recepción de contenidos (Formoso, 2016: 213).

Para realizar una fotografía del nuevo escenario de la televisión europea y determinar la importancia de las parrillas de programación en la transformación y evolución de los contenidos se consideran los países europeos con mayor consumo televisivo (Alemania, Italia, Francia, Holanda e Inglaterra).

Se enumeran los formatos de entretenimiento que predominan en los canales televisivos de cada país estudiado y se realiza un análisis de la ficción que se programa en los canales europeos y su audiencia. Además, se tienen en cuentas las audiencias y los puntos de share de cada canal analizado. La mención de los títulos de los programas o series emitidos en cada país permite referenciar si hay alguna analogía entre los programas más vistos en los canales de televisión de Europa.

\section{Alemania. Canales de televisión y audiencias}

En Alemania tras la llegada de la TDT se acrecentó el número disponible de canales y en un breve periodo de tiempo se pasó de de treinta a cincuenta canales de televisión. Los canales con más audiencia son los mismos que antes del año 2000: ARD, ZDF, RTL, SAT.1 y 
ProSieben, con VOX, RTLII y Kabel Einsdos canales públicos, la ZDF y Das Erste, los cuales son totalmente independientes entre sí (Hallenberger, 2013: 153).

$\mathrm{El}$ incremento de canales ha propiciado el descenso en las audiencias. ZDF se mantiene en la primera posición de las cadenas más vistas con un 12,4 por cien del share. La cadena pública ARD12 mantiene un 1 por cien. RTL desciende progresivamente las audiencias y en el periodo analizado el share estaba en un 11 por cien.

Por su parte, las cinco cadenas medianas han inmovilizado su audiencia: Sat. 1 tiene un 8.4 por cien ProSieben se sitúa en el 5,8 por cien del share, mientras que Vox 5,6 por cien, RTL II se sitúa, con un 3,9 por cien del share, tan solo un 0,1por cien por encima de su competidora directa, Kabel eins, 3,9 por cien.

Las cadenas digitales que han surgido en los últimos años Sat.1 Gold, RTL Nitro, Sixx, DMAX, ProSieben Maxx, Disney Channel y TLC han consolidado sus audiencias tras el crecimiento que experimentaron durante los últimos años.

La digitalización del sector audiovisual ha provocado el descenso de las audiencias de las ocho grandes cadenas alemanas ya que si se observan los porcentajes de seguimiento se puede valorar que durante el año 2009 se situaba en torno al 69,1 por cien, una cifra que ha disminuido progresivamente hasta el 63,2 por cien de la temporada 2014/15.

\subsection{Ficción y formatos televisivos en Alemania}

La ficción en este país no consigue los éxitos deseados. Predomina la ficción estadounidense cómica en ProSieben y policíaca en Sat1. La ficción policiaca es el género que predomina en la televisión alemana y es programado especialmente en las cadenas públicas y privadas. Desde hace 44 años en $\mathrm{ARD}^{6}$ se emite el contenedor de telefilmes Tatort, Mord mit Aussicht, (ARD) serie policiaca con tintes cómicos de 13 capítulos que consigue cuotas de pantalla de 20,9 por cien;Der Kriminalist (ZDF),

6 La emisión del 21 de septiembre de 2015 logró 13.130 .000 espectadores, su cifra más alta desde 1992 y obtuvo 36,7 por cien del share, el mejor desde 1993. 
cuya décima temporada ha obtenido una cuota media de pantalla del 15,6 por cien.

Tampoco la cadena RTL ha conseguido la audiencia deseada pese a la realización de producciones propias Der Knastarzt ,Schmidt - Chaos auf Rezept, Doc meets Dorfy Christine ${ }^{7}$. Vox, ha realizado la adaptación de la serie española Pulseras rojas.

Respecto a los formatos predomina el stand-up entre las nuevas apuestas de humor aunque la mayoría de los programas se encuadran en los géneros del monólogo y el sketch. Algunos ejemplos son Bülent \& seine Freunde (RTL), Nubr im Ersten (ARD), Ein Fall fürs All (ZDF) y Schwarz. Rot Pink (Sat.1).

Los concursos con formatos clásico como Wer wird Millionär, versión del británico Who Wants to Be a Millionaire?, experimentan un renacimiento. El público alemán se ha decantado en la temporada por el consumo de realitys que ha resultado ser uno de los géneros más abundantes en su parrilla.

Los programas de dating o formatos de pareja aportan un elemento novedoso en estas parrillas. Uno de los más destacables, por su reciente adaptación en otros mercados como el estadounidense y el español es Adam sucht Eva - Gestrandet im Paradies (RTL), versión del holandés Adam zkt. Eva (RTL 5) que en España se ha llamado Adam y Eva y se emitió en Cuatro.

\section{Italia. Canales de televisión y audiencia}

Las audiencias en los canales de televisión italianos son estables tras la digitalización. Rai Uno consigue una media de 17,6 por cien de share y es la cadena pública líder de audiencia. Canale 5, en segundo lugar con una media de 16,2 por cien y el tercer puesto es para Rai Due con un 6,7 por cien de share.

${ }^{7}$ http://www.dwdl.de/nachrichten/43176/rtl setzt christine und sekretaerinnen n 
Los datos de audiencia en las pequeñas cadenas digitales se han mantenido en lugar de aumentar ligeramente como había ocurrido en temporadas anteriores. Real Time, propiedad de Discovery Communications se mantiene como líder dentro de este grupo. Ofrece en su programación realitys y magacines de coaching, cocina y lifestyle y está orientado a mujeres de entre 25 y 54 años. La segunda opción es DMax, que emite formatos de desastres naturales, crímenes y contenidos similares dirigidos a un público masculino.

\subsection{Ficción y formatos televisivos en Italia}

Para el público italiano las series más exitosas son las de temática familiar y policiaca nacionales. La ficción española está muy presente en la televisión italiana y mantiene una influencia notable tanto en los contenidos originales como en las adaptaciones de los proyectos de ficción que realizan. Entre la adaptaciones destacan Braccialetti rossi, versión italiana en Rai Uno de Pulseras rojas con una duración media de cien minutos.

El canal público Rai Uno prepara una versión de Gran Hotel emitida en Antena 3 mientras que Canale 5 apuesta por una adaptación de la serie policiaca emitida en TVE1 Los misterios de Laura.

Además de las adaptaciones cabe destacar que los canales italianos durante los últimos años han emitido series en lata y dobladas al italiano de series españolas así, por ejemplo, destacar Il Segreto, título en italiano del serial de Antena 3 El secreto de Puente Viejo emitida en Canale 5, de lunes a viernes por la tarde y en prime time los domingos.

El canal público Rai Uno emite miniseries de dos episodios en el prime time durante dos días consecutivos. La strada dritta, La Bella e la Bestia son ejemplos de este tipo de ficción donde se narran episodios biografías de personajes conocidos por el público italiano o de personajes históricos. Con este tipo de productor suelen obtener audiencias. 
Surgen como en el resto de Europa un nuevo formato que ha conseguido notable éxito que son las shortcoms ${ }^{8}$. Rai Due emite varias con este formato como Una mamma imperfetta o Il candidato.

Los formatos apenas observan novedades. El magacín es el género los concursos de talentos se mantienen con fuerza. Entre los escasos estrenos del año 2015 figuran títulos como Mixologist, la sfida dei cocktail e Il re della griglia, ambos concursos de cocina en DMAX y el concurso de talentos fotográficos Scattastorie ; el reality de decoración Changing rooms en Real Time; el reality de animales $A$ cuccia di cuori en La5 y el de motor Motorhome en MTV Italia.

Los programas de variedades que durante años fueron un referente en las parrillas de programación italianas han dejado de emitirse porque tienen muy baja audiencia.

\section{Holanda. Canales de televisión y audiencias}

La televisión pública holandesa ha renovado su imagen y ha cambiado su nombre, NPO. Las cadenas Nederland 1, Nederland 2, Nederland 3, Zapp y Zappelin se han rebautizado como NPO 1, NPO 2, NPO 3, NPO Zapp y NPO Zappelin y las emisoras simplemente llevan las siglas NPO delante de su nombre.

\subsection{Ficción y formatos de televisión en Holanda}

En Holanda, la ficción no tiene una audiencia notable salvo alguna excepción como Nieuwe Buren que mantiene un 20, 3 por cien de audiencia. Los formatos de emisión más habituales son varios capítulos de 50 minutos de duración y las miniseries o emisiones en 2 capítulos no son comunes. No es común en Holanda la emisión de miniseries de 2 capítulos y es más común la emisión de varios capítulos de 50 minutos de duración como las serie como Noord Zuid o Gouden Bergen de 10 episodios.

Los talent shows como The Voice of Holland y Holland's Got Talent, los grandes concursos y realitys con los que mantiene un 17 por cien de

\footnotetext{
${ }^{8}$ Comedias breves
} 
audiencia funcionan muy bien en cadena privada RTL Nederland. Entre sus éxitos se encuentran el programa de supervivencia Expeditie Robinson, el reality de pruebas de conducir De slechtste chauffeur van Nederland, el reality de famosos Roy Donders: Stylist van het zuiden, el concurso de belleza Holland's Next Top Modely la nueva serie Bluf. RTL 7 (4,4\%) apuesta por el deporte y RTL 8(1,9\%) por series de ficción extranjeras.

Holanda ha sido proveedor de grandes formatos como el dating show Adam zket Eva, el talent show The Voice y los realitys Utopia y Big Brother que se ven en los canales de televisión de todo el mundo. Pero a pesar de ser un país exportador de formato, también recurre a ideas que vienen de fuera de sus fronteras. La oferta de talent show es amplia y variada en la televisión privada pero los programas de coaching y los nuevos espacios de humor que se han estrenado no han conseguido audiencia. Destacar que la batalla del late night la protagonizan NPO 1 y RTL 4 con formatos talk shows.

\section{Francia. Canales de televisión y audiencia}

La cadena privada TF1 es lider de audiencia y France 2 se consolida gracias al access prime time. Lo más visto en entretenimiento es el reality de supervivencia Koh-Lanta. En ficción la serie estadounidense Mentalist tiene notable audiencia.

Las cadenas históricas y las digitales descienden levemente su audiencia, a excepción de France 2 y D 8 con un 4 por cien. Canal Plus se mantiene estable. La cadena privada TF1 es líder con un 22,8 por cien de media y domina el prime time. El canal público France 2 mantiene un 13,6 por cien de share. Emite el concurso N'oubliez pas les paroles! que hace efecto arrastre y tiene buenos datos de audiencia. La tercera opción es la cadena privada M6 con un 10,6 por cien que emite series con éxito como NCIS. El canal público France 3 ampara un 9,1 por cien y Canal Plus un 3 por cien. Dentro de las pequeñas cadenas digitales, D8, del grupo Canal Plus, ocupa el quinto lugar, por detrás de France 3. La cadena de contenido generalista.TMC, generalista del grupo TF1 tiene un 3 por cien y le sigue W9, cadena juvenil del grupo M6, que registra la mayor bajada de la temporada con un descenso de 
tres décimas. Otras cadenas como la juvenil NRJ12, la generalista NT1, la pública France 4 y la infantil Gulli sufren un descenso de dos décimas y consiguen medias entre el 1,8 y el 1,6 por cien de cuota de pantalla.

\subsection{Ficción y formatos de televisión en Francia}

En Francia las series de producción propia no rentabilizan la audiencia mientras que la ficción americana consigue audiencias notables. Las temáticas más seguidas son las series policiacas y los dramedias familiares Mentalist,CriminalMind y Blacklist.

La ficción francesa destaca por su particular originalidad. Así el canal franco alemán Arte emitió la miniserie P'tit Quinquin que es de 4 capítulos y de 45 minutos. Está protagonizada por personajes esperpénticos pero al mismo tiempo muy humanos, interpretados por habitantes del norte de Francia, sin experiencia previa en el mundo de la actuación. La segunda ficción que destaca por su originalidad es Anarchy con una duración de 26 minutos en France 4. La originalidad de esta serie no radica en la temática ni en los aspectos técnicos sino en la interactividad con el espectador.

Otras series como Interventions que se emitió en TFI y el drama histórico Ceux de 14 emitido en France 3 no han conseguido audiencia suficiente como para ser renovados.

Y como en el resto de Europa las shortcoms se han incrementado en la televisión francesa. Las ventajas de este formato son: a) facilidad en la programación; b) tienen un ritmo corto y permiten la emisión diaria y,

c) fidelización del público sobre todo los jóvenes.

Los macrogéneros (información, entretenimiento, ficción, cine) son utilizados por TF1 con el objetivo de mantener su primacía en el mercado publicitario. El magacín se mantiene como formato de entretenimiento que está más presente en los canales de televisión franceses. Se programan también los concursos de talentos que en Francia suelen ser programados en el access prime time de lunes a viernes. En esta tendencia se enmarcan títulos como Objectif Top Chef. 


\section{Inglaterra. Canales de televisión y audiencia}

Los canales de televisión ingleses más importantes son BBC, ITV, Channel 4, BSkyB y Channel $5^{9}$. Los canales con más implantación son los canales en abierto que ya existían en la era analógica. ITV 1 y la BBC dominan el mercado de la producción propia y han situado sus series entre los líderes de audiencia de Reino Unido. BBC One mantiene el liderazgo y ha aumentado su audiencia. En su programación se encuentra el concurso culinario The Great British Bake Ofy series comoThe Missing.

La BBC dispone de 11 canales y es la cadena más vista. Le siguen los canales privados ITV con un 15, 4 por cien de audiencia media y Channel Four con un 4,7 por cien de cuota de pantalla. Channel 5 es el canal menos visto de los cinco principales y mantiene un dato de 3,9 por cien de share.

\subsection{Ficción y formatos de televisión en Inglaterra}

Los espectadores británicos consumen series de época, talent show y programas protagonizados por famosos. Las series de época Downton Abbey de ITV y Call the Midwife deBBC One, las series de detectives Broadchurch que se emite en ITV y Death in Paradise de BBC One, así como la miniserie biográfica Cilla de ITV. A los británicos les interesan las historias basadas en hechos reales. Wolf Hall aborda el ascenso al poder de Tomás Cromwell, el hijo de un herrero humilde que se convirtió en la mano derecha de Enrique VIII.

La comedia es un género que cuenta con muchos seguidores en Inglaterra pero no ha conseguido grandes audiencias los últimos años. Still Open All Hours (BBC One),Catastrophe (Channel 4) y Detectorists (BBC Four).

Son destacables los seriales que llevan en las parrillas de la televisión británica años como EastEnders en BBC One que está en antena desde 1985, Coronation Street de ITV, en antena desde 1960 y Emmerdale emitido en ITV desde 1972.

${ }^{9}$ http://www.barb.co.uk/trendspotting/data/multi-channel-development? s=4 
La colaboración entre británicos y estadounidenses ha dado lugar a ficciones de alta calidad como la miniserie de época $W$ olf Hall (BBC Two, PBS), la serie-comedia romántica Catastrophe (Channel 4), las series de suspense realizadas en coproducción The Missing (BBC One, Starz) y Fortitude (Sky Atlantic,Starz) y la serie de ciencia-ficción Intruders (BBC Two, BBC America).

BBC One e ITV se reparten los programas más vistos. El concurso de repostería The Great British Bake Off (BBC One) lidera la audiencia con un 49 por cien de share, seguida de dos programas protagonizados por famosos: el reality de supervivencia I'm a Celebrity...Get Me Out Of Here en ITV y el concurso de baile Strictly Come Dancing en BBC One. El concurso The Great British Bake Off está versionado en países como Holanda, Italia, Estados Unidos, Alemania , Francia y Australia.

Una temática habitual en la programación de las televisiones británicas es la educación donde se emiten programas como Educating The East End en Channel 4 y Bring Back Borstal en ITV. También la solidaridad es un tema recurrente, así, por ejemplo se interesa por colectivos minoritarios, temas sociales y víctimas de la crisis. Channel 4 y Channel 5 han abordado el tema de la inmigración con Make Leicester British y No Foreigners Here .

Las pequeñas cadenas son las principales proveedoras de humor. Así por ejemplo E4 estrenó con éxito el programa de cámara oculta Bad Robots; en ITV2, Blue Go Mad in Ibiza, en el que las cámaras siguen a cuatro artistas en Ibiza mientras que se enfrentan a situaciones embarazosas.

La exportación de formatos británicos sube un 5 por cien. Según el informe The Anual UK Television Exports Surv ${ }^{10}$ de la asociación Pact, la demanda de formatos británicos en el extranjero se ha incrementado en los últimos meses, impulsada por el aumento de ventas a Estados Unidos y China. El informe de Pact revela que la venta total de formatos británicos alcanzó un valor de 1.280 millones de libras (1.700

${ }^{10} \mathrm{http://www.thecreativeindustries.co.uk/media/311154/tv-exports-survey-fy-14-}$ $\underline{15 . p d f}$ 
millones de euros) en 2014, comparado con 1.220 millones de libras (1.600 millones de euros) en $2013^{11}$.

\section{Conclusiones}

Tras la implantación de la TDT los canales de televisión europeos han incrementado su número. Los liderazgos en las audiencias los mantienen los mismos canales que en la era analógica. Los contenidos emitidos en los diferentes canales de televisión analizados (Alemania, Italia, Francia, Holanda e Inglaterra) también son similares. En cuanto a la ficción además de la producción propia de cada país hay que destacar la emisión de ficción de origen americano. La ficción que se produce en Inglaterra y Alemania es destacada porque consigue audiencia en países del resto del mundo. La capacidad de la ficción inglesa para realizar coproducciones con Estados Unidos merece ser recalcada y tomada como referente a seguir por el resto de países.

Destaca el nacimiento de formatos reducidos de ficción (shortcooms) en Francia e Italia. Las duraciones de estos formatos están en torno a los 15 minutos frente a los 40 o 45 minutos de las series de primetime. Las miniseries tienen una duración de unos 60 minutos capítulo.

Los programas de entretenimiento tienen variedad de criterios según el país analizado. En Alemania los formatos clásicos vuelven a ocupar las parrillas televisivas. Holanda que ha sido tradicionalmente exportador de estos formatos, está comprando a Inglaterra nuevas ideas para programas. Mientras que en Holanda los realitys y los

11 bttp:// wnw.pact.co.uk/support/document-library/documents/uk-tv-exports-report-2014/ China es el mercado con mayor crecimiento. En el periodo analizado, registró un incremento del 40\%, lo que supone un total de 17 millones de libras (unos 22,7 millones de euros) en 2014, comparado con 12 millones de libras (unos 16 millones de euros) en 2013. Eso significa que el país asiático supera a Holanda y a España, que adquirieron contenidos británicos por un valor de 16 millones de libras (21,4 millones de euros). No obstante, Estados Unidos se mantiene como el mayor importador de formatos británicos (en 2014, el país adquirió contenidos de Reino Unido por un valor de 523 millones de libras -unos 698 millones de euros-, lo que supone un incremento del 10\%). Otros mercados destacados son Francia y Polonia (con un incremento del 21\%). 
programas con famosos ocupan la parrilla de programación, en Italia o Francia predominan los magacines de entretenimiento.

\section{Bibliografía}

Formoso , M. J. (2015): Los contenidos transmedia en la ficción de los canales generalistas en España. adComunica. Revista Cientifica de Estrategias, Tendencias e Innovación en Comunicación, 10, 09-07. DOI: http://dx.doi.org/10.6035/2174- 0992.2015.10.4.

Formoso, M.J. \& Martínez, S. (2016): La ficción nacional y los nuevos modelos narrativos en la autopromoción de Atresmedia. Icono 14, 14 (1), 29-11. doi: 10.7195/ri14.v14i1.910

Hallenberger, G. (2013): La televisión alemana en la era de la convergencia. En Vilches, L. Convergencia y Transmedialidad. La ficción después de la TDT en Europa e Iberoamérica. Barcelona: Gedisa.

bttp:/ / www.c21 media.net/

http:// tbivision.com/

bttp:/ / www.worldscreen.com/

bttp:// www.pact.co.uk/support/document-library/documents/uk-tv-exportsreport-2014/ 


\title{
Las técnicas inmersivas en televisiones públicas: aplicaciones y evolución
}

\author{
Sara Pérez Seijo \\ Francisco Campos Freire \\ Universidade Santiago de Compostela
}

Cómo citar: Pérez-Seijo, S. y Campos-Freire, F. (2017). Las técnicas inmersivas en las televisiones públicas: aplicaciones y evolución. En Túñez López, M.; Campos-Freire, F. y Silva Rodríguez A. (Eds.). Estudios sobre financiación, legislación e innovación en la Televisión Pública. Cuadernos Artesanos de Comunicación, cac126, pp 101-126. La Laguna (Tenerife): Latina.

DOI: $10.4185 / \mathrm{cac} 126$

$\mathrm{E}$ N SEPTIEMBRE de 2014 Des Moines Register publicaba Harvest of Change, un reportaje inmersivo que daría un giro a la producción periodística tradicional. Desde entonces, algunos medios han implementado las narrativas inmersivas para acercar al receptor al escenario informativo. Este capítulo se centra en analizar la evolución y las aplicaciones de las técnicas de realidad virtual e inmersivas por parte de las televisiones públicas europeas, con el fin de advertir el grado de calado del periodismo inmersivo en las mismas y sus usos más frecuentes. Los resultados de esta investigación comparativa permitirán advertir la existencia de patrones en cuanto a primeras aplicaciones se refiere y el éxito del periodismo inmersivo en el sector público.

Palabras clave: periodismo inmersivo; radiodifusoras públicas europeas; realidad virtual; inmersión; 360 grados. 
La rápida y creciente expansión de las tecnologías y el calado de la digitalización en el ecosistema mediático propician la continua aparición de nuevos escenarios, modelos y formatos. El momento presente se caracteriza por el surgir de tres marcos claros: el asentamiento del llamado periodismo ubicuo gracias a los dispositivos móviles, el desarrollo de un lenguaje multimedia más avanzado y la robotización del periodismo (Salaverría, 2016).

Esta comunicación se centra precisamente en uno de los nuevos lenguajes y narrativas multimedia: la inmersión digital en escena gracias a los recursos de la realidad virtual y a las técnicas de grabación 360 grados. Sus primeras aplicaciones reales en medios se encuentran en torno al año 2013, mas no sería hasta el 22 de septiembre de 2014 con el reportaje Harvest of Change de Des Moines Register cuando se comenzaría a hablar del surgir de una nueva corriente. Harvest of Change marcó el inicio de una nueva forma de hacer periodismo, un precedente que puede ser equiparado a la trascendencia que el reportaje Snow Fall de The New York Times tuviera en el 2012 para la narración multimedia.

Bautizado como periodismo inmersivo por Nonny de la Peña (2010), esta corriente consiste en "la producción de noticias mediante un método que permite a la gente obtener experiencias en primera persona de los eventos o situaciones descritas en los relatos informativos" (De la Peña et al, 2010). La producción de contenidos inmersivos se basa en dos modelos principales: las recreaciones tridimensionales con realidad virtual o las grabaciones 360 grados de los escenarios. Con todo, estas últimas piezas son las más frecuentes dado el ahorro temporal y económico que supone su producción frente a las anteriores en 3D.

Diversos medios y empresas de comunicación de todo el mundo desarrollan contenidos con realidad virtual con el fin de trasladar al receptor al lugar de los hechos, al escenario de la información. Los cascos o gafas de realidad virtual facilitan esa tarea ya que aíslan al receptor de la realidad en la que está -realidad primaria- y lo trasladan a la realidad del hecho noticioso o informativo -realidad secundaria(Pérez, 2015). El usuario se sumerge en otra localización donde, al igual que en su realidad primaria, puede observar en 360 grados lo que tiene a su alrededor. 
No obstante, todavía pervive una dicotomía en cuanto al consumo inmersivo en el sector de la comunicación. Si bien medios como The New York Times (Estados Unidos), Sveriges Television (Suecia), Clarín (Argentina) o Chosun Ilbo (Corea del Sur) adaptan todas sus piezas inmersivas para su experiencia en primera persona a través de gafas de realidad virtual, otros como France Télévisions (Francia) y Radiotelevisión Española (España) ofrecen tanto contenidos adaptados como sin adaptar, de tal forma que en estas ocasiones la visión 360 grados se logra con la interacción del usuario con el ratón en pantalla.

\section{Origen de las narrativas inmersivas digitales}

La influencia de las narrativas de los videojuegos y las amplias posibilidades de las tecnologías de realidad virtual y realidad aumentada han abierto nuevas vías en el panorama de la comunicación y de la información. La multinacional Sony bautizó el 2016 como el año cero de la realidad virtual dada su rápida expansión e implementación en ámbitos muy diversos, como fue el caso del periodismo. Si bien las técnicas y tecnologías no son nuevas, sí lo es su aplicación en los productos informativos.

La implementación de la realidad virtual y de las técnicas 360 grados por parte de las empresas de comunicación ha derivado en el periodismo inmersivo, una corriente que trata de acercar al receptor al escenario informativo mediante la inmersión virtual en escena. El fin no es otro que "meter al público en la historia" (Moloney, 2011: 80) y, por tanto, transmitirle la sensación de estar en el escenario del relato, la localización, "ahí" (De la Peña et al, 2010; Domínguez, 2015; The App Date, 26 de febrero de 2016).

Estados Unidos se asienta como la principal incubadora del periodismo inmersivo. Sus investigaciones en materia de realidad virtual y periodismo se remontan a los años 60. En 1966 la Universidad del Sur de California a través del Integrated Media Systems Center (IMSC) se consolidó como centro puntero en investigación multidisciplinar en internet y tecnologías multimedia, estando la realidad virtual y la inmersión entre sus temas de interés. 
En esta línea, uno de sus proyectos más destacados fue User-Directed News (UDN), una iniciativa en la que el IMSC intentó implementar tecnologías como el vídeo panorámico, el audio posicional, los módulos de reconocimiento de voz para navegar en la noticia, el rastreo de vídeo en 360 grados, el rastreo de los movimientos del usuario para crear una sensación de inmersión en el participante y la vinculación de los objetos del medio inmersivo con bases de datos de contenidos y ontologías de noticias.

A finales de los años 90 las narrativas inmersivas volvieron a ser un tema de interés entre los investigadores estadounidenses. El mando lo tomó entonces la Universidad de Columbia a través del Center for New Media. Lejos ya del testeo sin precedentes y de la pura teoría, el centro realizó los primeros experimentos prácticos: los situated documentaries documentales situados- (Hollerer et al, 1999), piezas audiovisuales informativas creadas por medio de sistemas de cámaras 360 grados.

Entre el 2000 y el 2001 la Universidad de Minnesota complementó la búsqueda del Center for New Media de narrativas inmersivas para aplicar en informaciones. Para ello celebró dos seminarios a través del Institute for New Media Studies: Playing the news: Journalism, interactive and narrative games y Sensing the News: What news technologies could mean for journalism. El primero pretendía crear un debate sobre la posible influencia de la lógica narrativa de los videojuegos en la creación de piezas informativas, mientras que el segundo, con un enfoque más práctico, buscaba advertir cómo integrar las tecnologías emergentes audio interactivo e inmersivo, fotografía y vídeo 360 grados, cámaras web o vídeo y fotografía en 3D- en los productos periodísticos para ofrecer experiencias de inmersión sensorial.

Ambas universidades sirvieron de precedente para el periodismo inmersivo. Sin embargo, las narrativas de esta corriente demoraron enormemente su incorporación al ámbito periodístico (Domínguez, 2013), posiblemente debido a condicionantes como la necesidad de incorporar nuevos perfiles profesionales a la plantilla del medio, a los costes de la tecnología y al difícil acceso a las mismas hasta antes de su popularización. 


\subsection{Tipos de productos inmersivos}

El periodismo inmersivo se asienta sobre dos tipos de formatos audiovisuales: las grabaciones 360 grados y las recreaciones tridimensionales. Si bien las primeras son las más populares en los medios de comunicación, las piezas 3D también tienen cabida para algunas empresas. Sin ir más allá, Harvest of Change, reportaje anteriormente mencionado, es un producto creado sintéticamente que permite avanzar por el escenario en 360 grados e interactuar con los diferentes elementos e iconos del espacio virtual.

Las recreaciones tridimensionales se basan en "la construcción de un espacio cien por cien digital por el que el usuario puede 'moverse' con libertad" (Domínguez, 2013: 104). La inmersión en estos productos sintéticos se logra mediante la identificación del usuario con un avatar digital, de tal forma que el sujeto ve el mundo virtual desde la perspectiva en primera persona del alter ego digital.

La técnica empleada no es desconocida, sino que se trata de una ocularización interna primaria (Gaudreault \& Jost, 1995), un recurso muy habitual en los videojuegos donde incluso puede mostrarse en pantalla alguna extremidad -brazos o piernas- del avatar del jugador. De la Peña (2010), Pavlik (2001) y Pryor (2000) sostienen que las recreaciones tridimensionales permiten expresar en su máximo potencial la inmersión en el relato, debido a la posibilidad de que el usuario experimente en un entorno sintético sensaciones tanto visuales como sensoriales

Ambos formatos, 360 o 3D, permiten la inmersión en primera persona en escena gracias al empleo de gafas o cascos de realidad virtual, una herramienta que elimina la frontera física o cuarta pared (Domínguez, 2015; Márquez, 2008) que impone el visionado de piezas a través de la pantalla de un ordenador o móvil.

Las narrativas inmersivas permiten así un consumo diferente y en primera persona de productos informativos. Estas técnicas permiten sumergir al usuario en la historia, pues si bien antes los periodistas 
debían intentar transmitirle al receptor sensaciones determinadas a través de texto, vídeo o imagen, ahora directamente cogen al espectador y lo trasladan al escenario del relato informativo (The App Date, 26 de febrero de 2016).

\section{Metodología}

Esta investigación tiene como objetivo advertir cómo el sector radiodifusor público europeo implementa las técnicas de realidad virtual y de 360 grados, también conocidas como inmersivas.

El marco temporal del estudio abarca desde el 3 de octubre de 2013, por ser la primera vez que una televisión europea pública estrenó contenido inmersivo, hasta el 1 de octubre de 2016, es decir, un periodo de tres años. En primer lugar, procedimos a la contextualización del tema de estudio, el periodismo inmersivo. Una vez ubicado temporalmente y definidas sus principales características, pasamos al análisis del objeto de la investigación.

Para ello seleccionamos la muestra a investigar, que en este caso coincidió con las siguientes televisiones de la Unión Europea de Radiodifusión (UER): Radio Televizioni Shqiptar (Albania), Radio Télévision Belge Francophone (Bélgica), Vlaamse Radio- en Televisieomroep (Bélgica), Danmarks Radio (Dinamarca), Yleisradio (Finlandia), France Médias Monde (Francia), France Télévisions (Francia), Radio France (Francia), Rikisútvarpið (Islandia), TG4 (Irlanda), Raidió Teilifís Éireann (Irlanda), Israel Broadcasting Authority (Israel), Radiotelevisione Italiana (Italia), Public Broadcasting Services Limited (Malta), Teleradio-Moldova (Moldavia), Rádio e Televisão de Portugal (Portugal), Norsk Rikskringkasting (Noruega), Romanian Radio Broadcasting (Rumanía), Societatea Română de Televiziune (Rumanía), Radiotelevisión Española (España), Sveriges Radio (Suecia), Sveriges Television (Suecia), Sveriges Utbildningsradio (Suecia), Schweizerischen Radio und Fernsehgesellschaf (Suiza) y British Broadcasting Television (Reino Unido).

Una vez identificada la muestra de análisis, revisamos cada una de sus páginas webs oficiales, canales de YouTube y aplicaciones para smartphones con el fin de encontrar todas las piezas inmersivas 
publicadas desde 2013 hasta el 1 de octubre de 2016. Una vez obtenida la información necesaria para la investigación, procedimos al análisis de los datos obtenidos mediante el uso de técnicas de carácter cuantitativo. Para facilitar la interpretación de los resultados, se clasificaron los datos en diferentes tablas y gráficas.

\section{Resultados}

El actual ecosistema mediático se caracteriza por la incesante búsqueda de innovación y mejoras. En un panorama informativo donde lo nacional traspasa fronteras gracias a las posibilidades que la red le permite, un proceso conocido como internacionalización (Peña, Lazkano \& García, 2016), los medios de comunicación luchan ahora en un escenario de competencia global, de ahí que la apuesta por la modernización y la adaptación a las últimas tendencias tecnológicas sea más notoria y necesaria.

Si Reino Unido y Francia tienden al empleo de docuwebs interactivos, ¿por qué nosotros en [insertar país] no? Desde el momento en que el público -entiéndase por esto población- al que tradicionalmente se dirigía un medio de comunicación tiene acceso a los contenidos de entes informativos foráneos, la urgencia por consolidarse pioneros en algún tema o herramienta tecnológica se convierte en fundamental, pues ninguna empresa busca crear en sus receptores un clima de decepción, obsolescencia y abandono tecnológico.

Ante esta situación, no es de extrañar que las televisiones públicas europeas aboguen por la implementación de nuevos lenguajes en sus productos y contenidos informativos. Una apuesta que puede ser entendida como una carrera por ser el mejor del conjunto, el más innovador, al fin y al cabo. En este sentido, la Unión Europa está siendo testigo del nacer de las narrativas inmersivas. La realidad virtual y las técnicas de grabación 360 grados permiten a los entes públicos el enriquecimiento del multimedia (Salaverría, 2016). Estos recursos representan una de las últimas tendencias del panorama informativo internacional, de ahí que las radiodifusoras públicas europeas traten de posicionarse en el continente y con respecto al resto del mundo como seguidoras fieles de la innovación. 
Esta investigación pretende realizar una comparativa de la velocidad de adaptación de las televisiones públicas europeas al llamado periodismo inmersivo digital. Por ende, hemos procedido a la revisión de los contenidos de los 24 entes examinados que forman parte del conglomerado de la Unión Europea de Radiodifusión. En esta búsqueda nos hemos encontrado que 13 de las 24 radiodifusoras apuestan ya por la inclusión del lenguaje digital inmersivo o de visión 360 grados en sus mensajes y contenidos periodísticos. Esta cifra, que sobrepasa la mitad de empresas del conjunto, da cuenta ya de la importancia que la corriente inmersiva ha alcanzado desde su primera aplicación práctica real en el periodismo en 2013.

El primer ente televisivo europeo en aplicar las técnicas de grabación 360 grados en sus productos fue la British Broadcasting Television (BBC) el 3 de octubre de 2013. Su debut consistió en un reportaje interactivo sobre el océano Atlántico compuesto por cuatro vídeos inmersivos grabados bajo las aguas de las Bahamas. Hasta el año siguiente ninguna otra radiodifusora aplicó tales innovadoras técnicas.

El paso lo dio Radiotelevisión Española (RTVE) el 13 de febrero de 2014, consolidándose como segunda televisión europea en implementar realidad virtual en sus productos. En la pieza publicada se sumergía al espectador en el estudio y plató del programa Emprende, de Canal 24h, para mostrarle el making-of del mismo. A la corporación española la siguió, meses más tarde, Yleisradio (YLE). La radiodifusora finlandesa dedicó su primer producto inmersivo al Día de la Independencia del país, celebrado anualmente el 6 de diciembre.

En 2015 la cifra volvió a aumentar, moldeando así la naciente corriente del periodismo inmersivo. La primera en unirse fue France Télévisions al retransmitir en 360 grados los partidos del Torneo de Roland Garros, celebrados entre el 24 de mayo y el 7 de junio. El 2 de septiembre de 2015 Danmarks Radio (DR) publicó también su primer producto inmersivo, al retransmitir en directo de la subida de un globo a 27,8 kilómetros de altura de la superficie terrestre. 
Tabla 1. Radiodifusoras públicas europeas que han implementado en alguna ocasión técnicas inmersivas.

\begin{tabular}{|c|c|c|c|}
\hline País & Radiodifusora & Aplica & No aplica \\
\hline \multirow{2}{*}{ Suecia } & $S V T$ & च & \\
\hline & UR & - & \\
\hline Suiza & SRG-SSR & & - \\
\hline \multirow[t]{2}{*}{ Rumanía } & ROR & & - \\
\hline & TVR & & - \\
\hline Portugal & RTP & - & \\
\hline Noruega & NRK & - & \\
\hline Moldavia & TRM & & - \\
\hline Albania & RTSH & & - \\
\hline \multirow{2}{*}{ Bélgica } & RTBF & & - \\
\hline & $V R T$ & - & \\
\hline Dinamarca & $\overline{D R}$ & - & \\
\hline Islandia & RÚV & - & \\
\hline \multirow[t]{2}{*}{ Irlanda } & RTÉ & - & \\
\hline & TG4 & & - \\
\hline Israel & $I B A$ & & $\square$ \\
\hline Italia & $\mathrm{R} A I$ & - & \\
\hline Malta & PBS & & - \\
\hline Finlandia & YLE & 匹 & \\
\hline \multirow{3}{*}{ Francia } & $F M M$ & & - \\
\hline & France Télévisions & घ & \\
\hline & Radio France & & - \\
\hline Reino Unido & $B B C$ & - & \\
\hline España & RTVE & - & \\
\hline
\end{tabular}

Fuente: Elaboración propia

En otoño dos nuevas televisiones aplicaron la realidad virtual en sus productos informativos. La primera fue Norsk Rikskringkasting (NRK), la cual se valió de cámaras 360 grados para mostrar el vestuario del programa P3 Gull el 28 de noviembre. Posteriormente, Sveriges Television (SVT) se atrevió con la retransmisión del show Musikhjälpens, celebrado del 13 al 19 de diciembre.

Con la llegada del 2016 seis nuevas televisiones apostarían por la implementación de las técnicas inmersivas en sus contenidos. Vlaamse 
Radio- en Televisieomroep (VRT) fue la primera de ellas. La radiodifusora subió a su página web el 15 de febrero un vídeo en el que ofrecía a los espectadores un recorrido por el, en aquel momento, nuevo plató informativo de la cadena. A esta la siguió Sveriges Utbildningsradio (UR) con la publicación, el 5 de abril de 2016, del cortometraje En skoldag. I virtual reality, sobre el acoso infantil en los colegios. Tan solo un día después se estrenaría Raidió Teilifís Éireann (RTÉ). El ente irlandés publicó el reportaje Big week on the farm, sobre corderos en las granjas.

\section{Imagen 1. Países europeos que implementan la realidad virtual en sus productos.}
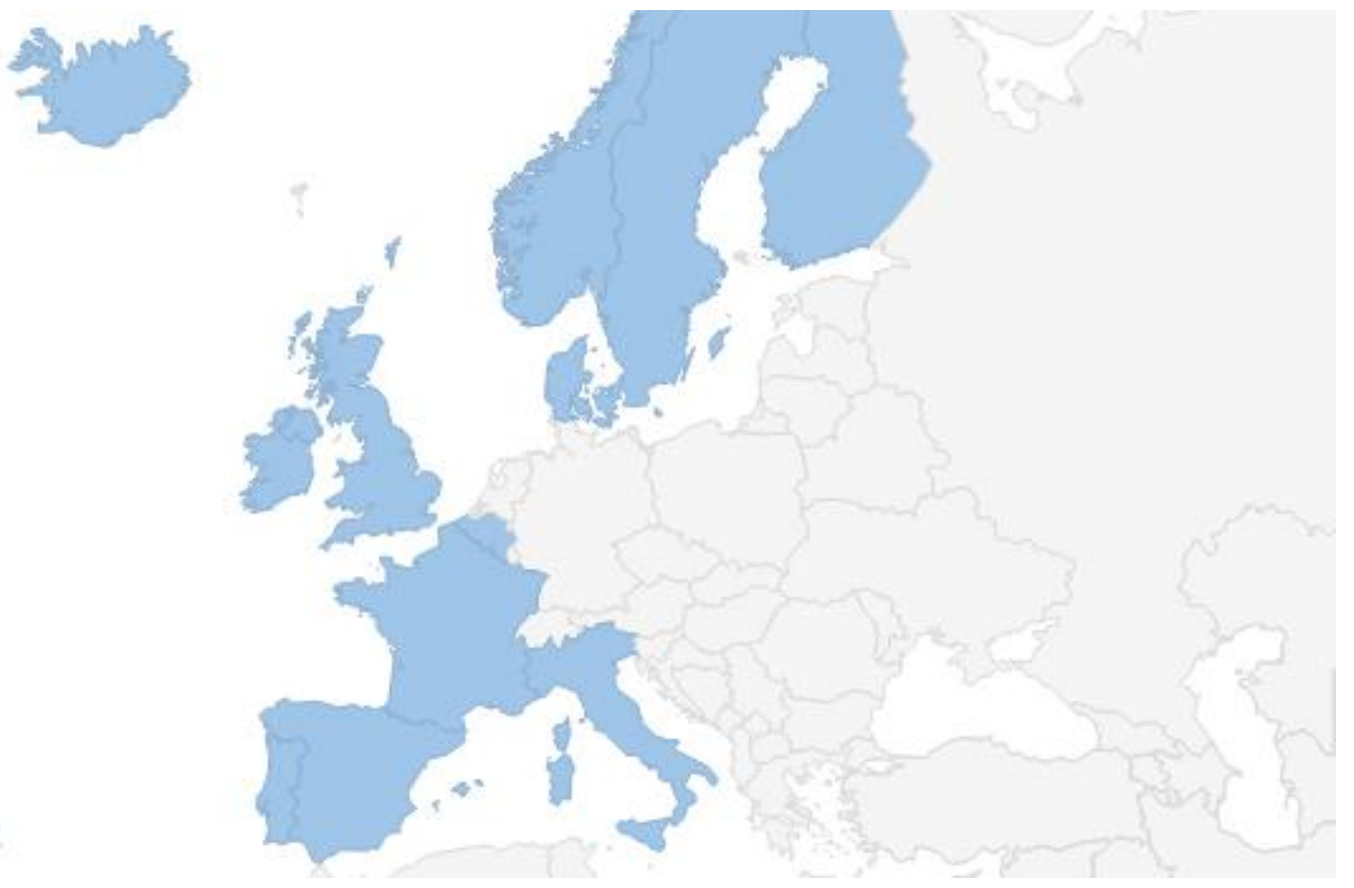

Fuente: Elaboración propia

En mayo otras dos televisiones se sumaron al periodismo inmersivo. La primera fue Rádio e Televisão de Portugal (RTP) con la emisión en directo, el 1 de mayo, de la final del programa Portugal Got Talent. Días después, el 9 de mayo, Radiotelevisione Italiana $(R A I)$ promocionó su nuevo programa Voyager con un vídeo en 360 grados, las mismas técnicas que usaría en el producto audiovisual que anunciaba.

La última en abogar por las narrativas inmersivas -hasta la fecha contemplada en esta investigación-, fue Rikisútvarpið (RÚV). La 
radiodifusora islandesa se estrenó en materia de realidad virtual el 19 de julio de 2016, mas a diferencia de las anteriores, exceptuando a la British Broadcasting Corporation (BBC), lo hizo con el estreno de varias piezas simultáneamente. De este modo, lanzó un total de 25 vídeos de exploración 360 grados en el que muestra una ruta de por el país durante todo un día.

Aunque el periodismo inmersivo se basa fundamentalmente en vídeos, lo cierto es que algunas empresas experimentan también con fotografías 360 grados. Así lo evidencia Sveriges Radio (SR). La radio pública sueca publicó el 10 de mayo de 2016 una colección de imágenes capturadas en 360 grados sobre las instalaciones del festival de Eurovisión. Con todo, SR se valdría de nuevo de estos recursos para mostrar a sus receptores los estadios olímpicos en agosto de ese mismo año.

\subsection{Previsión y adaptación al consumo móvil}

De las 24 televisiones públicas europeas contempladas en la muestra, tan solo 13 apostaron por el testeo y producción de contenidos mediante narrativas inmersivas de realidad virtual. No obstante, si bien el consumo de estos productos 360 grados está pensado para el uso de gafas de realidad virtual, puesto que permiten al usuario una experiencia en primera persona al aislarlo de la (su) realidad primaria y trasladarlo de lleno a una secundaria (Pérez, 2015), son escasas las radiodifusoras que plantearon su primer producto inmersivo para ser visionado mediante esta herramienta intermediaria.

El primer ente público que se entrenó en materia de realidad virtual con contenidos pensados y adaptados tanto para el consumo móvil como para gafas/cascos fue France Télévisions. Entre el 22 de mayo y el 7 de junio de 2015 retransmitió en 360 grados los partidos del Torneo de Roland Garros, dando la opción a los usuarios de visionar las competiciones o bien a través de una pantalla e interactuando con el ratón, o bien mediante gafas de realidad virtual.

Sveriges Television (SVT) fue la siguiente en publicar su primer producto inmersivo adaptado. La televisión sueca retransmitió del 13 al 19 de 
diciembre de 2015 el espectáculo Musikbjälpens mas, a diferencia de los otros entes, aprovechó la ocasión para estrenar también una aplicación móvil para el consumo inmersivo SVT 360, una plataforma dirigida al visionado de contenidos 360 grados mediante gafas de realidad virtual.

Sveriges Utbildningsradio (UR) cierra el trío de radiodifusoras visionarias que plantearon su producción inmersiva pensada directamente para un consumo en primera persona, es decir, por medio de unas gafas de realidad virtual. UR publicó el 5 de abril de 2016 en YouTube su primer reportaje 360 grados, el cual indexó a un reportaje multimedia publicado en la web en el que presentaba el proyecto.

Imagen 2. Demora en la adaptación del contenido inmersivo al consumo con gafas de realidad virtual.

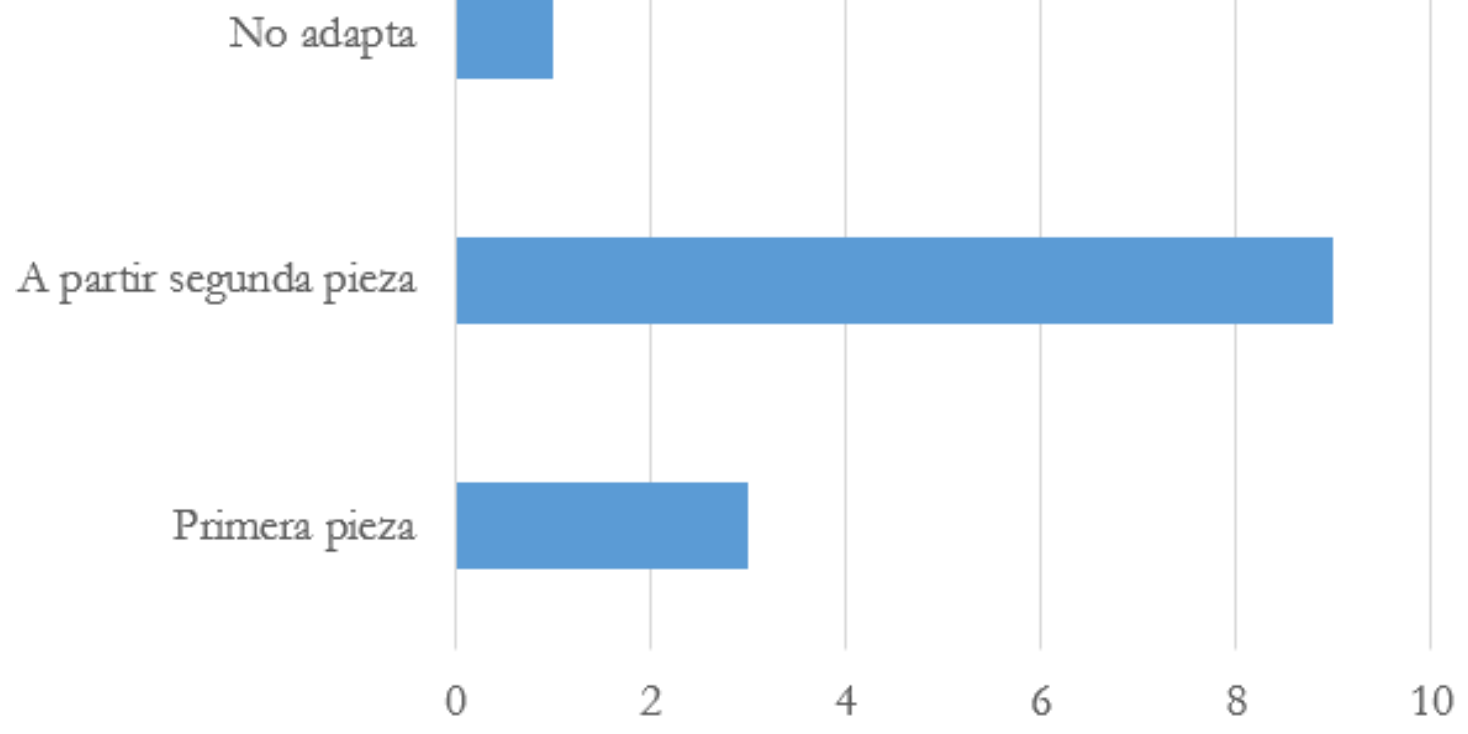

Fuente: Elaboración propia

El resto de televisiones, aunque inicialmente publicaron contenido cuyo consumo se reducía a la interacción 360 grados en pantalla, estrenaron más tarde productos inmersivos adaptados para el visionado con gafas. Todas lo hicieron a excepción de Rádio e Televisão de Portugal (RTP), debido a que hasta el 1 de octubre de 2016 -fecha de cierre de la recogida de datos de esta investigación- no volvió a producir contenido inmersivo desde su debut en mayo de 2016. 
Además, cabe destacar el caso de Danmarks Radio (DR). La radiodifusora noruega retransmitió en directo el 2 de septiembre de 2015 la subida de una cámara 360 grados sujeta a un globo a casi 30 kilómetros de altura de la superficie terrestre, pero esta emisión solo permitía un visionado con interacción en pantalla. Sin embargo, un día después, DR publicó el producto en YouTube habilitando la opción de consumo por medio de gafas de realidad virtual.

\subsection{Volumen de contenidos inmersivos publicados}

La tendencia predominante en el ámbito mediático es a asociar tiempo con cantidad. Por esa razón, no extraña que la British Broadcasting Corporation (BBC) y Radiotelevisión Española (RTVE) sean las dos televisiones públicas europeas que más contenido inmersivo hayan publicado hasta el momento.

Su primera aplicación de las técnicas de realidad virtual a los productos informativos ocurrió a principios de 2013 y de 2014 respectivamente, lo que implica aproximadamente tres años de experimentación inmersiva a sus espaldas. Ambas son seguidas por Yleisradio, cuyo debut tendría lugar a finales del 2014. Las tres acumulan en la actualidad más de diez piezas 360 grados producidas y publicadas en diferentes plataformas.

El ente que más destaca es Radiotelevisione Italiana $(R A I)$, dado que pese a su todavía incipiente trayectoria inmersiva -mayo de 2016- ya ha creado más de diez piezas 360 grados. Similar podría ser la situación de Ríkisútvarpið (RÚV), que debutó en junio de 2016, mas difiere en un aspecto fundamental: mientras que $R A I$ ha publicado productos de diversas temáticas, RÚV ha difundido del tirón una serie de 25 vídeos que juntos conforman una ruta de 24 horas de duración a lo largo de Islandia.

Aquellas televisiones que abogaron por el periodismo inmersivo entre noviembre de 2015 y abril de 2016 - Norsk Rikskringkasting (NRK), Vlaamse Radio- en Televisieomroep (VRT), Sveriges Utbildningsradio (UR) y Raidió Teilifís Éireann (RTÉ)- presentan una producción de contenidos 
360 grados moderada y paulatina, no superando ninguna las nueve piezas publicadas. Entre esas mismas fechas se encuentra también la iniciación de Sveriges Television (SVT), pero su apuesta ha sido superior a las cuatro anteriores.

La radiodifusora pública sueca difunde sus contenidos de realidad virtual a través de una aplicación propia, cuyo lanzamiento supuso una clara manifestación de voluntad 360 grados y así lo evidencian sus más de diez vídeos subidos.

Es importante señalar también que el único ente que tras su estreno no ha continuado creando contenido inmersivo ha sido Rádio e Televisão de Portugal (RTP).

Tabla 2. Volumen de piezas inmersivas publicadas por cada televisión pública europea.

\begin{tabular}{|c|c|c|c|c|c|}
\hline \multirow[t]{2}{*}{ País } & \multirow[t]{2}{*}{ Radiodifusora } & \multirow[t]{2}{*}{ Debut } & \multicolumn{3}{|c|}{$\mathbf{N}^{\circ}$ de piezas publicadas } \\
\hline & & & 1 & $2-9$ & +10 \\
\hline R.U. & $B B C$ & $03 / 10 / 2013$ & & & घ \\
\hline España & RTVE & $13 / 02 / 2014$ & & & " \\
\hline Finlandia & YLE & $03 / 12 / 2014$ & & & घ \\
\hline Francia & France Télévisions & $24 / 05 / 2015$ & & & " \\
\hline Dinamarca & $D R$ & $02 / 09 / 2015$ & & & घ \\
\hline Noruega & NRK & $28 / 11 / 2015$ & & $\mathbf{\square}$ & \\
\hline Sucia & SVT & $13 / 12 / 2015$ & & & $\square$ \\
\hline Bélgica & VRT & $15 / 02 / 2016$ & & च & \\
\hline Suecia & UR & $05 / 04 / 2016$ & & 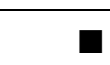 & \\
\hline Irlanda & RTÉ & $06 / 04 / 2016$ & & 口 & \\
\hline Portugal & RTP & $01 / 05 / 2016$ & घ & & \\
\hline Italia & $\mathrm{R} A I$ & $09 / 05 / 2016$ & & & घ \\
\hline Islandia & RÚV & $19 / 06 / 2016$ & & & n \\
\hline
\end{tabular}

Fuente: Elaboración propia 


\subsubsection{Tipo de contenidos publicados: retransmisiones en directo y making-of de programas}

Los contenidos inmersivos que más abundan son aquellos publicados en diferido, es decir, productos que tras su grabación arrastran consigo un tiempo determinado de montaje y edición. Con todo, algunas televisiones públicas europeas han visto una clara oportunidad en las técnicas 360 grados para las retransmisiones en directo de eventos o sucesos. Así lo han demostrado la British Broadcasting Television (BBC), Yleisradio (YLE), France Télévisions, Danmarks Radio (DR), Sveriges Television (SVT), Rádio e Televisão de Portugal (RTP) y Radiotelevisione Italiana $(\mathrm{R} A I)$.

\section{Tabla 3. Retransmisiones en directo realizadas por cada televisión.}

\begin{tabular}{|c|c|c|c|}
\hline País & Ente & Fecha & Tema \\
\hline $\begin{array}{l}\text { Reino } \\
\text { Unido }\end{array}$ & $B B C$ & $\begin{array}{l}24- \\
29 / 07 / 2014\end{array}$ & Juegos de Commonwealth. \\
\hline Finlandia & YLE & $06 / 12 / 2014$ & $\begin{array}{l}\text { Fiesta en el Palacio Presidencial por } \\
\text { el Día de la Independencia de } \\
\text { Finlandia. }\end{array}$ \\
\hline Dinamarca & $\overline{D R}$ & $02 / 09 / 2015$ & $\begin{array}{l}\text { Vista de la Tierra a 28,7 kilómetros } \\
\text { de altura. }\end{array}$ \\
\hline Finlandia & YLE & $06 / 12 / 2015$ & $\begin{array}{l}\text { Fiesta en el Palacio Presidencial por } \\
\text { el Día de la Independencia de } \\
\text { Finlandia. }\end{array}$ \\
\hline Suecia & SVT & $\begin{array}{l}13- \\
19 / 12 / 2015\end{array}$ & Espectáculo Musikhjälpens. \\
\hline Finlandia & YLE & $18 / 02 / 2016$ & $\begin{array}{l}\text { Celebración de la Penkkarit en } \\
\text { Helsinki. }\end{array}$ \\
\hline Suecia & SVT & $12 / 03 / 2016$ & Final del Melodifestivalen. \\
\hline Portugal & RTP & $01 / 05 / 2016$ & $\begin{array}{l}\text { Final del programa Portugal Got } \\
\text { Talent. }\end{array}$ \\
\hline Francia & $\begin{array}{l}\text { France } \\
\text { Télévisions }\end{array}$ & $\begin{array}{l}22 / 05- \\
05 / 06 / 2016\end{array}$ & Torneo Roland Garros. \\
\hline Francia & $\begin{array}{l}\text { France } \\
\text { Télévisions }\end{array}$ & $\begin{array}{l}13- \\
14 / 07 / 2016\end{array}$ & $\begin{array}{l}\text { Festejos del Día Nacional de } \\
\text { Francia. }\end{array}$ \\
\hline Italia & $\mathrm{R} A I$ & $\begin{array}{l}05- \\
21 / 08 / 2016\end{array}$ & $\begin{array}{l}\text { Competiciones de las Olimpiadas } \\
\text { de Río de Janeiro. }\end{array}$ \\
\hline
\end{tabular}

Fuente: Elaboración propia 
Al margen de las publicaciones emitidas en directo, algunos entes radiodifusores públicos europeos también han querido aprovechar las posibilidades de los 360 grados para mostrarles a sus audiencias el making-of o los estudios de producción de los programas que consumen. Radiotelevisión Española (RTVE) decidió estrenarse en materia de realidad virtual precisamente con la muestra de la grabación de un programa, mas otros como Norsk Rikskringkasting (NRK), British Broadcasting Corporation (BBC), Vlaamse Radio- en Televisieomroep (VRT) e Yleisradio (YLE) lo hicieron varias piezas después de haber publicado la primera.

\section{Tabla 4. Grabaciones de programas realizadas por cada televisión.}

\begin{tabular}{|l|l|l|l|}
\hline País & Ente & Fecha & Tema \\
\hline España & RTVE & $13 / 02 / 2014$ & $\begin{array}{l}\text { Making-of de Emprende, un programa del } \\
\text { canal 24h. }\end{array}$ \\
\hline Noruega & NRK & $28 / 11 / 2015$ & $\begin{array}{l}\text { Grabación de los vestuarios y camerinos } \\
\text { del programa P3 Gull. }\end{array}$ \\
\hline $\begin{array}{l}\text { Reino } \\
\text { Unido }\end{array}$ & BBC & $19 / 12 / 2015$ & $\begin{array}{l}\text { Cómo es el camino que los participantes } \\
\text { del programa The Voice UK deben hacer } \\
\text { antes de llegar al escenario. }\end{array}$ \\
\hline Bélgica & VRT & $15 / 02 / 2016$ & $\begin{array}{l}\text { Recorrido por el nuevo plató informativo } \\
\text { de la televisión. }\end{array}$ \\
\hline Finlandia & YLE & $14 / 09 / 2016$ & \begin{tabular}{l} 
Making-of del programa infantil Galaxi. \\
\hline
\end{tabular}
\end{tabular}

Fuente: Elaboración propia

\subsection{Plataformas de difusión de las piezas inmersivas}

La plataforma de vídeos YouTube dispone de un software que permite subir y reproducir vídeos 360 grados e incluso ofrece la opción de adaptar la pantalla para visionar la pieza con gafas de realidad virtual. Por esa razón, dadas las posibilidades que ofrece, no extraña que seis radiodifusoras, de las 13 que abogan por la inmersión en escena, hayan optado por publicar sus contenidos 360 grados exclusivamente en YouTube -indexados a las descripciones del producto en las webs propias-. Se tratan de Sveriges Utbildningsradio (UR), Yleisradio (YLE), 
Vlaamse Radio- en Televisieomroep (VRT), Norsk Rikskringkasting (NRK), Rikisútvarpið (RÚV) y Danmarks Radio (DR).

Los contenidos de los entes anteriormente mencionados pueden encontrarse en los diferentes canales que cada televisión ha creado en YouTube. Además, esta plataforma permite elaborar en cada canal una serie de listas de reproducción que engloban y relacionan vídeos. Así lo ha hecho Sveriges Utbildningsradio (UR), aunque de un modo más específico. La televisión organizó en su canal una lista de contenido inmersivo únicamente sobre su reportaje Mobbning i 360. Vlaamse Radioen Televisieomroep también se vale de YouTube, mas la radiodifusora belga descartó la idea de crear una lista para atreverse a crear un canal de 360 grados propio: VRT Virtual Reality.

Por el contrario, una empresa ha optado por difundir contenido inmersivo en plataformas de desarrollo propio, es decir, a través de una aplicación móvil o de su página web oficial. Así lo ha hecho Radiotelevisión Española (RTVE), que para las Olimpiadas de 2016 estrenó la aplicación Vive Río: Heroinas, mas habitualmente utiliza su propia web o la del laboratorio -lab.rtve.es- para subir productos inmersivos. Cabe destacar el caso del reportaje Urban beekeeping, un proyecto realizado en colaboración con Yorokobu, Vocento y El País, y que actualmente está disponible en el canal de YouTube VReak Channel o en la aplicación de realidad virtual $V$ Reak.

Tres televisiones de la muestra abogan por una difusión multiplataforma de sus contenidos inmersivos. British Broadcasting Corporation (BBC), Radiotelevisione Italiana $(\mathrm{R} A I)$ y France Télévisions. La radiodifusora pública de Reino Unido ha publicado contenido a través de sus canales en YouTube, destacando especialmente el de $B B C$ News dado que cuenta con una lista específicamente dedicada a los vídeos 360 grados que produce: 360 \#VR Immersive Journalism. Con todo, el proyecto con el que se estrenó en 2013 solamente está disponible en la sección de la web Ocean. Los avances tecnológicos y técnicos que ha ido aplicando hasta la actualidad han derivado en el desarrollo de la aplicación BBC Sport 360, creada para disfrutar de manera inmersiva de las Olimpiadas 2016. 
Por su parte, Radiotelevisione Italiana ( $R A I)$ también se ha valido, hasta el momento final de esta investigación, de tres plataformas para difundir sus productos inmersivos. La principal es su canal de YouTube, aunque a diferencia de otros ejemplos esta no cuenta con listas creadas para identificar los contenidos inmersivos. Además, también dispone de piezas 360 grados publicadas en la web Voyager.rai.it. Junto a esto, al igual que la $B B C$, la televisión italiana optó por desarrollar la aplicación $\mathrm{R} A I$ Rio, pensada para el disfrute inmersivo de las Olimpiadas de 2016.

\section{Imagen 3. Plataformas usadas para la difusión de contenidos inmersivos}

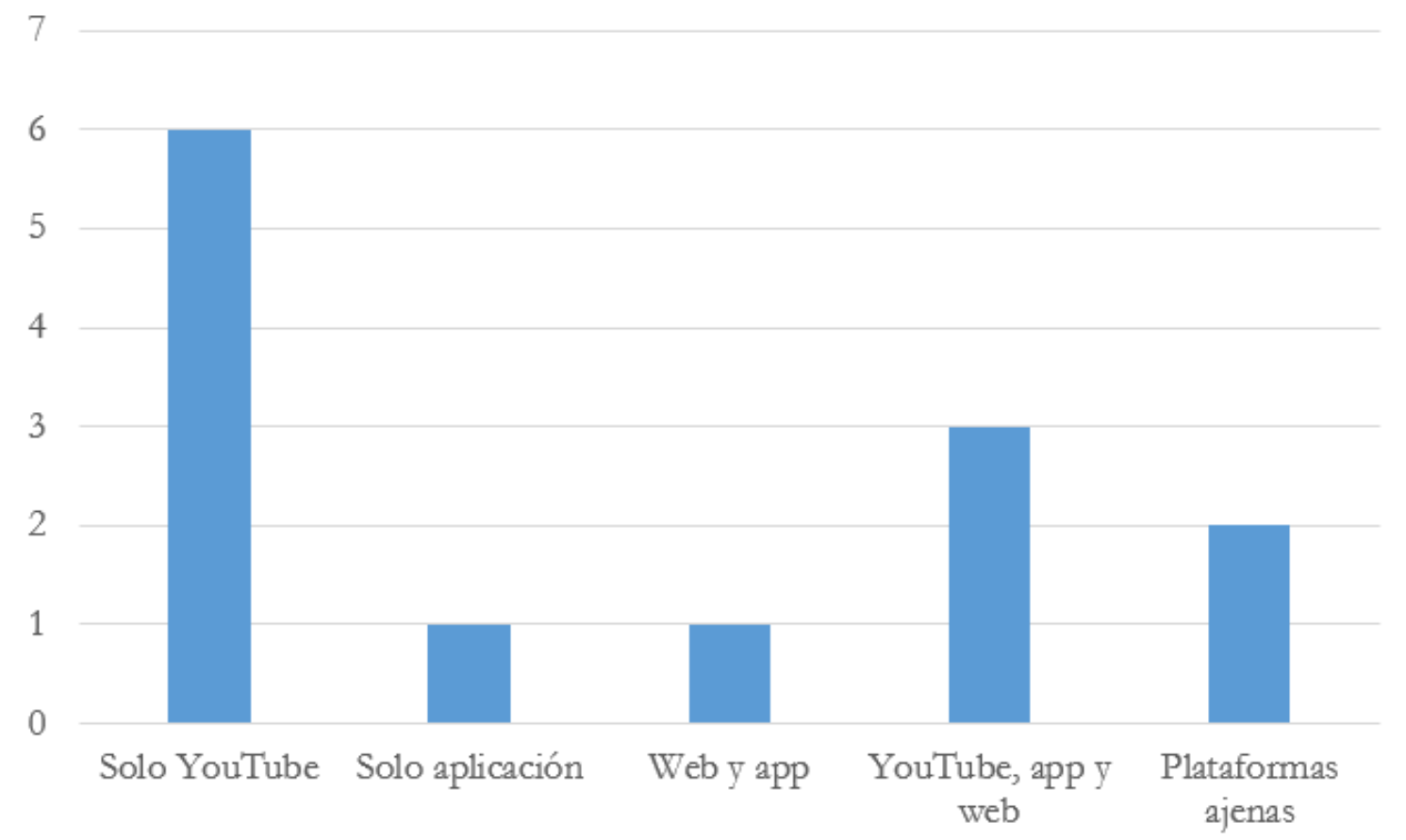

Fuente: Elaboración propia

Por su parte, la televisión pública francesa lanzó en mayo de 2016 una aplicación para visionar en directo y en 360 grados el Torneo de Roland Garros, pero también se vale de la web y de YouTube para publicar piezas de realidad virtual. Sveriges Television $(S V T)$ es la que más se diferencia del resto. La radiodifusora sueca ha desarrollado una estrategia de periodismo inmersivo consistente en la difusión de productos 360 grados a través, única y exclusivamente, de su aplicación de realidad virtual SVT 360. 
Finalmente, los dos casos restantes presentan particularidades propias. Por un lado, Ríkisútvarpid (RÚV) no difundió sus producciones inmersivas en su web, sino que lo hizo a través del canal de YouTube Sigur Rós el grupo que ponía la banda sonora a la pieza. Y, por otro, Rádio e Televisão de Portugal colaboró con MOG Technologies para la producción de su primer producto inmersivo, el cual retransmitió en directo a través de la página web de esta empresa tecnológica.

\subsection{Temáticas dedicadas a los contenidos inmersivos}

Con el fin de advertir las tendencias u orientaciones temáticas de las televisiones públicas europeas a la hora de producir contenido inmersivo, hemos elaborado una tabla conformada por siete categorías o temas.

Tabla 5. Temáticas de las piezas inmersivas.

\begin{tabular}{|c|c|c|c|c|c|c|c|}
\hline Ente & $\begin{array}{l}\text { Denuncia } \\
\text { social }\end{array}$ & Ciencia & $\begin{array}{l}\text { Cultura } \\
\text { y viajes }\end{array}$ & Fauna & Deportes & Música & Programas \\
\hline$B B C$ & 口 & 口 & च & $\square$ & 口 & च & च \\
\hline$R A I$ & & & 口 & & घ & & \\
\hline$R T V E$ & $\square$ & & 口 & & च & & 口 \\
\hline$R T P$ & & & & & & & घ \\
\hline$D R$ & घ & - & च & & च & & \\
\hline $\boldsymbol{R} \boldsymbol{U}^{\prime} \boldsymbol{V}$ & & & च & & & & \\
\hline$R T E ́$ & ש & & $\square$ & & & & घ \\
\hline$S V T$ & & & & & & च & \\
\hline$U R$ & ש & & & & & & \\
\hline$V R T$ & 口 & & & & च & & 口 \\
\hline$Y L E$ & & & $\square$ & & & $\square$ & $\square$ \\
\hline NRK & & & 口 & $\square$ & & a & $\square$ \\
\hline $\begin{array}{l}\text { France } \\
T V\end{array}$ & & & $\square$ & & $\square$ & & \\
\hline TOTAL & 6 & 2 & 9 & 2 & 6 & 4 & 7 \\
\hline
\end{tabular}

Fuente: Elaboración propia

El primero es "denuncia social", donde se incluyen todas las piezas que visibilizan o critican una situación injusta y/o negativa e incluso que reivindican mejoras sociales. El siguiente tiene que ver con todo el 
mundo científico, desde experimentos prácticos hasta viajes astronómicos. También hemos incluido una sección de cultura y viajes, así como una vinculada con el mundo animal, terrestre o marino. Los deportes y la música, por separado, también tienen cabida en nuestra tabla, puesto que se tratan de temas ampliamente reconocidos y aceptados mediáticamente por el público. Finalmente, optamos por la inclusión de un apartado para la grabación íntegra de programas o de making-of usando técnicas 360 grados.

Tal y como se aprecia en la tabla 5, los productos inmersivos vinculados con la cultura y los viajes son la apuesta más común de las radiodifusoras públicas europeas ( 9 entes). De cerca les sigue la grabación de la producción o del making-of de programas (7 entes), así como las piezas de denuncia social y de deportes (6 entes ambos). Las que menos presencia tienen en televisiones son, por el momento, las temáticas relacionadas con la ciencia y la fauna.

\section{Discusión y conclusiones}

El periodismo inmersivo, gracias a las técnicas 360 grados o de realidad virtual, ofrece a los usuarios una experiencia en primera persona de la pieza informativa. Las televisiones, por su parte, disponen así de un formato que les permite sumergir a los receptores en el lugar de los hechos, el escenario real de la información.

Por esa razón, no extraña que 13 de las 24 televisiones públicas europeas examinadas implementen ya en sus productos audiovisuales las narrativas y recursos inmersivos. Esta cifra, que supera la mitad de la muestra, es un claro ejemplo de la tendencia in crescendo del periodismo inmersivo, una corriente que ha calado en buena parte del panorama occidental mediático -televisiones, periódicos, etc.

En Europa la apuesta por estas técnicas se distribuye de manera curiosa sobre el mapa. Las televisiones públicas del norte y oeste del continente son las que, hasta la fecha final de esta investigación, han implementado la inmersión virtual en sus productos. La primera fue la British Broadcasting Television (BBC) en 2013, seguida por Radiotelevisión 
Española (RTVE) y Yleisradio (YLE) en 2014. En el 2015 la curiosidad por la realidad virtual comenzó a expandirse y France Télévisions, Dansmarks Radio (DR), Norsk Rikskeringkasting (NRK) y Sveriges Television (SVT) abogaron también por el periodismo inmersivo, manteniendo un trabajo paulatino y continuado hasta el momento presente (2016).

Con todo, la explosión se produjo en el 2016. Un total de seis entes saltaron al periodismo inmersivo entre febrero y julio, ambos meses incluidos: Vlaamse Radio- en Televisieomroep (VRT), Sveriges Utbildningsradio (UR), Raidió Teilifís Éireann (RTE), Rádio e Televisão de Portugal (RTP), Radiotelevisione Italiana (RAI), Ríkisútvarpid (RÚV). Esta concentración en la primera mitad del año evidencia el nivel de calado que dichas técnicas presentan en el panorama de las radiodifusoras públicas europeas. Precisamente en un contexto de búsqueda de nuevas e innovadoras formas de contar la información, las grabaciones 360 grados y la realidad virtual se asientan como un frente ampliamente posible.

Un hecho que destaca es que, de los seis entes que implementaron por primera vez la realidad virtual en 2016 (hasta octubre, este no incluido), solo uno haya producido contenido pensado para su consumo con gafas o cascos, Sveriges Utbildningsradio (UR). La situación resulta curiosa dado el nivel de evolución que en ese año adquirió la realidad virtual, contando para su disfrute con múltiples instrumentos y herramientas a precios más asequibles que en sus comicios unos años atrás.

No obstante, en 2015 la cifra de televisiones que adaptaron su primer contenido para una experiencia con gafas de realidad virtual era de dos: France Télévisions y Sveriges Television (SVT). El resto de radiodifusoras abogaron por la adaptación del producto a posteriori de su estreno, un hecho significativo que puede estar relacionado con la consolidación ya de la narrativa inmersiva como un recurso más y no como un testeo inicial de la tecnología de realidad virtual. La única que no se incluye en esta selección es Rádio e Televisão de Portugal (RTP), dado que hasta el final de esta investigación solo había producido una pieza y esta no estaba adaptada para gafas. 
En cuanto al volumen de producción inmersiva de cada televisión pública europea, no sorprende que las cinco primeras en iniciarse en la corriente periodística sean las que más contenidos hayan publicado hasta la fecha de cierre de esta investigación. Se tratan de British Broadcasting Television (2013), Radiotelevisión Española (2014), Yleisradio (2014), France Télévisions (2015) y Danmarks Radio (2015). En octavo puesto, según la fecha de estreno en materia de realidad virtual, estaría Sveriges Radio a finales de 2015.

Destaca el caso de Radiotelevisione Italiana (RAI) y Ríkisútvarpið (RÚV) por disponer, pese a su primera implementación inmersiva en mayo y junio de 2016 respectivamente, de un volumen de piezas publicadas superior a diez. Los productos de $R A I$ son reportajes de diversa índole, más el caso de RÚV es diferente: este ente publicó en un solo día y del tirón una serie de 25 vídeos que juntos conforman una ruta de 24 horas a lo largo de Islandia.

El resto de radiodifusores, a excepción de la única pieza con la que cuenta Rádio e Televisão de Portugal (RTP), han publicado hasta octubre de 2016 entre 2 y 9 piezas.

Por otra parte, se ha advertido que las radiodifusoras públicas europeas han topado en la realidad virtual una utilidad que va más allá de la producción de reportajes, de historias informativas. De este modo, algunas han aprovechado las técnicas 360 grados para la realización de retransmisiones en directo. La inmersión en escena permite que el espectador pueda disfrutar de una experiencia en primera persona como si estuviera en el lugar de los hechos.

Tras el análisis de las emisiones en vivo de las 13 televisiones, podemos concluir que este uso se reserva para días señalados en el territorio o para eventos muy determinados y que mueven masas: el Melodifestivalen, la final del programa Portugal Got Talent, el Día Nacional de Francia, las Olimpiadas, los juegos de Commonwealth, el Día de la Independencia de Finlandia, el Musikkhälpens y la Penkkarit. La única excepción es una pieza de Danmarks Radio (DR) en la que se emite en directo las vistas de un globo a casi 30 kilómetros de altura con respecto a la Tierra. Cabe destacar que el ente que más 
retransmisiones realizó hasta octubre de 2016 es Yleisradio (YLE), con un total de tres. A este le sigue France Télévisions, con dos emisiones 360 grados en vivo.

Otra de las posibilidades que las televisiones han advertido es la de trasladar al espectador a lo que hay detrás de las cámaras, mostrarle lo que no ve en pantalla habitualmente. De este modo, los making-of y los tours 360 grados por los estudios o platós se han asentado como una opción ocasional.

La primera en sumergir al espectador en la grabación de un programa fue Radiotelevisión Española (RTVE) en 2014, una estrategia que Yleisradio (YLE) imitó en 2016. En cuanto a los recorridos por las instalaciones, un total de tres entes lo han intentado: Norsk Rikskringkasting (NRK), British Broadcasting Corporation (BBC) y Vlaamse Radio- en Televisieomroep (VRT). Solo 5 de 13 televisiones han optado por probar este uso alejado del habitual reportaje o pieza informativa en sentido estricto, pero dado el corto proceso de vida de las narrativas inmersivas digitales, sería excesivo augurarle un futuro éxito o fracaso. En estos casos, el tiempo lo dirá.

En cuanto a las plataformas empleadas para la difusión de contenidos, YouTube se posiciona como la principal. Un total de ocho televisiones públicas europeas confían en ella para la subida de sus piezas 360 grados, dado que la plataforma permite adaptar y consumir los productos bien con la interacción del ratón o bien a través de gafas o cascos de realidad virtual. Sin embargo, solo seis recurren a YouTube como único recurso para la transmisión de contenidos inmersivos: Sveriges Utbildningsradio (UR), Yleisradio (YLE), Vlaamse Radio- en Televisieomroep (VRT), Norsk Rikskringkasting (NRK), Rikisútvarpid (RÚV) y Danmarks Radio (DR).

France Télévisions, British Broadcasting Corporation (BBC) y Radiotelevisione Italiana $(\mathrm{R} A I)$ complementan la difusión en YouTube con la publicación de vídeos 360 grados también en aplicaciones de desarrollo propio y en sus páginas webs. 
Radiotelevisión española (RTVE) es una de las cuatro radiodifusoras restantes que rechaza el uso de la plataforma anterior. La televisión pública española aboga por publicar sus piezas inmersivas en su página web o, en el caso de las Olimpiadas de 2016, en una aplicación de creación propia.

De todas estas destaca la estrategia de Sveriges Television ( $S V T$ ), ente que difunde únicamente sus productos 360 grados a través de su aplicación $S V T$ 360. Ni en la web ni en YouTube ha publicado contenido hasta la fecha final de esta investigación.

Ríkisutvarpid (RÚV) y Rádio e Televisão de Portugal (RTP) son los casos más curiosos. Ninguna de las dos televisiones ha publicado piezas en alguna plataforma propia, ya sea la web, una aplicación o un canal en YouTube. En definitiva, los productos de ambas fueron difundidos a través de plataformas ajenas, con cuyos responsables mantenían una relación de colaboración durante la producción de las pertinentes piezas.

Finalmente, hemos analizado también las temáticas a las que respondían las diferentes piezas de cada radiodifusora pública europea hasta octubre de 2016. El fin era advertir qué temas son los más elegidos o comunes a la hora de producir contenidos inmersivos. Los resultados son claros. Un total de nueve entes han elaborado productos relacionados con la cultura y los viajes, mientras que siete también han abogado por la grabación de o del making-of de un programa. Muy de cerca les siguen las temáticas de denuncia social y de deportes, siendo seis entes en ambos casos los que en alguna ocasión apostaron por informaciones de esta índole.

En definitiva, el periodismo inmersivo se asienta como una estrategia de innovación con un calado creciente en el panorama radiodifusor público. Prueba de ello son las 13 de las 24 empresas examinadas que implementaron al menos en más de dos ocasiones -salvo Rádio e Televisão de Portugal (RTP) - las técnicas 360 grados y de realidad virtual en sus productos audiovisuales. 
La evolución del consumo y de las tecnologías deriva en la necesidad de la adaptación de las piezas para una experiencia con cascos o gafas de realidad virtual, mas en esto las televisiones todavía tienen mucho camino por recorrer. No se trata de la ausencia de medios y herramientas, dado que YouTube facilita esta tarea, sino de una posible falta de iniciativa a la hora de apostar por ofrecer una experiencia inmersiva directamente en primera persona. A sus escasos tres años de vida, el periodismo inmersivo todavía terminó de eclosionar en 2016.

\section{Bibliografía}

De la Peña, N., Weil, P., Llobera, J., Giannopoulos, E., Pomés, A., Spaniang, B., Friedman, D., Sánchez-Vives, M. \& Slater, M. (2010). Immersive Journalism: immersive virtual reality for the first-person experience of news. Presence: Teleoperators and virtual environments, 19 (4), 291-301. doi: 10.1162/PRES_a_00005

Domínguez, E. (2013). Periodismo inmersivo: La influencia de la realidad virtual y del videojuego en los contenidos informativos. Barcelona: Editorial UOC.

Domínguez, E. (2015). Periodismo inmersivo o cómo la realidad virtual y el videojuego influyen en la interfaz e interactividad del relato de actualidad. El Profesional de la Información, 24 (4), 291301. doi: $10.3145 /$ epi.2015.jul.08

Gaudreault, A. \& Jost, F. (1995). El relato cinematográfico: Cine y narratología. Barcelona: Paidós.

Márquez, I. (2008). Avatares del ciberespacio. La inmersión en la Realidad Virtualy en la interacción en red [Trabajo para el Diploma de Estudios Avanzados]. Universidad Complutense de Madrid, España.

Moloney, K.T. (2011). Porting transmedia storytelling to journalism [Tesis doctoral]. Colorado.edu. http://goo.gl/cvWfvp

Peña, S., Lazkano, I. \& García, D. (2016). La transición digital de los diarios europeos: nuevos productos y nuevas audiencias. Comunicar, 46, 27-36. https://doi.org/10.3916/C46-2016-03

Pavlik, J.V. (2001). Journalism and new media. New York: Columbia University Press.

Pérez-Seijo, S. (2015). Periodismo inmersivo: de público a actor de la información. En I Simposio de la Red Internacional de 
Investigación y Gestión de la Comunicación. Pontevedra, España.

Pryor, L. (2000). Immersive News Technology: Beyond Convergence. Ojr.org. http://goo.gl/FMRM2X

Salaverría, R. (2016). "Los medios de comunicación que vienen". En

VV.AA., Innovación y desarrollo de los cibermedios en España (Coord., Sádaba, C., García, J.A \& Martínez, M.P.). Navarra:

Ediciones Universidad de Navarra.

The App Date (2016). The App Date Immersive journalism.

Espacio.fundacionelefonica.com. https://goo.gl/zJOPRj

Reconocimientos: Los resultados de este artículo forman parte de las actividades de difusión del proyecto del Programa estatal de Fomento de la Investigación Científica y Técnica de Excelencia, subprograma estatal de Generación de Conocimiento del Ministerio de Economía y Competitividad de España sobre "Indicadores de gobernanza, financiación, rendición de cuentas, innovación, calidad y servicio público de las RTV europeas aplicables a España en el contexto digital" (Referencia CSO2015-66543- P). 


\title{
Comunicación online y trafico web de las televisiones públicas en Europa
}

\author{
José Miguel Túñez-López \\ Universidade Santiago de Compostela \\ Carmen Costa-Sánchez \\ Universidade da Coruña
}

Cómo citar: Túñez-López, M. y Costa-Sánchez, C. (2017). Comunicación online y trafico web de las televisiones públicas en Europa. En Túñez López, M.; Campos-Freire, F. y Silva Rodríguez A. (Eds.). (2017) Estudios sobre financiación, legislación e innovación en la Televisión Pública. Cuadernos Artesanos de Comunicación, cac126, pp 127-142. La Laguna (Tenerife): Latina.

DOI: $10.4185 / \mathrm{cac} 126$

T AS TELEVISIONES públicas europeas han sido analizadas audiencias y, más recientemente, compromiso público. Este capítulo se acerca a ese objeto de estudio desde una perspectiva que permita identificar estrategias de comunicación online observando el papel de las redes sociales en la generación de tráfico web. En un contexto 2.0, los canales públicos europeos deben mejorar sus principales líneas de relación online con los internautas y sus estrategias en social media, mayoritariamente desaprovechadas como escenarios de reclutamiento de audiencia web. En redes sociales, Facebook es la mayor pasarela de acceso. A gran distancia, Twitter desarrolla un papel simbólico.

Palabras clave: identidad corporativa; televisión; televisión pública; estrategia de comunicación. 
Las televisiones públicas afrontan un contexto de cuestionamiento y crítica agudizado por la reciente crisis económica, que ha conllevado cierres de canales públicos autonómicos en España y, también, a nivel europeo. El cuestionamiento de su sistema de financiación con fondos públicos ha obligado a las respectivas corporaciones a incrementar sus niveles de transparencia sobre el destino de los gastos y sobre la necesidad de mejorar su reputación (Fernández Lombao y Campos, 2013).

A esto se añade, en términos contextuales, el cambio en el perfil de las audiencias -cada vez más participativas- y las nuevas dinámicas de comunicación e información online, una auténtica revolución desde la óptica de los mass media. La digitalización de los procesos, la atomización de las audiencias, la multiplicación de la oferta de libre acceso mediante la TDT, el surgimiento de diversas plataformas de pago y la consolidación de Internet y los nuevos medios como dispositivos de consumo conducen hacia una nueva etapa en la dinámica y el alcance de la televisión pública (Manfredi, 2011).

Este conjunto de factores conduce a poner el foco de atención en las estrategias de comunicación online de los entes públicos europeos. Por medio del acercamiento a lo que comunican y cómo lo comunican, pretende identificarse la identidad corporativa deseada desde los órganos de gestión, así como la filosofía o principios que guían sus actuaciones.

La identidad corporativa es un concepto complejo que parte de la lingüística y la semiótica. Incluye cómo se comporta, cómo se relaciona, cómo y qué comunica, los símbolos que usa y los rasgos que la diferencian de otras organizaciones (Túñez, 2012). Se trata de la personalidad de la organización, por eso también se la denomina, personalidad corporativa. Según Capriotti (1999), la Identidad Corporativa representa el conjunto de características centrales, perdurables y distintivas de una organización, con las que la propia organización se autoidentifica (a nivel introspectivo) y se autodiferencia (de las otras organizaciones de su entorno). La reputación y la proyección de identidad ha de trabajarse también en el entorno online (Aced, 2012). 
Hasta el momento, de manera prioritaria, los estudios sobre las televisiones públicas europeas se han consolidado en torno a tres ejes de análisis, uno de ellos mucho más reciente:

- Las estrategias de programación, es decir, los contenidos que ofertan a las audiencias en términos de formatos y géneros televisivos y de estudios concretos sobre alguno de dichos contenidos;

- Las audiencias y su evolución, en relación a la acogida de programas y parrillas de programación y la competencia generada por la eclosión de canales y los aciertos de las emisoras privadas a este respecto;

- Responsabilidad Social Corporativa, gobernanza, rendición de cuentas y transparencia, línea de investigación de los últimos años, que responde al contexto de cuestionamiento y perspectiva crítica previamente descrito (Campos-Freire y López Cepeda, 2011; López Cepeda y Manfredi, 2013; López_Olano, 2016).

En esta tercera línea de investigación se enmarca el análisis de la web desde la óptica de la Comunicación Corporativa y, más en concreto desde el paradigma relacional, porque permitiría responder a interrogantes comunes relativos al lugar que ocupan las webs corporativas de los principales canales públicos europeos en los rankings de referencia, cuál es la relación entre visitas web y población atendida o cubierta por cada canal, cuáles son los vectores que guían el planteamiento comunicativo de las televisiones públicas en la Red, qué feedback reciben de la audiencia a través del socialmedia y específicamente de las redes sociales, y cuáles son los canales o escenarios de interacción social más utilizados.

Colectivamente, el interés por analizar y tener respuesta a estas cuestiones estriba en que significan una forma de revisar las características del modelo de interrelación de las televisiones públicas con las audiencias y, a la vez, permitirían conocer su capacidad de adaptación a los retos y a las necesidades de la comunicación 2.0. La literatura científica previa no ha abordado esta cuestión desde la medición o monitorización de datos, por lo que la aproximación al 
análisis del tráfico web que se presenta en este capítulo puede considerarse un punto de partida para estudios posteriores sobre el tráfico online y al peso de las redes sociales de los canales públicos en un nuevo escenario de interacción con los públicos que, a la vez, puede servir de canalizador de tráfico que incremente su audiencia web y, por tanto, la visibilidad de la cadena.

\section{Tabla 1. Muestra de estudio}

\begin{tabular}{|c|c|c|c|c|}
\hline País & \multicolumn{2}{|l|}{ Canal } & Web corporativa & Items de análisis \\
\hline España & $\begin{array}{l}\text { Radiotelevisión } \\
\text { Española }\end{array}$ & RTVE & rtve.es & $\begin{array}{l}\text { Posición global en el } \\
\text { ranking de webs. }\end{array}$ \\
\hline Francia & France Televisions & FT & $\underline{\text { francetelevisions.fr }}$ & $\begin{array}{l}\text { Tráfico de visitas } \\
\text { estimado. }\end{array}$ \\
\hline Italia & $\begin{array}{l}\text { Radiotelevisione } \\
\text { Italiana }\end{array}$ & RAI & $\underline{\text { rai.it }}$ & Proyección del número \\
\hline Portugal & $\begin{array}{l}\text { Rádio e Televisão } \\
\text { de Portugal }\end{array}$ & RTP & rtp.pt & $\begin{array}{l}\text { de visitas sobre la } \\
\text { población de cada país }\end{array}$ \\
\hline Alemania & $\begin{array}{l}\text { Arbeitsgemeinschaft } \\
\text { der öffentlich- } \\
\text { rechtlichen } \\
\text { Rundfunkanstalten } \\
\text { der Bundesrepublik } \\
\text { Deutschland } \\
\text { Zweites Deutsches } \\
\text { Fernsehen, }\end{array}$ & ARD & $\underline{\text { ard.de }}$ & $\begin{array}{l}\text { Número de páginas } \\
\text { visitadas. } \\
\text { Tiempo de duración } \\
\text { media de las visitas. } \\
\text { Tasa de rebote (bounce } \\
\text { rank) o número de } \\
\text { visitas que solo acceden }\end{array}$ \\
\hline $\begin{array}{l}\text { Gran } \\
\text { Bretaña }\end{array}$ & $\begin{array}{l}\text { British Broadcasting } \\
\text { Corporation }\end{array}$ & $\mathrm{BBC}$ & $\underline{\mathrm{bbc} \cdot \mathrm{com} /}$ & $\begin{array}{l}\text { a una página y } \\
\text { abandonan la web. } \\
\text { Acceso del tráfico } \\
\text { diferenciando entre las } \\
\text { visitas que llegan a la } \\
\text { web de cada organismo } \\
\text { de un modo directo, a } \\
\text { través de buscadores, } \\
\text { por enlaces o referencias } \\
\text { y desde social media. } \\
\text { Análisis del tráfico que } \\
\text { accede a la web desde las } \\
\text { redes sociales. En este } \\
\text { caso se revisó, también, } \\
\text { las redes que más } \\
\text { frecuentemente sirven } \\
\text { de plataforma de acceso } \\
\text { a la web. }\end{array}$ \\
\hline
\end{tabular}

Fuente: Elaboración propia. 
Se ha elegido como objeto de estudio la web corporativa online por ser el vehículo más adecuado para la proyección de la identidad corporativa en el ecosistema digital (Martí, Álvarez y Domínguez, 2010) y se ha recurrido a conformar una muestra intencional o por conveniencia (y por tanto no probabilística) formada por Radiotelevisión Española, RTVE (España), France Televisions, FT (Francia), Radiotelevisione Italiana, RAI (Italia), British Broadcasting Corporation, BBC (Gran Bretaña), Rádio e Televisão de Portugal, RTP (Portugal) y Arbeitsgemeinschaft der öffentlich-rechtlichen Rundfunkanstalten der Bundesrepublik Deutschland, ARD y Zweites Deutsches Fernsehen, ZDF (Alemania).

Se trabajó con los datos obtenidos en Alexa (www.alexa.com) y Similarweb (www.similarweb.com), dos de las referencias web más utilizadas para planificación de marketing online. En ambos casos, los datos solo deben considerarse como tendencias y no reflejan un resultado estrictamente fiel del tráfico web, pero ambas suponen formas alternativas fiables para aproximarse a una información que las entidades consideran reservada y no compartible.

En ambas plataformas, el periodo de análisis se extiende a los últimos seis meses, es decir, de octubre de 2016 a marzo de 2017, ambos incluidos. La recogida y el análisis de la información se realizó en los primeros días de abril de 2017.

Los ítems concretos del análisis realizado han sido: la posición global en el ranking de webs; el tráfico de visitas estimado; la proyección del número de visitas sobre la población de cada país (con datos demográficos de 2014); el número de páginas visitadas; el tiempo de duración media de las visitas; la tasa de rebote (bounce rank) o número de visitas que solo acceden a una página y abandonan la web; el acceso del tráfico diferenciando entre las visitas que llegan a la web de cada organismo de un modo directo, a través de buscadores, por enlaces o referencias y desde social media; el análisis del tráfico que accede a la web desde las redes sociales. En este caso se revisó, también, las redes que más frecuentemente sirven de plataforma de acceso a la web.

El estudio pretende ser exploratorio y continuar profundizando en la creación de indicadores comparativos que permitan establecer 
estrategias de benchmarking. Los resultados se muestran por canales (organizaciones) y en términos generales de conjunto en el acceso desde redes sociales.

\section{Arbeitsgemeinschaft der öffentlich-rechtlichen}

Rundfunkanstalten der Bundesrepublik Deutschland

(Consorcio de instituciones públicas de radiodifusión de la República Federal de Alemania)

La lectura de marcadores de Alexia y Similarweb es coincidente al situar a la ARD como el canal con mayor porcentaje de tráfico que accede directamente a la web (de seis a siete de cada diez visitas) y el que tiene menor implantación desde redes sociales (no llega a uno de cada diez). Tiene una alta tasa de rebote, una media de 2 páginas por visita y un tiempo de permanencia medio de 2 minutos.

\section{Tabla 2. Datos de tráfico web de ARD}

\begin{tabular}{|c|c|c|c|c|c|c|c|c|c|}
\hline \multirow[b]{2}{*}{ ARD } & \multirow[b]{2}{*}{$\begin{array}{l}\text { Globa } \\
1 \text { rank }\end{array}$} & \multirow[b]{2}{*}{$\begin{array}{c}\text { Visita } \\
s\end{array}$} & \multirow{2}{*}{$\begin{array}{c}\text { \% sobre } \\
\text { població } \\
n\end{array}$} & \multirow[b]{2}{*}{$\begin{array}{l}\text { Bounc } \\
\text { e rank }\end{array}$} & \multirow[b]{2}{*}{$\begin{array}{l}\text { Pags } \\
\text { visita }\end{array}$} & \multirow[b]{2}{*}{$\begin{array}{c}\text { Tiemp } \\
\quad o\end{array}$} & \multicolumn{3}{|c|}{ Acceso tráfico desde } \\
\hline & & & & & & & $\begin{array}{c}\text { Buscado } \\
t\end{array}$ & $\begin{array}{c}\text { Direct } \\
o\end{array}$ & Link \\
\hline Alexa & 5.830 & nd & nd & 66,30 & 2,12 & 2,09 & 15,81 & 68,38 & 14,87 \\
\hline $\begin{array}{c}\text { Similarwe } \\
\mathrm{b}\end{array}$ & 5.964 & $10.6 \mathrm{M}$ & 13,09 & 6 & 2,04 & 2,1 & 17,35 & 64,27 & $7,($ \\
\hline
\end{tabular}

Fuente: www.alexa.com y www.similarweb.com. Elaboración propia.

\section{British Broadcasting Corporation}

\section{(Corporación Británica de Radiodifusión)}

Es, como era de prever, la mejor situada en rankings de resultados y su audiencia supera a la suma de la de los restantes canales analizados. Tiene, sin embargo, una tasa de rebote elevada. La proporción de visitantes sobre la población del país referencial se dispara hasta quintuplicarla debido a la internacionalización de la marca.

La mayoría del tráfico accede de modo directo, pero es la que ofrece altos índices de acceso desde redes sociales y desde enlaces referenciados en otros soportes. 
Es evidente la notoriedad de la BBC ya que el tráfico desde buscadores es el más bajo del grupo de estudio. También es la que mayor actividad genera en Reddit, la plataforma de discusión sobre noticias de actualidad, algo a lo que ayuda, por comparación con otros canales, que ésta sea en inglés.

\section{Tabla 3. Datos de tráfico web de $B B C$}

\begin{tabular}{|c|c|c|c|c|c|c|c|c|c|}
\hline \multirow[b]{2}{*}{ BBC } & \multirow[b]{2}{*}{$\begin{array}{l}\text { Globa } \\
1 \text { rank }\end{array}$} & \multirow[b]{2}{*}{$\begin{array}{l}\text { Visita } \\
s\end{array}$} & \multirow{2}{*}{$\begin{array}{l}\text { \% sobre } \\
\text { població } \\
n\end{array}$} & \multirow[b]{2}{*}{$\begin{array}{l}\text { Bounc } \\
\text { e rank }\end{array}$} & \multirow[b]{2}{*}{$\begin{array}{l}\text { Pags } \\
\text { visita }\end{array}$} & \multirow[b]{2}{*}{$\begin{array}{l}\text { Tiemp } \\
o\end{array}$} & \multicolumn{3}{|c|}{ Acceso tráfico desde } \\
\hline & & & & & & & $\begin{array}{l}\text { Buscado } \\
r\end{array}$ & $\begin{array}{l}\text { Direct } \\
o\end{array}$ & Link \\
\hline Alexa & 109 & nd & & 53,70 & 2,72 & 4,15 & 17,62 & 39,63 & 35,65 \\
\hline $\begin{array}{l}\text { Similarwe } \\
\mathrm{b}\end{array}$ & 135 & $333 \mathrm{M}$ & 522,47 & 61,35 & 2,45 & 2,42 & 23,59 & 35,32 & 22,93 \\
\hline
\end{tabular}

Fuente: www.alexa.com y www.similarweb.com. Elaboración propia.

\section{France Télévisions.}

(Primer grupo audiovisual francés)

La televisión pública francesa es la que sale peor parada del análisis comparativo de los siete canales europeos ya que su posicionamiento en los rankings es notablemente más bajo, su tasa de rebote la más elevada, el número de páginas visitadas de los menores y los tiempos de visita apenas superan el minuto. Su tráfico llega principalmente a través de buscadores y el aporte de las redes sociales es apenas perceptible.

Tabla 4. Datos de tráfico web de FT

\begin{tabular}{|c|c|c|c|c|c|c|c|c|c|}
\hline FT & \multirow{2}{*}{$\begin{array}{c}\text { Global } \\
\text { rank }\end{array}$} & Visitas & \% sobre & \multirow{2}{*}{$\begin{array}{c}\text { Bounce } \\
\text { población }\end{array}$} & rank & $\begin{array}{l}\text { Pags } \\
\text { visita }\end{array}$ & Tiempo & \multicolumn{3}{|c|}{ Acceso tráfico desde } \\
\hline Alexa & 217.726 & nd & & 75,10 & 1,50 & 1,38 & 40,24 & 32,93 & 18,29 \\
\hline $\begin{array}{c}\text { Similarwe } \\
\text { b }\end{array}$ & 195.389 & $185.7 \mathrm{~K}$ & 2,8 & 59,92 & 2,49 & 1,02 & 44,38 & 31,67 & 22,30 \\
\hline
\end{tabular}

Fuente: www.alexa.com y www.similarweb.com. Elaboración propia.

\section{Radiotelevisione Italiana}

(Radiotelevisión Italiana) 
El mayor número de páginas y el mayor tiempo de permanencia de los visitantes se registra en la web de la RAI. La coincidencia de ambos proveedores de datos sobre este particular contrasta con su discrepancia sobre el modo de acceso directo o por buscadores.

\section{Tabla 5. Datos de tráfico web de RAI}

\begin{tabular}{|c|c|c|c|c|c|c|c|c|c|}
\hline \multirow{2}{*}{ RAI } & \multirow{2}{*}{$\begin{array}{c}\text { Global } \\
\text { rank }\end{array}$} & \multirow{2}{*}{ Visitas } & \multirow{2}{*}{$\begin{array}{c}\text { \% sobre } \\
\text { población }\end{array}$} & \multirow{2}{*}{$\begin{array}{c}\text { Bounce } \\
\text { rank }\end{array}$} & \multirow{2}{*}{$\begin{array}{l}\text { Pags } \\
\text { visita }\end{array}$} & \multirow{2}{*}{ Tiempo } & \multicolumn{3}{|c|}{ Acceso tráfico desde } \\
\hline & & & & & & & Buscador & Directo & Link \\
\hline Alexa & 2.975 & nd & & 43,40 & 3,50 & 6,13 & 39,82 & 49,03 & 7,30 \\
\hline Similarweb & 2.603 & $11.7 \mathrm{M}$ & 18,96 & 48,55 & 7,44 & 9,47 & 44,91 & 33,14 & 16,61 \\
\hline
\end{tabular}

Fuente: www.alexa.com y www.similarweb.com. Elaboración propia.

\section{Rádio e Televisão de Portugal}

(Radio y Televisión de Portugal)

Proyectando las visitas sobre la población del país, la web de la RTP es porcentualmente la más visitada, aunque hay que tener en cuenta que también es la que aloja mayor número de canales para dar cobertura al área lusófona, principalmente en países africanos con vínculos históricos con Portugal. La tasa de rebote es, no obstante, elevada.

\section{Tabla 6. Datos de tráfico web de RTP}

\begin{tabular}{|c|c|c|c|c|c|c|c|c|c|}
\hline \multirow{2}{*}{ RTP } & \multirow{2}{*}{$\begin{array}{c}\text { Global } \\
\text { rank }\end{array}$} & \multirow{2}{*}{ Visitas } & \multirow{2}{*}{$\begin{array}{c}\text { \% sobre } \\
\text { población }\end{array}$} & \multirow{2}{*}{$\begin{array}{c}\text { Bounce } \\
\text { rank }\end{array}$} & \multirow{2}{*}{$\begin{array}{l}\text { Pags } \\
\text { visita }\end{array}$} & \multirow{2}{*}{ Tiempo } & \multicolumn{3}{|c|}{ Acceso tráfico desde } \\
\hline & & & & & & & Buscador & Directo & Link \\
\hline Alexa & 12.207 & nd & & 60,20 & 2,33 & 3,1 & 35,72 & 38,17 & 5,69 \\
\hline Similarweb & 10.356 & $4.9 \mathrm{M}$ & 45,31 & 58,89 & 2,99 & 3,43 & 36,04 & 32,58 & 11,78 \\
\hline
\end{tabular}

Fuente: www.alexa.com y www.similarweb.com. Elaboración propia.

La RTP es, con diferencia sobre las televisiones públicas analizadas, el canal con una web a la que más usuarios llegan a través de redes sociales, entre 18 a 20 de cada cien. También de los que muestra un marcado equilibrio entre los que acceden directamente y los que recurren a buscadores. 


\section{Radiotelevisión Española}

Cuatro de cada diez visitantes de su web llegan a través de buscadores y tan solo cinco de cada cien lo hacen desde redes sociales. Tercera posición en los rankings mundiales de las webs consultadas, con 2.5 páginas y un tiempo superior a los 3 minutos por visita, pero con tasa de rebote superior al $50 \%$.

\section{Tabla 7. Datos de tráfico web de RTVE}

\begin{tabular}{|c|c|c|c|c|c|c|c|c|c|}
\hline \multirow{2}{*}{ RTVE } & \multirow{2}{*}{$\begin{array}{c}\text { Global } \\
\text { rank }\end{array}$} & \multirow{2}{*}{ Visitas } & \multirow{2}{*}{$\begin{array}{c}\text { \% sobre } \\
\text { población }\end{array}$} & \multirow{2}{*}{$\begin{array}{c}\text { Bounce } \\
\text { rank }\end{array}$} & \multirow{2}{*}{$\begin{array}{l}\text { Pags } \\
\text { visita }\end{array}$} & \multirow{2}{*}{ Tiempo } & \multicolumn{3}{|c|}{ Acceso tráfico desde } \\
\hline & & & & & & & Buscador & Directo & Link \\
\hline Alexa & 2.462 & nd & & 55,10 & 2,59 & 3,24 & 48,43 & 41,85 & 4,07 \\
\hline Similarweb & 2.881 & $18.9 \mathrm{M}$ & 39,59 & 54,59 & 2,58 & 3,13 & 43,68 & 34,71 & 15,08 \\
\hline
\end{tabular}

Fuente: www.alexa.com y www.similarweb.com. Elaboración propia.

\section{Zweites Deutsches Fernsehen}

(Segunda Televisión Alemana)

Después de la $\mathrm{BBC}$, es el canal que consigue la mayor ubicación en ranking, la menor tasa de rebote de las siete analizadas y altos porcentajes de acceso directo.

Tabla 8. Datos de tráfico web de $Z D F$

\begin{tabular}{|c|c|c|c|c|c|c|c|c|c|}
\hline \multirow{2}{*}{ ZDF } & \multirow{2}{*}{$\begin{array}{c}\text { Global } \\
\text { rank }\end{array}$} & Visitas & $\begin{array}{c}\text { \% sobre } \\
\text { población }\end{array}$ & $\begin{array}{c}\text { Bounce } \\
\text { rank }\end{array}$ & $\begin{array}{c}\text { Pags } \\
\text { visita }\end{array}$ & \multirow{2}{*}{ Tiempo } & \multicolumn{3}{|c|}{ Acceso tráfico desde } \\
\cline { 7 - 10 } & 2.462 & nd & & 55,10 & 2,59 & 3,24 & 34,29 & 53,71 & 7,60 \\
\hline Alexa & 2.45 indor & Directo & Link \\
\hline Similarweb & 2.881 & $18.9 \mathrm{M}$ & 29,38 & 54,59 & 2,58 & 3,13 & 27,53 & 46,77 & 22,06 \\
\hline
\end{tabular}

Fuente: www.alexa.com y www.similarweb.com. Elaboración propia.

\section{Tráfico desde las redes sociales: hegemonía de Facebook}

El acceso a la web desde redes sociales es bajo en casi todos los canales, con la excepción de Portugal. Haciendo una estimación media de los porcentajes que ofrecen Alexa y Similar web, ARD y RTP serían los extremos con menos y más público web desde social media, pero, en general, las redes sociales, pese a su popularidad y elevadas tasas de 
uso, no son hasta el momento el principal catalizador de público hacia las webs de las televisiones públicas.

Tabla 9. Tráfico web desde las redes sociales

\begin{tabular}{|c|c|c|}
\hline Canal & Alexa & Similarweb \\
\hline ARD & 0,95 & 0,63 \\
\hline BBC & 7,10 & 15,28 \\
\hline FT & 8,54 & 1,15 \\
\hline RAI & 3,85 & 4,22 \\
\hline RTP & 20,41 & 18,37 \\
\hline RTVE & 5,65 & 5,26 \\
\hline ZDF & 4,94 & 3,16 \\
\hline
\end{tabular}

Fuente: www.alexa.com y www.similarweb.com. Elaboración propia

No se deben hacer comparativas directas porque los porcentajes de ambas plataformas difieren significativamente en el caso de algún canal, como Francetelevisions, pero es sin embargo muy significativo el análisis de tendencias de las redes que son proveedoras de mayor volumen de tráfico.

\section{Gráfico 1. Tráfico web desde las redes sociales}

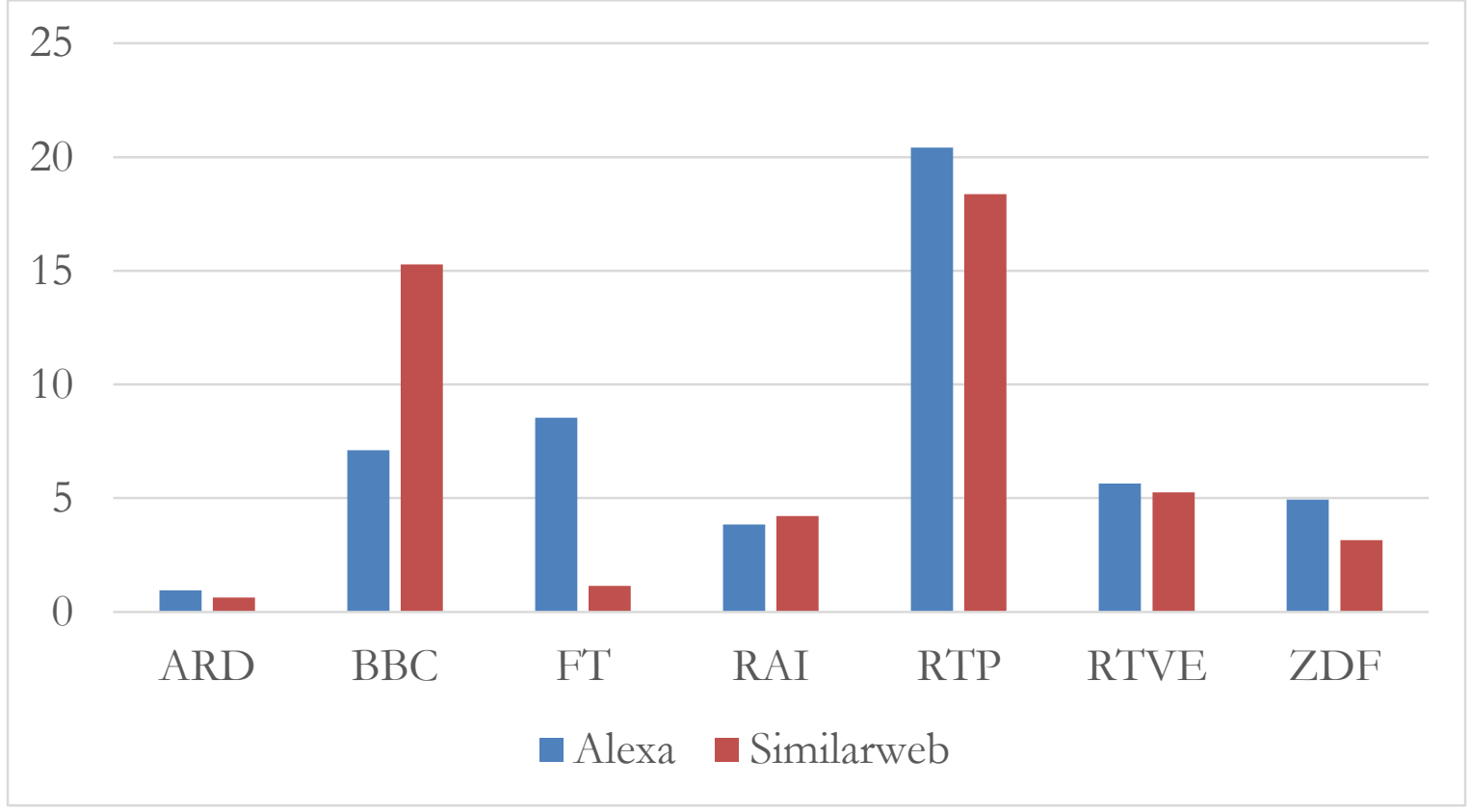

Fuente: www.alexa.com y www.similarweb.com. Elaboración propia. 
En todos los casos Facebook concentra más de la mitad de los usuarios que hacen click hacia la web televisiva, apenas es perceptible el peso de Twitter (excepto en el caso de RTVE) y, aunque hablemos de audiovisual, de YouTube que solo despunta porcentualmente en los casos alemanes (ARD y ZDF) pero no son cifras absolutas significativas porque ambos tienen globalmente índices muy bajos de tráfico desde las redes.

Instagram solo canaliza tráfico en la RAI. En los datos de BBC, RTP y ZDF se cuela en los resultados Reddit.

Estos resultados se alinean con trabajos anteriores (Túñez y Costa, 2016) en los que se concluyó que los espacios de encuentro en redes sociales no son comunidades de multiparticipación interactiva del medio y sus seguidores, sino presencias casi simbólicas limitadas en varios casos a facilitar de modo instantáneo que los contenidos que el medio tiene en su web puedan ser compartidos en los perfiles que cada usuario tiene en redes sociales pero no se permite la participación en el perfil de la cadena televisiva.

Refuerza esta idea, el hecho de que solo en tres de los canales analizados se pudiera acceder a la figura del defensor del espectador/ lector.

\section{Tabla 10. Desglose del tráfico desde las redes sociales}

\begin{tabular}{|c|c|c|c|c|c|c|c|c|}
\hline & \multicolumn{7}{|c|}{ Redes sociales } \\
\cline { 2 - 10 } CANAL & $\boldsymbol{F b}$ & $\boldsymbol{T} \boldsymbol{Y}$ & $\boldsymbol{Y t} \boldsymbol{b}$ & $\boldsymbol{W a}$ & Link & $\boldsymbol{N} \boldsymbol{V}$ & $\boldsymbol{R d}$ & $\boldsymbol{I n}$ \\
\hline ARD & 65,40 & 9,45 & 15,50 & 2,20 & & 2,07 & & \\
\hline BBC & 59,24 & 11,29 & 4,00 & & 0,90 & & 21,2 & \\
\hline FT & 64,56 & & 2,95 & & 32,49 & & & \\
\hline RAI & 80,95 & 7,05 & 8,47 & 1,49 & & & & 0,45 \\
\hline RTP & 93,16 & 2,39 & 1,76 & & 0,14 & & 2,3 & \\
\hline RTVE & 67,00 & 20,37 & 9,19 & 0,95 & 0,66 & & & \\
\hline ZDF & 68,60 & 6,96 & 16,73 & 1,30 & & & 3,8 & \\
\hline
\end{tabular}

Fuente: www.alexa.com y www.similarweb.com. Elaboración propia. 
El presente análisis pone en evidencia que la intención comunicativa no siempre tiene relación directa con los resultados online generados. Llama especialmente la atención el caso de France Télévisions, pues su apuesta por los espectadores se pone en evidencia desde la concepción de su web corporativa como Francetéléspectateurs, un espacio pensado para la transparencia hacia las audiencias, que cuentan como fórmulas de participación con un club de telespectadores, de entre quienes se eligen a los participantes en el consejo consultivo de programación, y de la figura del mediador televisivo al que pueden dirigirse las audiencias para cada uno de los canales.

Sin embargo, la intención del canal público francés de convertirse en el canal de las/ los franceses, no se ve refrendado por los datos disponibles. RTP, por el contrario, no plantea una web corporativa que destaque en su planteamiento del rol de las audiencias, pero su gestión de comunidad en Facebook le permite gozar de un índice de acceso elevado desde esta red social.

Gráfico 2. Tráfico web desde Facebook, Twitter y TouTube.

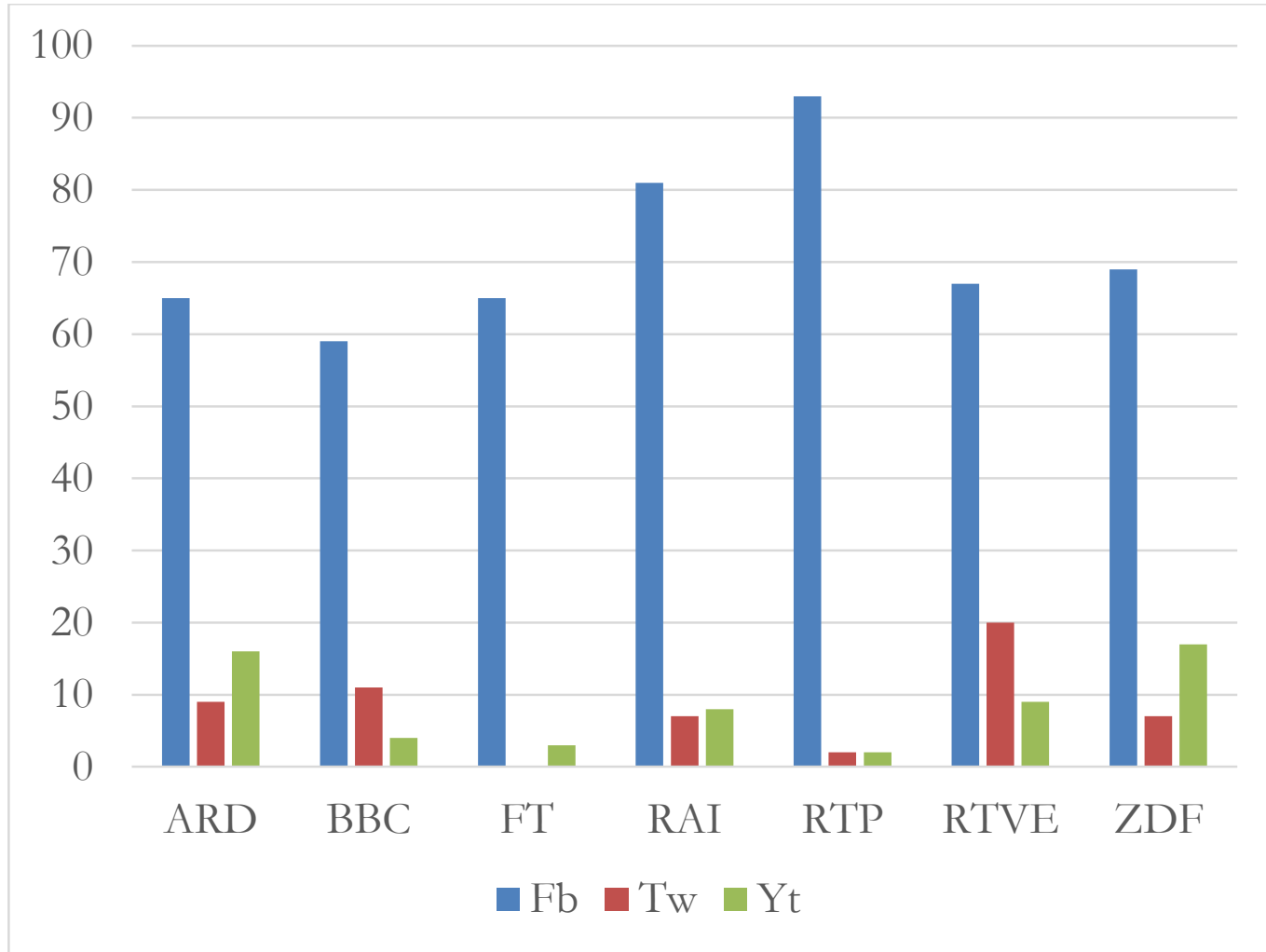

Fuente: www.alexa.com y www.similarweb.com. Elaboración propia. 
El interés por comunicar transparencia por los canales públicos debe transformarse en transparencia 2.0, es decir, transparencia dialógica, donde sean las audiencias las que busquen al canal y su información, donde exista interés desde los espacios 2.0. El contexto actual reserva ese potencial a escasos canales.

\section{Balance de éxito en social media}

El balance de fans, suscriptores y seguidores en los principales canales de social media apunta, comparativamente, al éxito de BBC en la arena digital, especialmente a través de la marca informativa, es decir, BBC News que funciona como medio de referencia a nivel mundial.

A pesar de que la web de RTP destaca como la más visitada desde redes, su éxito de seguidores apunta a términos medios o medio-altos, por lo que el contenido y la estrategia se revelan cómo interesante objeto de próximos estudios.

France Télévisions confirma su bajo éxito en medios sociales con el grado de fidelización más bajo en todas las redes, por lo que surge nuevamente el tema del desajuste entre intencionalidad comunicativa y resultados. RTVE se encuentra entre las de menor impacto en Youtube y en LinkedIn, mientras que los canales alemanes no destacan de manera especial en ningún ámbito.

\section{Tabla 11. TV y redes sociales}

\begin{tabular}{|c|r|r|r|r|r|}
\hline CANAL & \multicolumn{1}{|c|}{$\boldsymbol{F b}$} & \multicolumn{1}{c|}{$\boldsymbol{T}_{\boldsymbol{W}}$} & \multicolumn{1}{c|}{$\boldsymbol{Y} \boldsymbol{t} \boldsymbol{b}$} & \multicolumn{1}{c|}{ Link } & \multicolumn{1}{c|}{$\boldsymbol{I n}$} \\
\hline ARD & 216.663 & $469 \mathrm{~K}$ & 303.908 & - & $17 \mathrm{k}$ \\
\hline BBC & 41.561 .210 & $8.37 \mathrm{M}$ & 1.341 .402 & 773.973 & $100 \mathrm{~K}$ \\
\hline FT & 91.573 & $162 \mathrm{~K}$ & 133.668 & 27.829 & $11,1 \mathrm{~K}$ \\
\hline RAI & 37.2531 & $72.1 \mathrm{M}$ & 1.454 .268 & 39.733 & $93 \mathrm{~K}$ \\
\hline RTP & 455.673 & $461 \mathrm{~K}$ & 470.981 & 11.172 & $30,9 \mathrm{~K}$ \\
\hline RTVE & 611.334 & $1.04 \mathrm{M}$ & 208.205 & 4.138 & $29 \mathrm{k}$ \\
\hline ZDF & 584.366 & $1.1 \mathrm{M}$ & 91.302 & 7.799 & - \\
\hline
\end{tabular}

Fuente: www.alexa.com y www.similarweb.com. Elaboración propia. 


\section{E1 panorama web}

La revisión de las cifras de trafico web de las televisiones públicas europeas analizadas y del peso de las redes como canales de conexión con la audiencia y de captación de visitantes para la web nos permite ver, en conjunto, perfiles coincidentes en la todavía baja canalización desde redes sociales, lo que incide en el carácter de comunicación bidireccional simbólica pero no realmente interactiva de las webs de las televisiones públicas. Los contenidos circulan hacia perfiles personales de usuarios en las redes sociales, pero no hay un retorno a la web a modo de clic en sus contenidos. Globalmente, el análisis se pueden extraer las siguientes aportaciones:

- En las redes sociales, Facebook es el líder indiscutible con porcentajes de retorno de tráfico hacia la web (entre un mínimo de $60 \%$ hasta un máximo de $93 \%$ ) que desbordan a cualquier otro de sus directos competidores, especialmente Twitter y, lo que es significativo en el caso de webs de medios audiovisuales, YouTube.

- La infrautilización de otros social media para crear relaciones e interés por los contenidos, además de posicionarse como marca, plantea la baja adaptación de los canales públicos europeos al nuevo contexto tecnológico-social, donde Facebook convive con nuevos medios en un ecosistema digital múltiple y fragmentado, donde cada uno plantea una función diferenciada.

- El empleo de Twitter y de YouTube, los otros medios sociales de mayor penetración, debe ser evaluado para identificar cambios en la estrategia que pudieran convertir unas plataformas potenciales en mecanismos de acceso directo y de participación de las audiencias.

- Públicos con características distintas realizan un uso de los medios sociales también distinto, en este sentido, audiencias más jóvenes se mantienen al margen de Facebook y optan por el uso de nuevas redes sociales (Snapchat, Instagram, Whatsapp).

- Una estrategia multimedia correctamente planteada debe seleccionar canales teniendo en cuenta los públicos. Si bien Facebook, por el momento, garantiza una audiencia amplia de una 
edad adulta, debe tenerse presente el grado de madurez de la red social y la posibilidad de planteamiento de nuevos canales para nuevos públicos.

- La asunción de la transparencia como emblema por los entes de radiotelevisión pública ha conducido a difundir información corporativa de diverso tipo (económica, de Recursos Humanos, de Responsabilidad Social Corporativa, de programación, etc.), pero falta apostar por una transparencia 2.0 que todavía no se ha conseguido y dar forma a esa intencionalidad comunicativa en información de interés, atractiva y comprensible (divulgativa) para la ciudadanía.

- El estudio es una aproximación inicial a la gestión de las relaciones con públicos y audiencias y se enmarca en un amplio proyecto de análisis que pretende identificar y analizar los indicadores de gobernanza, financiación, innovación y calidad de servicio público de las televisiones europeas para, una vez identificados, trabajar sobre la potencial elaboración de indicadores sintéticos aplicables a las televisiones públicas en España.

- La necesidad de monitorizar la marca y sus relaciones con los públicos se ha convertido en una de las prioridades de la gestión de la comunicación online para conocer los resultados obtenidos a nivel de imagen, reputación y posicionamiento.

- La dificultad de medir intangibles convierte la generación de indicadores en una herramienta que se pretende resulte de utilidad para llegar a resultados objetivables y comparativos.

\section{Bibliografía}

Aced, C. (2013). Relaciones Públicas 2.0: cómo gestionar la comunicación corporativa en el entorno digital. Barcelona: UOC.

Campos-Freire, F. y López Cepeda, A. (2011). La nueva gobernanza y la televisión pública en España. En Eptic online: revista electronica internacional de economia política da informaçao, da comuniçao e da cultura, 13(1), 63-85. 
Capriotti, P. (1999). Planificación estratégica de la imagen corporativa. Barcelona: Ariel.

Fernández Lombao, T. y Campos Freire, F. (2013) La

Responsabilidad Social Corporativa en las radio-televisiones

públicas de Europa. En Cuadernos info, (33), 145-157.

López Cepeda, A. \& Manfredi, J.L. (2013). Análisis de la

transparencia de las páginas web de los principales medios de

comunicación audiovisuales en España. En Trípodos, 1(32), 45-

62.

López-Olano, C. (2016). La pluralitat dels informatius en les televisions públiques i la responsabilitat social corporativa (RSC), amb atenció al cas de RTVV. En Comunicació. Revista de recerca $i$ d'anàlisi [abans Treballs de Comunicació], 33(2), 9-27.

Manfredi Sánchez, J.L. (2011). Escenarios y retos de la televisión pública en España. En adComunica. Revista de Estrategias,

Tendencias e Innovación en Comunicación, (1), 49-62.

Martí D., Álvarez, M.L. y Domínguez, S. (2010). Reputación y responsabilidad desde webs corporativas. En Área Abierta.

Revista de comunicación audiovisual y publicitaria, 26, 1-22.

Túñez-López, JM (2012). La comunicación en las organizaciones, Sevilla: Comunicación Social.

Túñez-López, M. y Costa-Sánchez, C. (2016). Imagen e intencionalidad comunicativa de las principales televisiones públicas europeas. Aproximación comparativa al estado de la cuestión. En Actas del II Simposio de la Red Internacional de Investigación de Gestión de la Comunicación, 836-848.

Reconocimientos: Los resultados de este artículo forman parte de las actividades de difusión del proyecto del Programa estatal de Fomento de la Investigación Científica y Técnica de Excelencia, subprograma estatal de Generación de Conocimiento del Ministerio de Economía y Competitividad de España sobre "Indicadores de gobernanza, financiación, rendición de cuentas, innovación, calidad y servicio público de las RTV europeas aplicables a España en el contexto digital" (Referencia CSO2015-66543- P). 


\title{
Posicionamiento en Facebook de las Televisiones Autonómicas con lengua propia
}

\author{
Clide Rodríguez-Vázquez \\ Valentín-Alejandro Martínez-Fernández \\ María-Magdalena Rodríguez-Fernández \\ Óscar Juanatey- Boga \\ Universidade da Coruña
}

Cómo citar: Rodríguez-Vázquez, C., Martinez-Fernández, V.A., RodríguezFernández. M.M. y Juanatey-Boga, O. (2017). Posicionamiento en Facebook de las Televisiones Autonómicas con lengua propia. En Túñez López, M.; Campos-Freire, F. y Silva Rodríguez A. (Eds.). Estudios sobre financiación, legislación e innovación en la Televisión Pública. Cuadernos Artesanos de Comunicación, cac126, pp 143-169. La Laguna (Tenerife): Latina. DOI: 10.4185/cac126

7 RAS EL IMPACTO que la crisis económica ha propiciado en las 1 televisiones regionales europeas, entre ellas las autonómicas españolas, se inició un proceso de reforma entre los años 2000 y 2006 en el que se priorizó el cumplimiento de su misión y obligaciones de servicio público articulado sobre las bases de preservar las culturas locales, la acentuación de las identidades a través de la promoción de la lengua propia y proximidad de los operadores regionales a sus audiencias. Este capítulo analiza el posicionamiento online de las Televisiones Públicas Autonómicas Españolas con lengua propia, IB3, TV3, CRTVG y EITB a través del análisis comparativo de sus Fanpage corporativas y sus principales parámetros de información: contenido, interactividad y visibilidad.

Palabras clave: televisión pública autonómica; identidad lingüística; misión; servicio público; redes sociales; Facebook 
El ecosistema comunicativo actual, donde se enmarcan los medios de comunicación público, en concreto nuestro objeto de estudio, las Televisiones Públicas Autonómicas Españolas (a partir de ahora TPAs) con lengua propia, está configurado por una serie de factores sobrevenidos por la presencia de un entorno digital que les confiere diversas peculiaridades tales como una gran variedad de canales que fomenta la fragmentación de las audiencias, aumento de la inversión publicitaria en las versiones online de dichos medios, nuevos generadores de demanda de contenidos a través de los diferentes dispositivos tecnológicos, una reconfiguración de la cadena de valor y tal como señala Campos (2013) por "una fuerte competencia de las mega plataformas globales de distribución y accesibilidad directa de los contenidos".

En lo que respecta a la fragmentación de audiencias, hay que retrotraerse al año 2004 cuando el indicador de la audiencia diaria per cápita empezó a aumentar llegando a los 211 minutos por persona y día (3 horas y media). En 2007, 2008 y 2009, cuando entran en escena los nuevos modelos de televisión acentuando su impacto social, se produjeron records históricos de consumo con 223, 227 y 226 minutos por persona y día respectivamente (Corporación Multimedia, 2010: 166), lo que supuso para los canales temáticos un incremento de su audiencia del $87 \%$ entre los dos últimos años de la década, tal y como le sucedió a TV3 con un aumento neto del consumo de la oferta de canales (Acenture/FORTA ${ }^{12}, 2012$ ).

En relación a la inversión publicitaria $\operatorname{Infoadex}^{13}$ (2016) ha dado a conocer que la inversión real estimada registrada por el mercado publicitario en 2015 se situó en un volumen de 11.742,2 millones de euros, lo cual representa un crecimiento del 4,7\% sobre los 11.211,2 millones de euros alcanzados en el año anterior. De este modo, la tasa de crecimiento de los medios convencionales ha sido del 7,5\%, pasando de los 4.665,9 millones de euros registrados en 2014 a los 5.016,7 millones de inversión en 2015, lo cual supone que el porcentaje obtenido sobre el total del mercado por los medios convencionales en

\footnotetext{
12 FORTA: Federación de Organismos de Radio y Televisión Autonómicos.

13 Infoadex: empresa referente en el seguimiento de la actividad publicitaria en España.
} 
2015 fue del 42,7\%, un punto superior respecto al año anterior tal y como se observa en el Cuadro 1.

\section{Imagen 1: Inversión publicitaria en medios convencionales.}

\begin{tabular}{|c|c|c|c|c|c|c|c|}
\hline \multicolumn{8}{|c|}{$\begin{array}{l}\text { INVERSIÓN REAL ESTIMADA (en millones de euros) } \\
\text { Todos los medios - años } 2011 / 2012 / 2013 / 2014 / 2015\end{array}$} \\
\hline \multicolumn{2}{|c|}{ MEDIOS CONVENCIONALSS } & \multirow{2}{*}{$\begin{array}{r}2011 \\
25,8\end{array}$} & \multirow{2}{*}{$\begin{array}{r}2012 \\
22,5\end{array}$} & \multirow{2}{*}{$\begin{array}{r}2013 \\
20,2\end{array}$} & \multirow{2}{*}{$\begin{array}{r}2014 \\
16,2\end{array}$} & \multirow{2}{*}{$\begin{array}{r}2015 \\
22,0\end{array}$} & \multirow{2}{*}{$\% 15 / 14$} \\
\hline (ine $\left.{ }^{p}\right)$ & Cine & & & & & & \\
\hline Diarios & Diarios & 967,0 & 766,3 & 662,9 & 656,3 & 658,9 & 0,4 \\
\hline Dominicales & Dominicales & 67,1 & 52,0 & 38,7 & 37,7 & 37,8 & 0,2 \\
\hline \multirow[t]{8}{*}{ Exterior } & Carteleras & 59,2 & 52,2 & 45,0 & 45,5 & 47,3 & 3,8 \\
\hline & Lonas & 12,7 & 12,1 & 8,8 & 8.2 & 9,1 & 10,5 \\
\hline & Luminosos & 13,5 & 10,9 & 9,5 & 10,0 & 10,3 & 2,1 \\
\hline & Mobiliario (exterior + interior + cabinas) & 184,1 & 155,6 & 147,0 & 148,9 & 152,0 & 2,0 \\
\hline & Monopostes (14) & 20,1 & 18,1 & 17,9 & 16,6 & 16,8 & 1,2 \\
\hline & Transporte & 88,5 & 70,7 & 47,7 & 78,7 & 84,6 & 7,5 \\
\hline & Otros & 16,7 & 6,8 & 6,2 & 6,6 & 7,3 & 10,7 \\
\hline & Total Exterior & 394,8 & 326,3 & 282,0 & 314,7 & 327,4 & 4,0 \\
\hline \multicolumn{8}{|l|}{ Internet (1) } \\
\hline \multirow[t]{2}{*}{ Fijo } & Enlaces patrocinados & 459,9 & 462,5 & 487,7 & 560,9 & 612,0 & 9,1 \\
\hline & Formatos gráficos ${ }^{[2]}$ & 419,6 & 372,8 & 340,2 & 429,8 & 535,7 & 24,6 \\
\hline \multirow[t]{2}{*}{ Móvil } & Formatos graficos $[2]$ & 19,7 & 45,2 & 68,4 & 85,5 & 102,1 & 19,4 \\
\hline & Total Intemet & 899,2 & 880,5 & 896,3 & $1.076,2$ & $1.249,8$ & 16,1 \\
\hline Radio & Radio & 524,9 & 453,5 & 403,6 & 420,2 & 454,4 & 8,1 \\
\hline \multirow[t]{3}{*}{ Revistas } & Inform. general, femeninas, ... (a) & 213,6 & 183,1 & 148,3 & 152,2 & 153,8 & 1,1 \\
\hline & Otras & 167,5 & 130,6 & 105,5 & 102,0 & 101,4 & $-0,6$ \\
\hline & Total Revistas & 381,1 & 313,7 & 253,9 & 254,2 & 255,2 & 0,4 \\
\hline \multirow[t]{6}{*}{ Televisión } & Canales de pago & 60,2 & 43,1 & 43,6 & 59,3 & 71,9 & 21,2 \\
\hline & TV. autonónimicas & 198,0 & 126,8 & 120,4 & 128,7 & 132,3 & 2,8 \\
\hline & TV. locales & 2,0 & 1,5 & 1,3 & 1,3 & 2,0 & 53,8 \\
\hline & NV. nacionales en abierto & $1.977,0$ & $1.643,9$ & $1.538,1$ & $1.701,1$ & $1.805,1$ & 6,1 \\
\hline & Total Television & $2.237,2$ & $1.815,3$ & $1.703,4$ & $1.890,4$ & $2.011,3$ & 6,4 \\
\hline & SUBTOTAL MEDIOS CONVENCIONALES & $5.497,1$ & $4.630,0$ & $4.261,0$ & $4.665,9$ & $5.016,7$ & 7,5 \\
\hline
\end{tabular}

Fuente: Infoadex (2016)

De estos medios convencionales la televisión sigue siendo el que más publicidad atrae con una participación del 40,1\%, lo que supone un crecimiento de la inversión experimentado por este medio en el año 2015 del 6,4\%, situando su cifra en 2.011,3 millones de euros frente a los 1.890,4 millones del año anterior. Muy de cerca está Internet con un incremento en 2015 del 16,1\% gracias a la inversión publicitaria de 1.249,8 millones de euros frente a los 1.076,2 millones de 2014, supone el $24,9 \%$ del total de los medios convencionales. Uno de los motivos de este crecimiento es la utilización de modelos de negocio diferentes a los del canal offline y menos intrusivos y disruptivos como es el marketing de afiliación o la compra programática entre otros. 
Sin embargo, de cara al año 2017 parece que para España las previsiones son menos optimistas, pues se estima una contracción de la inversión publicitaria de hasta el 5,2\% (Warc, 2016).

\section{Función de la Televisión Pública Autonómica}

Cronológicamente las TPAs inician su andadura con diferentes suertes en el año 1982 y con unos objetivos claros: difundir y promover la cultura, las tradiciones, la lengua propia y la realidad social e institucional de las comunidades autónomas a través de un servicio público de proximidad al mismo tiempo que asumieron el papel de precursoras y desarrolladoras de una industria audiovisual innovadora en el ámbito autonómico (Acenture/FORTA, 2012).

\section{Imagen 2: Cronología de aparición y evolución en el número de canales en España.}

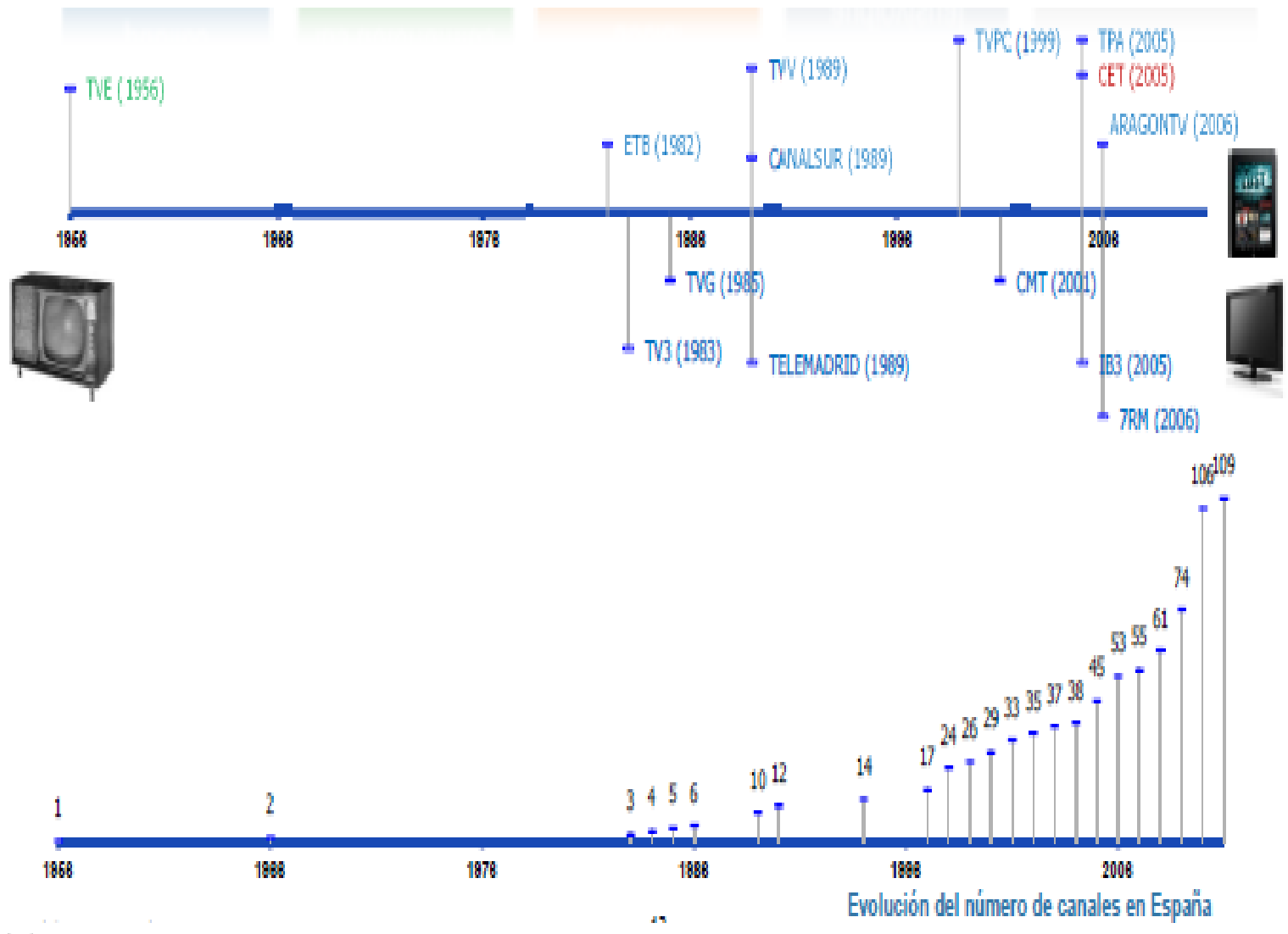

Fuente: Acenture/Forta, 2012

La misión de servicio público de las TPAs se vio redefinida por un proceso de reforma que tuvo su génesis en el año 2006, toda vez que 
la mayoría de televisiones públicas nacionales europeas (francesa, irlandesa, portuguesa, belga, italiana e inglesa) habían concluido ya las suyas (Azurmendi, 2007). Dicha reforma otorgó a la sociedad un papel destacado, ya que la condición de servicio público exigía que fuesen satisfechas las demandas de información, cultura, educación y entretenimiento de la población, al mismo tiempo de promover el pluralismo, la participación y demás valores constitucionales garantizando su acceso a cualquier persona (Estatuto de la Radio y la Televisión, 1980).

A su vez, el papel activador de la cultura como una de las misiones de servicio público se vertebró a través de tres elementos básicos: la lengua propia, la realidad cultural y el patrimonio social y cultural inherentes a cada territorio, al ser el objetivo último el fomento de la cohesión social y la pertenencia territorial (Acenture/FORTA, 2012).

Las lenguas propias o cooficiales de algunas comunidades autónomas españolas se consideran un elemento clave de la identidad de sus respectivos pueblos, motivo por el cual sus TPAs (EITB, CRTVG,TV3 e IB3) incluyen contenidos y, en general programaciones que van dirigidas conforme señala Arzumendi (2013) a servir a los hablantes de cada una, a los que estén aprendiéndolas o a los que desearían aprenderlas, sin olvidar a quienes tienen interés por la lengua y las culturas autóctonas, además de preservarlas y potenciarlas. De esta forma estos entes se transforman en vehículos útiles a la par que necesarios para el conocimiento de la lengua, la normalización lingüística y la generación de un sentimiento de mayor cercanía y filiación (identificación).

En relación a la realidad cultural y social de cada comunidad parece demostrado que las TAPs han propiciado un mayor alcance de las acciones culturales al fomentar su mayor visibilidad gracias a su gran cobertura mediática y poder realizar productos de mejor calidad. Además, han contribuido a la defensa de la cultura del territorio y a la identidad de la comunidad.

Por último, en relación al patrimonio social y cultural de cada territorio, cabe destacar que el papel de las TAPs ha sido el de dinamizadoras de 
las autonomías al erigirse como vehículo del sector audiovisual y como soporte de la comunicación comercial del tejido industrial local que, sin esta instrumentalización, no sería competitivo ante grandes corporaciones (Acenture/FORTA, 2012).

\section{Evolución de las Televisiones Públicas Autonómicas Españolas}

Ante la visión actual del sector audiovisual de acuerdo a lo reflejado por el Observatorio del Ocio y el Entretenimiento Digital (2010) "donde se adivina cercana la mutación de los medios de comunicación considerados tradicionales no sólo en cuanto a sus líneas programáticas o audiencias, sino en su mismo funcionamiento como empresa, su gestión interna y su financiación", parece necesario para la comprensión de esta situación una revisión de los principales hechos que han abocado a la misma.

\subsection{La televisión regional: orígenes}

En el año 1987 el Consejo de Europa elaboró algunos informes donde se ponían de manifiesto las inquietudes de los diferentes estados miembros en relación a la necesidad de crear organizaciones audiovisuales con representatividad regional y, por lo tanto, no centralizada y con características culturales, sociales y lingüísticas relevantes. En el mismo sentido, en el ámbito académico, surgieron voces que abogaban por el nexo de unión y de relevancia que debería construirse entre la comunicación y las políticas audiovisuales en el desarrollo de las regiones europeas (Musso et al, 1991).

Autores como De Moragas y Garitaonaindía (1994) dedicaron parte de su obra a realizar una taxonomía de siete modelos la cual atendía al tipo de emisión que realizaban; además, acuñaron un nuevo concepto, el de televisión de proximidad en el que intentaron unificar los términos ya existentes de televisión regional y local, aunque ellos mismos reconocieran años más tarde (1999) que no siempre televisión regional era sinónimo de proximidad, dado que algunas cadenas locales o regionales eran "meros repetidores de contenidos de exportación". 


\subsection{Primeras aproximaciones a la televisión regional en España: década de los noventa}

La descentralización estatal a favor de las autonomías favoreció el desarrollo y la implantación de las televisiones regionales en España. Así, en 1982, bajo el amparo de la ley del Tercer Canal, empieza sus emisiones la primera cadena de la televisión regional de España, la ETB del País Vasco. Dos años más tarde, en 1984, sería la televisión catalana TV3, a la que le sucedieron cuatro más en los años siguientes: Galicia, en 1985; Andalucía, en 1988; y, Madrid, junto con la Comunidad Valenciana, en 1989.

A partir de esta situación empieza a cobrar interés conocer los retos a los cuales se enfrentaban estas televisiones, los modelos que se desarrollaban o la importancia que empezaba a adquirir la industria audiovisual en el progreso de las regiones y la conformación de identidades o su trascendencia en el desarrollo social y económico de las comunidades (Morán, 2000 y Bustamante, 2000).

Autores como Sampedro (1996) o Domínguez (2000) demostraron a través de su obra que lo que verdaderamente era importante en esos momentos incipientes de desarrollo del audiovisual regional era disipar dudas sobre su funcionamiento, la legitimidad de su coexistencia con otros medios públicos estatales o la supuesta politización de su gestión.

\subsection{La adecuación de las televisiones públicas autonómicas a la TDT: Siglo XXI}

Con la llegada de la "nueva era" algunos de los temas de análisis sobre el mercado audiovisual autonómico tuvieron continuidad. Tal es el caso de la recurrente inquietud derivada de la función de servicio público de estas televisiones, principalmente por la importancia que tienen en el desarrollo de las regiones más deprimidas como fue el caso de estudio de la Comunidad Autónoma de Extremadura (Vacas, 2000).

Otro de los temas que más análisis ha generado ha sido el de las políticas de gestión y control de las televisiones regionales en Europa y, cómo no, en España. Martínez (2000) habla de la instrumentalización 
que algunos gobiernos habrían hecho de estas televisiones y de cómo el sector audiovisual depende, en algunos casos, de las instituciones regionales.

Sin embargo, el verdadero caballo de batalla ha sido la gestión de la financiación debido a la situación de crisis económica vivida recientemente en todo el mundo y por consiguiente en el continente europeo y España.

A raíz de esa coyuntura, a partir de 2006 la mayoría de las televisiones regionales europeas, incluidas las españolas, iniciaron un proceso de reforma que supuso la redefinición como servicio público y un cambio de prioridades en el mismo, lo cual provocó, desde el año 2010, que el problema al que se supeditó su valor de desempeño cambiara, pasando a cobrar máximo protagonismo la financiación, o para ser más exactos, la disminución de la previsión para todas las partidas en relación a años anteriores, tal y como se aprecia en el cuadro siguiente.

Tabla 1. Presupuestos televisiones públicas autonómicas con lengua propia

\begin{tabular}{|l|r|r|c|r|r|}
\hline Tv & 2011 & 2012 & 2013 & 2014 & 2015 \\
\hline Baleares & & 50.786 .591 & 36.700 .000 & 34.050 .000 & 34.100 .000 \\
\hline Cataluñ & 444.515 .17 & 378.550 .34 & 378.550 .34 & 293.058 .16 & 343.470 .22 \\
a & 5 & 7 & 7 & 7 & 3 \\
\hline Galicia & 125.748 .28 & 118.639 .67 & 107.943 .27 & 103.638 .09 & 110.680 .57 \\
& 3 & 7 & 5 & 2 & 1 \\
\hline P.Vasco & 181.584 .16 & 175.156 .27 & 175.156 .27 & 135.005 .87 & 138.960 .35 \\
& 9 & 7 & 7 & 7 & 7 \\
\hline
\end{tabular}

Fuente: INE (2016)

Las consecuencias de este cambio de preferencias sobre las televisiones regionales europeas y locales con lengua propia han sido múltiples, pero "incidentes en un mismo aspecto: el de la neutralización de su misión pública de televisiones de identidad y proximidad" (Arzumendi, 2013). 
Por último, otro de los aspectos más relevantes que ha generado un gran interés es la adaptación del modelo de negocio de las televisiones públicas de carácter autonómico al nuevo contexto digital protagonizado por el apagón analógico y la posterior implantación de la Televisión Digital Terrestre (TDT) y el modo de adaptarse a los cambios que estaban por llegar para ser sostenibles en el futuro (Reig, Ramos y Barriga, 2012; Miguel de Bustos, Galindo y Casado del Río, 2012). Fruto de esta preocupación surgieron además diferentes reflexiones recogidas en las actas generadas en el XX Congreso Internacional de Comunicación, celebrado en Tenerife, en el año 2008 y dedicado al futuro del sector audiovisual autonómico (Bustamante, 2009). Otro de los aspectos de análisis relacionado con la adaptación digital de las televisiones regionales es la influencia que la TDT ha tenido en la continua pérdida de audiencia de las televisiones generalistas después de su implantación (De Mesa, 2000).

\section{Las redes sociales y las Televisiones Públicas Autonómicas}

La aparición de las redes sociales para la industria audiovisual ha supuesto importantes cambios relacionados con la forma de interactuar con su público, pero sobre todo con la manera de producir y distribuir contenidos; en palabras de Flores (2013), "el individuo se transforma en su propio canal y medio de información para generar, difundir, recibir e interactuar", ya que cualquier persona puede convertirse en una fuente potencial de información con los recursos electrónicos adecuados (Maarek, 2014). En este nuevo paradigma de la comunicación los modelos de producción y distribución multiplataforma se erigen como nuevos adalides del cambio al periodismo digital al generar sus contenidos gracias al fenómeno crossmedia (Lozano y García, 2016).

Es en este contexto en el que las Redes Sociales, como elemento más característico y de mayor repercusión de la web 2.0, deben constituirse no sólo como un vehículo de comunicación bidireccional (Gruning, 2014), sino también de simetría interactiva, es decir, "relaciones que se desarrollan entre actores con conductas independientes pero situados en planos de igualdad y de influencia mutua, en la que ambos tienen capacidad de emisión masiva, de iniciativa en el manejo de sus 
relaciones y de respuesta individual o grupal a sus comunicaciones" (Túñez-López, 2015).

Según datos de la Fundación Telefónica (2016), en España esta tendencia ya empieza a reflejarse en el ámbito personal y empresarial; en el personal porque aumenta el número de personas que combinan el uso de medios tradicionales y digitales, pasando del 7\% al 13,1\% y en el empresarial, para las entidades de mayor tamaño las redes sociales son ya una realidad como una herramienta más en la actividad diaria junto a otras más tradicionales como las comerciales o el marketing; del mismo modo, en el entorno de las medianas y pequeñas empresas el uso de los medios sociales está presente ya en el 55\% de ellas con perfiles en alguna red social.

Ante este contexto, todas las TPAs como organismos públicos que son deben de tener en cuenta su función de servicio público y conseguir con sus públicos una relación transparente en la que se refleje la función institucional. Para ello es necesaria una comunicación directa para ser comprendidas, accesibles, útiles y transparentes para borrar cualquier atisbo de duda sobre su gestión (Túñez-López y CostaSánchez, 2016).

Esta coyuntura requiere que los medios sociales se utilicen como herramientas de comunicación que permitan a los gestores de los entes audiovisuales optimizar sus estrategias de actuación para la consecución de su misión pública en la que la televisión de identidad y proximidad son objetivos prioritarios. Para ello han de prestar especial atención al contenido como motor del medio social, a la visibilidad y a la interactividad.

En la actualidad el consumo personalizado del contenido evoluciona hacia un consumo social, en el que varios usuarios ven a la vez el mismo contenido e interaccionan por medio de aplicaciones sociales. Conviven de este modo, varios modelos de consumo de contenidos: la emisión masiva a grandes públicos; la emisión personalizada y el consumo social. Se trata de un cambio profundo que tiene influencia en diversos terrenos como en la gestión de los contenidos o en la forma en la que se emite la publicidad. Además, desde el punto de vista 
tecnológico supone un desafío muy importante, pues las televisiones tienen que estar preparados para la emisión de los contenidos para audiencias elevadas, pero de una forma personalizada (Fundación Telefónica, 2016).

\section{Metodología}

Este trabajo tiene como objetivo realizar una aproximación al posicionamiento online a través de una muestra intencional formada por las Televisiones Públicas Autonómicas Españolas con lengua propia en la actualidad, IB3, TV3, CRTVG y EITB. El fin último de este análisis consiste en caracterizar la presencia de estos entes en el entorno online a través del análisis comparativo de sus Fanpage corporativas y sus principales parámetros de información: contenido, interactividad y visibilidad, para determinar cómo proyectan su identidad y qué prioridad les dan a su presencia en Facebook como principal red social en relación al diseño de sus estrategias de actuación para la consecución de su misión pública.

\section{Tabla 2: Fanpage Analizadas.}

\begin{tabular}{|l|l|}
\hline & Fanpage \\
\hline IB3 & https://www.facebook.com/IB3org/ \\
\hline TV3 & https://www.facebook.com/tv3 \\
\hline CRTVG & https://www.facebook.com/CRTVG \\
\hline EITB & https://www.facebook.com/eitb/ \\
\hline
\end{tabular}

Fuente: Elaboración propia

El motivo por el que nuestro ámbito de estudio se circunscribe a las televisiones autonómicas con lengua propia se deriva del objetivo de la propia misión de servicio público de estos organismos: televisiones de proximidad y de identidad para preservar las culturas locales a través, por ejemplo, de la promoción de la lengua.

De este modo, las Comunidades Autónomas de Baleares, Cataluña, Galicia y País Vasco territorios con herencia política, social y cultural diferenciada del resto de España cuentan con lenguas cooficiales: catalán, gallego y euskera, respectivamente, que interesan ser 
promocionadas además por contar con televisiones públicas que ayuden a tal fin (Arzumendi, 2013).

Si hablamos de Cataluña y Baleares como comunidades con la misma lengua cooficial, el catalán, debemos dar algunos datos sobre el idioma como clave de su identidad. Según el VIII Informe Sobre la Situación de la Lengua Catalana (2014) presentado por el Observatori de la Lengua en Cataluña, la Comunidad Valenciana y las Islas Baleares (los tres territorios principales que agrupan la mayor parte del dominio lingüístico $\left.{ }^{14}\right)$, en el año 2013 sabían hablar el catalán dos terceras partes de la población $(64,3 \%, 8,5$ millones de personas. Ver cuadro 4), lo entendía el $90,8 \%$ de la población (11,9 millones de personas), sabía leerlo el 70,5\% (9,2 millones de personas) y escribirlo menos de la $\operatorname{mitad}(46,1 \%, 6$ millones de personas).

Por territorios, Cataluña tenía valores proporcionales superiores a la media, en todas las competencias y Valencia y las Islas Baleares tenían competencias menores a la media, también en todas las competencias. Las Islas Baleares observaban valores más similares a los de la media. Si tenemos en cuenta los datos de habitantes de la Comunidad Catalana y Balear del año 2014 y 2015 (ver Cuadro 4) podemos afirmar que la tendencia en relación al conocimiento de la lengua se mantiene.

Con respeto a la situación actual del gallego, y conforme muestran los datos publicados en diciembre de 2014 por el Instituto Gallego de Estadística (IGE), se produjo un incremento en el número de personas que dice tener un grado alto de conocimiento oral y escrito de la lengua y casi la totalidad de la población afirma entenderla, aunque puede observarse un descenso intergeneracional, al ser la generación joven la que tiene una mayor capacidad para la lectura y la escritura.

Así, el 98\% de la población (más de 2 millones de habitantes en 2013. Ver cuadro 4) declara entender mucho o bastante el gallego y el $97,16 \%$ afirma saber hablarlo. El 83\% afirma saber escribirlo y el $97 \%$ sabe

\footnotetext{
${ }^{14}$ En el dominio lingüístico se incluye también la Comunidad Valencia que en esta investigación no se tiene en cuenta ya que su televisión autonómica, Canal 9, dejó de emitir en el año 2013.
} 
leerlo. En cuanto al uso, en 2013 el 31,2\% de los gallegos habla siempre en gallego; este porcentaje es muy similar al del año 2008 (30,29\%), pero 12 puntos inferior al registrado hace diez años. Por otro lado, el porcentaje de población que habla más gallego que castellano disminuyó 6,44 puntos respecto al año 2008 hasta situarse en el $20,29 \%$, mientras que el que habla más castellano que gallego casi no varió en los últimos cinco años: 22,7\% en 2008 y 22,26\% en 2013. Por último, algo más del $26 \%$ de los residentes en Galicia habla siempre castellano, 6 puntos porcentuales más que en 2008.

La lengua gallega se está consolidando poco a poco como un idioma de prestigio dentro de los medios de comunicación. La creación en 1984 de la Compañía de Radio y Televisión Gallega (CTRVG), fue determinante y supuso uno de los elementos de prestigio e identidad para la lengua, lo que la sitúa en una posición de clara ventaja con respeto a las otras lenguas europeas evaluadas por el comité de expertos del Consejo de Europa para el cumplimiento de la CELRM ${ }^{15}$.

Por último, en relación a los datos de la V Encuesta Sociolingüística de la Comunidad Autónoma del País Vasco (2011), recogidos en el Cuarto Informe sobre el Cumplimiento en España de la Carta Europea de las Lenguas Regionales o Minoritarias, del Consejo de Europa 2010 2013, la sociedad vasca muestra dos características significativas: un envejecimiento progresivo de la población y un aumento importante de la inmigración extranjera (6,5\% de la población de 2011) durante los últimos años, lo que hace más importante el desarrollo de una televisión en lengua autóctona que ayude en su conocimiento y que además cree identidad.

En esta comunidad el $32 \%$ de sus habitantes de 16 años o más es bilingüe (600.000 habitantes), el 17,2 \% bilingüe pasivo y el 50,8 \% castellano hablantes (erdaldun). En los últimos 20 años, el porcentaje de personas que utilizan el euskera tanto o más que el castellano se ha incrementado en 4,5 puntos, situándose actualmente en el $20 \%$ de la población; otro $8,9 \%$ utiliza el euskera, pero en menor medida que el castellano; sin embargo, es en los ámbitos de uso más formales donde más ha crecido su uso. En el hogar el aumento ha sido más discreto,

${ }^{15}$ CELRM: Carta Europea de las Lenguas Regionales y Minoritarias 
excepto en las relaciones con los hijos e hijas, y entre los hermanos y hermanas, donde continúa creciendo.

Las actitudes favorables a la promoción del euskera han aumentado durante los últimos 20 años; actualmente, se muestra favorable el $62 \%$ de la población; es decir, 7 puntos más que en 1991, lo que permite vaticinar una larga vida a la televisión autonómica.

Tabla 3. Habitantes de las comunidades con lengua propia

\begin{tabular}{|l|l|l|l|l|l|}
\hline Comunidad & $\mathbf{2 0 1 1}$ & $\mathbf{2 0 1 2}$ & $\mathbf{2 0 1 3}$ & $\mathbf{2 0 1 4}$ & $\mathbf{2 0 1 5}$ \\
\hline Baleares & 1.095 .456 & 1.104 .322 & 1.112 .736 & 1.120 .470 & 1.129 .430 \\
\hline Cataluña & 7.504 .024 & 7.496 .369 & 7.443 .574 & 7.399 .601 & 7.394 .576 \\
\hline Galicia & 2.771 .651 & 2.765 .747 & 2.753 .230 & 2.739 .332 & 2.725 .160 \\
\hline País Vasco & 2.184 .016 & 2.179 .984 & 2.170 .900 & 2.165 .334 & 2.162 .309 \\
\hline
\end{tabular}

Fuente: INE (2016). Elaboración propia.

\section{Tabla 4. Aspectos relacionados con cada ítem}

\begin{tabular}{|l|l|l|}
\hline Contenido & Interactividad & Visibilidad \\
\hline $\begin{array}{l}\text { Frecuencia de publicación de los } \\
\text { posts }\end{array}$ & $\begin{array}{l}\text { Respuesta } \\
\text { usuarios }\end{array}$ & $\mathrm{N}^{\text {o de fans }}$ \\
\hline Formato de los posts & Engagemente & $\begin{array}{l}\text { Likes (media), } \\
\text { Comentarios } \\
\text { (media), } \\
\text { Sharesperpost (media) }\end{array}$ \\
\cline { 3 - 3 } Categoría de la información & Longitud de los posts \\
\hline
\end{tabular}

Fuente: Elaboración propia.

De acuerdo al objetivo de nuestra investigación, pareció pertinente seguir los criterios de análisis que con anterioridad habían utilizado autores como: Huertas, Setó y Míguez (2014); Rodríguez-Fernández, Rodríguez-Vázquez y Martínez-Fernández (2016) y RodríguezVázquez, Teijeiro-Álvarez y Blázquez-Lozano (2016), en relación a los siguientes parámetros: contenido, interactividad y visibilidad. 
Para obtener el propósito planteado y, en relación a la naturaleza cuantitativa de estos parámetros, hemos utilizado la herramienta LikeAlyzer (http://www.likealyzer.com/). Esta interfaz permite medir los valores de nuestro interés y conocer aspectos relacionados con la eficacia de las Fanpage analizadas, además de ayudarnos a identificar deficiencias y poder plantear posibles soluciones.

\section{Resultados}

A continuación, se muestran los resultados obtenidos del análisis de las Fanpage objeto de estudio a través de la herramienta Likealyzer.

\subsection{Contenido}

El último estudio realizado de manera conjunta entre el Content Marketing Institute y la Direct Marketing Association (2014) ha arrojado como resultado que prácticamente la totalidad de las empresas inglesas desarrollan estrategias de content marketing, en especial en las redes sociales. $\mathrm{Y}$ es que, en la transformación digital, el contenido se ha erigido el rey de Internet. Sin embargo, el panorama español difiere ligeramente, ya que en España aunque el $90 \%$ de las empresas desarrollan este marketing sólo el 56,2\% determina que Facebook sea la red más importante para generar negocio (Hoyreka, 2015). Contenido de calidad, apropiado y personalizado para cada cliente fomenta una interacción más eficiente con las marcas y en el tiempo un mayor engagement.

En este sentido la empresa Nielsen anunció en el mes de agosto de este mismo año el inicio de operaciones de Social Content Ratings (SCR) a través de la primera medición estandarizada de la actividad en Twitter y Facebook relacionada con contenidos de televisión en México, Australia, Italia y Estados Unidos. Nielsen incluye soluciones y herramientas para la medición de la efectividad publicitaria en Social TV, que ayudarán a las televisiones a maximizar el impacto social en sus estrategias multiplataforma.

En relación a esta realidad y al éxito del contenido se analiza la frecuencia de las publicaciones y su formato (Tabla 3). En los sites 
estudiados los datos ponen de manifiesto que existen importantes y significativas diferencias entre ellos. La televisión catalana TV3 con casi 46 publicaciones diarias y la vasca EITB, con 17 animan de forma muy activa a sus fans ${ }^{16}$, lo que les permite interactuar de manera adecuada con sus seguidores.

En relación al formato de las publicaciones efectuadas y, habida cuenta que su frecuencia es la adecuada, cabe destacar que su variedad también lo es, por lo que la interacción está garantizada. Las televisiones IB3 y la TV3 emplean tres formatos dándole prioridad a los vídeos en el primer caso y a los enlaces en el segundo; la CRTVG equilibra sus publicaciones entre los enlaces y los vídeos y por último la EITB tan sólo utiliza enlaces.

Es importante señalar que para algunos autores (Cárcamo y Marcos, 2014) las imágenes es el tipo de publicación que más acciones provoca en los usuarios porque no requieren, por lo general, de una gran inversión de tiempo para su fijación, además de poco esfuerzo de atención foveal. Sin embargo, en el mundo audiovisual el vídeo predomina ya que permite redirigir al fan para que pueda visualizar de nuevo los contenidos de su interés.

Tabla 5: Facebook, post por día, porcentaje según tipo

\begin{tabular}{|l|l|l|l|l|}
\hline \multirow{2}{*}{} & \multicolumn{4}{|l|}{ Frecuencia publicación de los posts* } \\
\cline { 2 - 5 } & IB3 & TV3 & CRTVG & EITB \\
\cline { 2 - 5 } & 2.12 & 45.7 & 6.99 & 17.32 \\
\hline \multirow{5}{*}{ Formato de posts y porcentaje** } \\
\hline Foto & $16,7 \%$ & $4,2 \%$ & ----- & ----- \\
\hline Link & $12,5 \%$ & $50 \%$ & $50 \%$ & $100 \%$ \\
\hline Status & ----- & ---- & ---- & ---- \\
\hline Vídeos & $70,8 \%$ & $45,8 \%$ & $50 \%$ & ----- \\
\hline Otros & ----- & ---- & ---- & ---- \\
\hline
\end{tabular}

* Post por día; ** último mes 12/09/2016-12/10/2016

Fuente: Elaboración propia.

${ }^{16}$ Likealyzer indica en sus mediciones que se deben hacer publicaciones diarias. 
Por último, la monitorización de estas Fanpage nos permite conocer que el tipo de información que suministran (queja, comentario, sugerencia o pregunta) dista del mejor escenario. Es cierto que se realizan comentarios a las publicaciones hechas; sin embargo, todas adolecen de lo mismo, la falta de preguntas. Si se efectuaran más cuestiones a los fans, la interacción con ellos sería mayor, además de tener más posibilidades de aumentar su visibilidad.

\subsection{Interactividad}

Este parámetro está estrechamente relacionado con el contenido y, por consiguiente, con el tipo y las frecuencias de publicación, ya que la interactividad se mide, entre otras variables, a través de las respuestas que los fans tienen en relación a esos post; de tal forma, si comparamos los datos en relación al tipo de publicación efectuada con las reacciones surgidas, obtenemos el indice de respuesta.

Así, tal y como se aprecia en la fig. 1, de las cinco publicaciones más exitosas de cada televisión los links y los vídeos son los dos tipos de publicaciones que más reacciones han provocado en los usuarios en todas las televisiones, aunque podemos observar algunas diferencias.

Del total de publicaciones que ha efectuado la Televisión Balear IB3 las fotos $(16,7 \%$ del total de las publicaciones) no han tenido ninguna repercusión; no obstante, los link (12,5\%, del total de publicaciones) han tenido más importancia, sobre todo de "me gusta"; aunque las publicaciones más exitosas han sido cuatro vídeos que han conseguido 95 "me gusta", 5 "comentarios" y 28 "comparticiones". Hay que destacar que esta televisión tiene el $70,8 \%$ de sus publicaciones en vídeos, por ello se puede concluir que a la vista de los resultados su contenido no es demasiado exitoso ya que la interacción no es significativa.

En el caso de la TV3 sus publicaciones de más impacto fueron tres vídeos (45,8\% del total de publicaciones) de diferentes temáticas que generaron mucha interactividad de tal forma que tuvieron 1.359 "me gusta", 55 "comentarios" y 145 "comparticiones". El otro tipo de post con más repercusión fue el enlace (50\% del total de publicaciones), en 
concreto dos que generaron un poco menos de reacciones que los vídeos con 938 "me gusta”, 42 "comentarios" y 105 "comparticiones". Las fotos no han tenido ningún éxito.

La experiencia más exitosa de la CRTVG ha sido la conseguida por tres vídeos y dos enlaces. Si tenemos en cuenta que sus publicaciones han estado equilibradas a través de estos dos tipos de post queda claro que los vídeos han generado un interés bajo, en concreto les han gustado a 158 fans, han hecho comentarios sobre ellos sólo 6 personas y los han compartido 64 veces, por lo que tampoco alcanzan demasiada interacción con sus publicaciones.

Figura 1. Reacciones de los usuarios por tipo de post de las cinco publicaciones más exitosas en los últimos 30 días

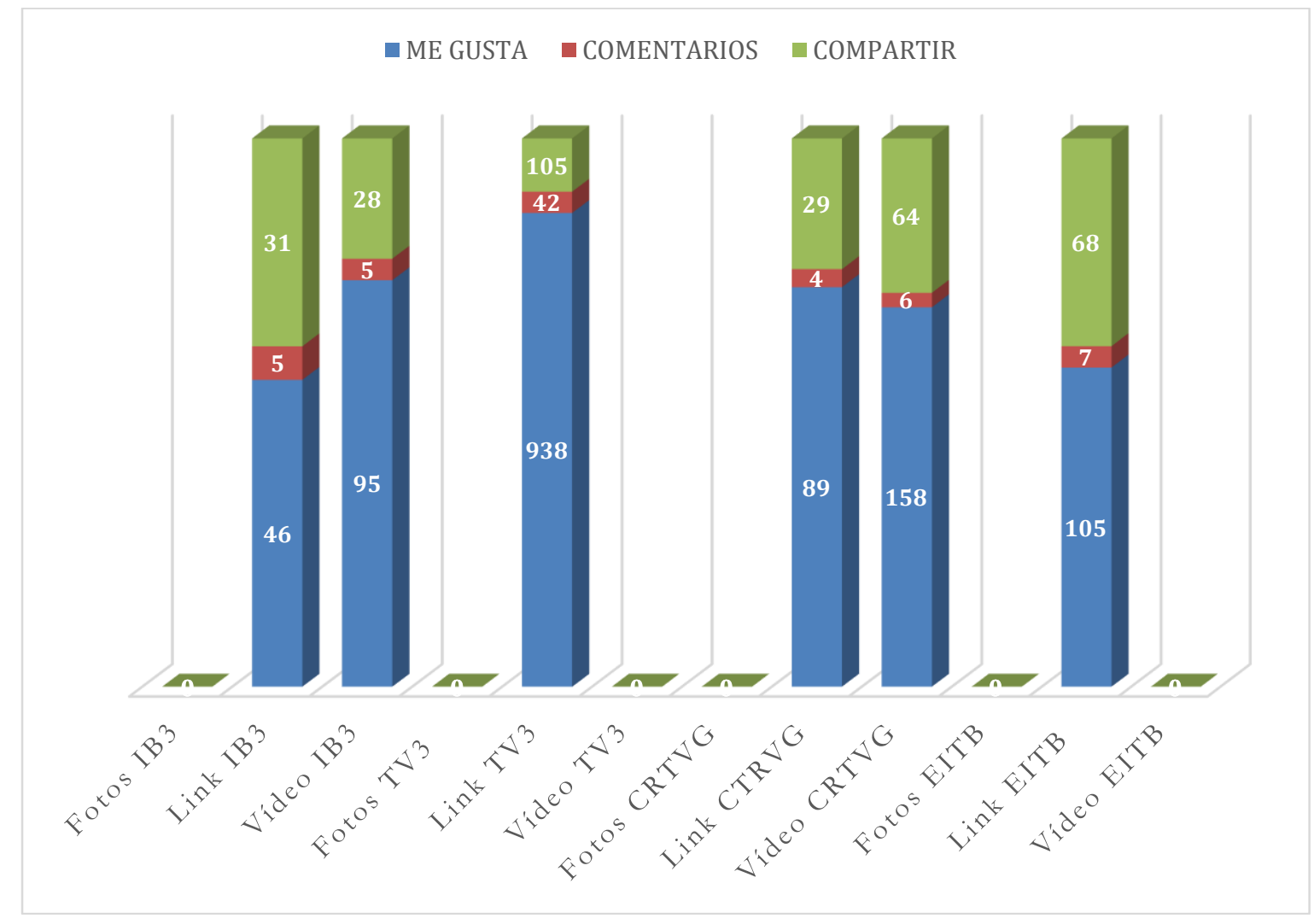

Fuente: Elaboración propia.

Finalmente, la EITB del País Vasco apostando el 100\% de sus publicaciones a los enlaces no ha conseguido una interactividad alta ya 
que los cinco enlaces más populares tan sólo han conseguido 105 "me gusta", 7 "comentarios" y 68 "comparticiones".

El engagement rate o grado de compromiso es otro de los parámetros que nos permite conocer la interactividad al medir sus reacciones ante las publicaciones efectuadas. Para calcularlo hay que dividir el PTAT (People Talking About This) o $\mathrm{n}^{\circ}$ de interacciones (Likes, Comments $\&$ Shares) que se han producido en un período determinado entre el $\mathrm{n}^{\circ}$ total de fans (fans +No fans) y multiplicarlo por 100, obteniendo de este modo el porcentaje de engagement (Valerio, Herrera-Murillo y Rodríguez-Martínez, 2014; Huertas, Setó y Míguez, 2014).

Tabla 6: $\mathrm{N}^{\mathrm{o}}$ de fans, post por día PTAT y Engagement

\begin{tabular}{|l|l|l|l|l|}
\hline & IB3 & TV3 & RTVG & EITB \\
\hline N de fans* $^{\mathbf{o}}$ de & 15.608 & 446.078 & 28.912 & 32.770 \\
\hline Post por día* & 2.12 & 45.7 & 6.99 & 17.32 \\
\hline PTAT** & 17 & 2.855 & 945 & 168 \\
\hline Engagement & $0,11 \%$ & $0,64 \%$ & $3,27 \%$ & $0,51 \%$ \\
\hline
\end{tabular}

*en el momento del análisis 12/10/2016; **porcentaje

Fuente: Elaboración propia.

Según la herramienta de análisis que hemos utilizado, se necesitaría un grado de compromiso mayor al 7\% para que ese éxito e interactividad en Facebook fuera significativo. Ninguno de los casos analizados llega a esa ratio (ver tabla 4). Sólo la CRTVG con un 3,27\% estaría un poco más cerca del éxito buscado, aunque con el número de fans que tienen podrían hacer mucho más. En el otro extremo está la TV3, ya que con sus 446.078 fans se genera una fidelidad muy baja, resultado que permite afirmar que el éxito no sólo está en el número de fans, sino en una buena interacción con ellos, un contenido de calidad y una variedad y frecuencia de post adecuadas.

Cvijikj y Michahelles (2013) consideran que existen diferentes factores tales como los formatos de los contenidos, el momento de la publicación o la longitud de la misma que podrían influir, de manera tanto positiva como negativa, en el engagement que reciben las diferentes 
publicaciones cuyo impacto variaría en relación al manejo que las televisiones hagan de los mismos.

\subsection{Visibilidad}

Este último criterio de análisis sirve para evaluar cuáles son los elementos más relevantes e importantes para conseguir una mayor presencia en la red y de forma más eficiente (ver tabla 8).

Un ítem básico para su medición es el número de fans. En la monitorización efectuada se observa que, en términos generales, el mayor volumen de seguidores está en las Fanpage de la televisión autonómica TV3 con casi medio millón de seguidores, número que le podría reportar unas métricas mucho más interesantes que las actuales y por lo tanto mucho más éxito. Le sigue la televisión vasca EITB y la gallega CRTVG, para finalizar el ranking de seguidores con la televisión balear IB3.

Otro índice representativo de la presencia en la red de estas televisiones es la media de "likees", "comentarios" y "shares" por cada publicación efectuada. Este índice está estrechamente relacionado con el total de fans, con los posts publicados diariamente y las interacciones $\mathrm{O}$ reacciones de los usuarios a esas publicaciones.

Sobre este parámetro destacan dos resultados; en primer lugar, la media más alta la tiene la TV3 dato que se corresponde con un importante volumen de seguidores y frecuencias de publicación muy altas lo cual indica que los posts tienen un gran interés para sus fans y provocan muchas reacciones y por ende una mayor visibilidad en la red.

En segundo lugar, el caso de la EITB se encuentra en la antítesis del caso anterior ya que, con un buen número de fans las reacciones que consiguen a cada una de las 17 publicaciones diarias es un número muy bajo; 11, lo que indica que sus publicaciones despiertan ínfimo interés. 
Tabla 7: $\mathrm{N}^{\circ}$ de fans, post por día, media de "me gusta", "comentarios" y "comparticiones"

\begin{tabular}{|c|c|c|c|c|}
\hline & IB3 & TV3 & CRTVG & EITB \\
\hline $\mathbf{N}^{\circ}$ de fans* & 15.608 & 446.078 & 28.912 & 32.770 \\
\hline Post por día* & 2.12 & 45.7 & 6.99 & 17.32 \\
\hline $\begin{array}{l}\text { Likes } \\
\text { Comentarios } \\
\text { Shares } \\
\text { per post (media)* }\end{array}$ & 15 & 150 & 25 & 11 \\
\hline Longitud de los posts $* *$ & $\begin{array}{l}\text { Entre } \\
100 / 500\end{array}$ & $\begin{array}{l}\text { Entre } \\
100 / 500\end{array}$ & $\begin{array}{l}\text { Entre } \\
100 / 500\end{array}$ & \begin{tabular}{|l} 
Entre \\
$100 / 500$
\end{tabular} \\
\hline
\end{tabular}

*en el momento del análisis 12/10/2016; ** caracteres

Fuente: Elaboración propia.

Por último, la longitud de los posts es otro elemento que ayuda a determinar la visibilidad de una Fanpage. Un estudio publicado por Track Social (2012) indica que las publicaciones con una longitud de texto grande (más de 1000 caracteres) no son exitosas en términos del número de los "me gusta" que reciben, "comentarios" y "comparticiones"; según Likealyzer mensajes entre 100 y 500 caracteres son los más apreciados por los fans, De esta forma, respecto al análisis que nos ocupa, todas las televisiones están bien posicionadas sin destacar ninguna. Los fans valoran en mayor medida estas publicaciones cortas lo que genera más respuestas y consecuentemente más visibilidad e interactividad.

\section{Conclusiones}

La incursión de las redes sociales en el sector audiovisual ha promovido cambios sustanciales, tanto en la forma de interactuar con su público, como en el modo de producir y distribuir contenidos.

En este sentido, en España cabe destacar el caso de las televisiones públicas autonómicas con lengua propia, las cuales han nacido con una clara vocación: transmitir la identidad cultural de su comunidad a través del idioma propio y servir de dinamizador económico y social.

Ante este contexto al aunar, por un lado, las televisiones públicas autonómicas con lengua propia (IB3, TV3, CRTVG y EITB) y por otro, 
la red social Facebook se muestran los resultados concernientes al análisis del posicionamiento online de las distintas cadenas a través del estudio de los siguientes parámetros: Contenidos, Interactividad y Visibilidad.

En lo concerniente al contenido es importante que en las redes sociales, tal cual es el caso de Facebook, las televisiones públicas autonómicas con lengua propia aboguen por el desarrollo de contenidos originales, únicos, creativos y de calidad en aras de fomentar la interactividad y visibilidad de los usuarios. En esta investigación se puede apreciar que las cadenas ámbito de estudio, no optimizan este parámetro tal y como deberían, así:

- En lo que respecta a la frecuencia de publicaciones sólo TV3 y EITB alcanzan datos aceptables.

- El formato que más emplean las cadenas analizadas para realizar el mayor número de publicaciones son los links, seguido de los vídeos.

- El tipo de información que suministran las Fanpages presenta poca variedad. A pesar de los comentarios que los fans realizan, la interacción con los mismos es más bien escasa.

En lo que respecta a la interactividad, parámetro estrechamente relacionado con el contenido, es una variable importante al ofrecer información acerca del feedback entre las cadenas y sus seguidores en Facebook. Las páginas en este caso no consiguen que sus fans adquieran un importante grado de compromiso ya que los resultados evidencian que:

- De acuerdo a las cinco publicaciones más exitosas, en las respuestas de los usuarios a los posts priman los links y vídeos, al ser los que generan una mayor reacción. No obstante, los datos en términos generales no son nada halagüeños.

- La cadena que más engagement genera es CRTVG pero aun así, dista mucho de alcanzar el óptimo establecido. En el extremo opuesto, se encuentra IB3 con el grado de compromiso más bajo. 
- En cuanto a la visibilidad, este parámetro contribuye a fomentar la presencia en la red y por ende la eficiencia, en este caso los resultados muestran que:

- La cadena que presenta más fans es TV3, seguida de EITB, CRTVG e IB3.

- La televisión que alcanza una media de likes, comentarios y comparticiones mayor es TV3 y la que menos EITB.

- La longitud de post empleada en todos los casos es adecuada, al mantenerse dentro de lo óptimos establecidos, lo cual favorece a que los fans se puedan llegar a interesar más por las publicaciones.

A la vista de todos los resultados obtenidos se puede precisar que las televisiones públicas autonómicas españolas con lengua propia hasta el momento, no muestran una adecuada optimización al no aprovechar las oportunidades que les ofrece la red social Facebook como canal de información y promoción. Mejorar la interactividad y visibilidad han de ser objetivos prioritarios si lo que desean es conseguir un buen posicionamiento online.

\section{Bibliografía}

Acenture/FORTA (2012). Informe sobre el papel de la Televisión Pública Autonómica en España. Recuperado el 25 de octubre de 2016 de https:/ goo.gl/1JdDXx

Aubach Guiu, MT. y Lacoba, R. (1996) Comunicación audiovisualy

desarrollo de regiones. Actas del II congreso internacional.

Universidad Pontificia de Salamanca: Servicio de Publicaciones. ISBN: 84-7299-466-X.

Azurmendi, A. (2007). La reforma de RTVE. En Azurmendi, A. (Dir.) La reforma de la televisión pública española. Valencia: Tirant lo Blanch.

Azurmendi, A. (2013). Reformas de la televisión regional europea con lengua propia en el contexto actual de crisis. En Revista Latina de Comunicación Social, 68. La Laguna (Tenerife): Universidad de La Laguna, pp. 355-382, recuperado el 1 de noviembre de 2016, de https://goo.gl/9WVCwY.DOI: 10.4185/RLCS-2013-981 
Bustamante, E. (2000). Las telecomunicaciones como factor decisivo de la competitividad y la cohesión regional. En Aubach Guiu, M. T. y Lacoba, R. (1996) Comunicación audiovisualy desarrollo de regiones. Actas del II congreso internacional. Universidad Pontificia de Salamanca: Servicio de Publicaciones.

Bustamante, E. (coord.) (2009). El audiovisual digital: politicas y estrategias desde las comunidades autónomas. Tenerife: Gestión Insular para el Deporte, la Cultura y el Ocio.

Campos-Freire, F. (2013). Las políticas europeas de gestión del sector audiovisual: restructuración de la TV pública y concentración digital. En Coord., Rúas Araújo, X. y Martínez-Fernández, VA (2013) Comunicación, Política y Redes en Europa. Porto: Media XXI.

Cárcamo, L. y Marcos, M. (2014). Prensa en Facebook: la importancia de la imagen en la web social. Primer Congreso Internacional Infoxicación: mercado de la información y psique. Sevilla.

Consejo de Europa (1987a). El rol de la comunicación en el desarrollo regional, Estraburgo. En Musso, P. et al (1991) Régions d'Europe et télévision. París: Editions Miroirs.

Consejo de Europa (1987b). Symposium Presse, Télévision et

Régions d'Europe, Cracovia, octubre. En Musso, P. et al (1991)

Régions d'Europe et télévision. París: Editions Miroirs.

Consejo de Europa (2014). Cuarto Informe sobre el Cumplimiento en España de la Carta Europea de las Lenguas Regionales o Minoritarias. Estrasburgo. Recuperado el 5 de noviembre de 2016 de https://goo.gl/q6c6Mp

Corporación Multimedia (2010). Datos de audiencias de Televisión 2009: El último año de la era analógica. En Academia, DELATV. (2010) La industria audiovisual en España. Escenarios de un futuro digital. ISBN 978-84-937306-7-3. Recuperado el 01 de noviembre de 2016 de https://goo.gl/GBeqGv

Cvijikj, P. y Michahelle, F. (2013). Online engagement factors on Facebook brand pages, Social Network Analysis and Mining. DOI 10.1007/s13278-013-0098-8

De Moragas Spà, M. y Garitaonaindía, C. (1995). Decentralisation in the Global Era. Television in the Regions, Nationalities and Small Countries of the European Union. Londres: John Libbey. ISBN: 0861964756

De Moragas Spà, M; Garitaonaindía, C y López, B. (coord.) (1999). Televisión de proximidad en Europa: experiencias de descentralización en 
la era digital, Bellaterra, Servicio de publicaciones de la Universidad Autónoma de Barcelona.

Domínguez, A. (2000). El marco jurídico-constitucional de la televisión autonómica y local. Anales de la Facultad de Derecho, 17, pp. 59-120. ISSN 0075-773X

Flores, JM. (2013). Contenidos y servicios periodísticos en las redes sociales. Madrid: Fragua.

Fundación Telefónica (2016). La Sociedad de la Información en España 2015. Barcelona: Ariel. Recuperado el 27 de octubre de 2016 de https://goo.gl/XzDQeg

Grunig, JE. (2009). Paradigms of global public relations in an age of digitalization. PRism, no 2, pp. 1-19. Recuperado el 4 de noviembre de 2016 de https://goo.gl/5GcQMD

Hoyreka (2015). I Informe de marketing de contenidos en España 2015. Madrid: Hoyreka Contenido S.L.

Huertas, A; Setó, D. y Miguez, M. (2014). Comunicación de Destinos Turísticos a través de las Redes Sociales. El Profesional de la Información, $\mathrm{n}^{\circ} 1$, pp. 15-21. http:/ /dx.doi.org/10.3145/epi.2015.ene.02

Instituto Galego de Estatística (IGE) (2014). Enquisa de condicións de vida das familias. Coñecemento e uso do galego. Ano 2013. Xunta de Galicia.

Ley 4/1980, de 10 de enero, de Estatuto de la Radio y la Televisión. Lozano, L. y García, B. (2016). La gestión y discurso de las televisiones en Twitter en la jornada electoral. Análisis de caso de@TVGalicia y@telediario_tve en el 26J.Actas del II Simposio de la Red Internacional de Investigación de Gestión de la Comunicación (XESCOM) De los Medios y la Comunicación de las organizaciones a las redes de valor. Ecuador. ISBN: 978-9942-25-054-4 Maarek, PJ (2014). Politics 2.0: New Forms of Digital Political Marketing and Political Communication. Trípodos, n ${ }^{\circ} 34$, pp.13-

22. Facultat de Comunicació i Relacions Internacionals Blanquerna. ISSN: 1138-3305

Martínez, MA. (2000). Televisión y video en Galicia. La intervención de la institución autonómica en el sector audiovisual. Universidad

Complutense de Madrid: Servicio de Publicaciones.

Miguel de Bustos, JC; Galindo, F. y Casado del Río, MA. (2012).

Servicio público y nuevas tecnologías. La adaptación de las 
autonómicas al nuevo escenario. En Miguel de Bustos, JC. y Casado del Rio, MA. (Coords) (2012) Televisiones Autonómicas. Evolución y crisis del modelo público de proximidad Barcelona: Gedisa. ISBN 9788497847254.

Morán, M. (2000). Audiovisual y nuevas tecnologías de la información y la comunicación: el necesario protagonismo de las regiones. En Rodríguez, MM; Rodríguez, C. y Martínez, VA. (2015). La Comunicación del Camino de Santiago y los Medios Sociales. CISTI'2015 - 10 Conferencia Ibérica de Sistemas y Tecnologias de Información, Portugal: Aveiro.

Morgan, JA. (2012). Optimizing Facebook Engagement - Part 3: The Effect of Post Length. Track Social, junio:

https://goo.gl/1jguLX. Recuperado el 7 de noviembre de 2016.

Observatori de la Lengua Catalana (2014). VIII Informe sobre la situació de la lengua catalana. Barcelona: Xarxa Cruscat.

Observatorio del Ocio y el Entretenimiento Digital (2010). La nueva legitimación de la Televisión Pública en España, en Ocendi, julio: Recuperado el 4 de noviembre de 2016 de https://goo.gl/mxxwc1

Pulizzi, J. y Combemale, C. (2014). Content Marketing in the UK: 2013 Benchmarks, Budgets, and Trends. Reino Unido: Content marketing Institute.

Reig, R; Ramos, D. y Barriga, MJ. (2012). La TDT y las televisiones autonómicas: conformación de un modelo en un contexto problemático. En Miguel de Bustos, JC. y Casado del Río, MA (Coords) Televisiones Autonómicas. Evolución y crisis del modelo público de proximidad. Barcelona: Gedisa. ISBN 9788497847254.

Rodríguez-Vázquez, C; Teijeiro-Álvarez, M. y Blázquez-Lozano, F (2017). Evaluation of the Fanpages of Spanish universities: public versus private institutions. Universal Access in the Information Society, pp. 1-9. DOI: 10.1007/s10209-017-0530-3

Sampedro, V. (1996). Televisións rexionais: cadeas políticas. Revista A Trabe de Ouro.

Sánchez Revilla, MA. (2016). Estudio Infoadex de la inversión publicitaria en España. Recuperado el 25 de octubre de 2016 de https://goo.gl/Oz3Rww

Túñez-López, M. (2015). Modelo de simetría interactiva. Revista Mediterránea de Comunicación, 6(2): 5-7. Recuperado el 1 de 
noviembre de 2016 de https://goo.gl/rDXjV1.

doi:10.14198/MEDCOM2015.6.2.14.

Túñez-López, M y Costa-Sánchez, C. (2015). Imagen e intencionalidad de las principales televisiones públicas europeas. Aproximación comparativa al estado de la cuestión. Actas del II Simposio de la Red Internacional de Investigación de Gestión de la Comunicación (XESCOM) De los Medios y la Comunicación de las organizaciones a las redes de valor. Ecuador. ISBN: 978-9942-25054-4

Vacas, F. (coord) (2000). Televisión y desarrollo. Las regiones en la era digital, Badajoz, Consejería de educación, ciencia y tecnología, Junta de Extremadura. ISBN: 84-95251-37-X

Valerio, G; Herrera-Murillo, D y Rodríguez-Martínez, MC (2014). Asociación entre el momento de publicación en las redes sociales y el engagement: estudio de las universidades mexicanas. DOI: http://dx.doi.org/10.5294/pacla.2014.17.3.8 Warc (2016). Average The Latest Consensus Ad Forecast. Reino Unido.

Reconocimientos: Los resultados de este artículo forman parte de las actividades de difusión del proyecto del Programa estatal de Fomento de la Investigación Científica y Técnica de Excelencia, subprograma estatal de Generación de Conocimiento del Ministerio de Economía y Competitividad de España sobre "Indicadores de gobernanza, financiación, rendición de cuentas, innovación, calidad y servicio público de las RTV europeas aplicables a España en el contexto digital" (Referencia CSO2015-66543- P). 



\title{
Modelos de financiación de los canales de televisión pública en Latino América
}

\author{
Mónica López-Golán \\ Nancy Graciela Ulloa-Erazo \\ Pontificia Universidad Católica del Ecuador Sede Ibarra
}

Cómo citar: López-Golán, M. y Ulloa-Erazo, N. (2017). Modelos de financiación de los canales de televisión pública en Latino América._En Túñez López, M.; Campos-Freire, F. y Silva Rodríguez A. (Eds.). (2017) Estudios sobre financiación, legislación e innovación en la Televisión Pública. Cuadernos Artesanos de Comunicación, cac126, pp 171-182. La Laguna (Tenerife): Latina.

DOI: $10.4185 / \operatorname{cac} 126$

T AS DIFERENTES fórmulas de financiacion que bajo el nombre 1 de televisión pública se desarrollan en algunos de los países de la región latinoamericana centran el interés de este capitulo, que se aproxima a conocer la diversidad de modelos existentes y a realizar una valoración general de las situaciones estructurales de los canales analizados y su relación con los índices de audiencias. Para ello se seleccionan tres grupos de medios públicos: con sistema de financiación pública/ privada, los que solo reciben contribuciones del gobierno y los que se autofinancian sin recibir ayuda estatal, y se evalúa si esta diversificación de fuentes de financiación ayuda a garantizar la eficiencia y autonomía de estos medios.

Palabras clave: Televisión pública; Latinoamérica; financiación; recursos públicos y privados; autofinanciación. 
La televisión, pese a ser uno de los medios tradicionales y sentirse cada vez más amenazado por la inmediatez de internet, todavía mantiene su liderazgo como medio de comunicación más consumido al día dentro del contexto mundial. Durante 2015, el tiempo de consumo fue de 3 horas y 2 minutos de promedio diario (EURODATA, 2016). Sin embargo, la tendencia apunta hacia una dirección, el consumo de contenidos audiovisuales a través de los nuevos formatos, sobre todo, entre las audiencias más jóvenes.

En Latinoamérica, desde que irrumpe en las sociedades de la región, la televisión se ha ido consolidando como el medio de difusión más importante. Actualmente, debido a los avances tecnológicos, que traen consigo la diversificación de plataformas y la consiguiente fragmentación de audiencias, y a las continuas transformaciones de carácter político que experimentan los diferentes países, el panorama audiovisual latinoamericano se presenta cambiante y complejo. Su estructura viene determinada, fundamentalmente, por tres dinámicas relacionadas con: a) el elevado nivel de concentración del sector mediático provocando el nacimiento de grandes grupos mediáticos, b) el marcado carácter comercial de la televisión frente a una posición más marginal ocupada por los medios de servicio público y c) una alta centralización vinculada a los centros urbanos como principales productores de contenidos (Llorente y Cuenca, 2013).

La historia de la televisión pública latinoamericana está marcada por los problemas de financiamiento y la escasez de recursos. La tradicional respuesta por parte del medio para resolver esta situación ha sido buscar apoyo económico estatal, afectando dicha solución a la línea editorial (Sturm y Nalvarte, 2016) y dotando al gobierno de mecanismos para actuar como importante operador comunicacional. Sin excepciones, cada país ha tenido estaciones de radiodifusión consideradas "públicas" sin tener claro el significado de este concepto ni la misión que han de cumplir en una región sometida a ciclos alternos de democracia y autoritarismo (Waisbord, 2014). Durante la década de los 90 fueron apareciendo intentos de reforma de la tradicional televisión gubernamental hacia un tipo de canal con más compromiso con los principios de autonomía política y producción diversificada, aunque solo en casos excepcionales. 
Hoy en día, el gran desafío para la consolidación de un sistema de comunicación pública independiente es obtener recursos económicos que no dependan únicamente del estado para garantizar su eficiencia y la autonomía de dichos canales.

En esta comunicación veremos como la tendencia de las experiencias de televisiones públicas latinoamericanas está marcada, en general, por una diversificación de financiamiento donde la iniciativa pública recibe fondos públicos y privados. Aunque también existen excepciones de modelos de televisiones públicas con un sistema de autofinanciamiento que les permite más independencia del gobierno y una imparcialidad a la hora de diseñar la programación.

\section{Los principios}

Al hablar de los principios de la televisión pública, mucho antes de que llegase la televisión a América Latina, John Reith, director general de la BBC durante más de una década y defensor de una radiotelevisión independiente y pública, establecía cuatro elementos definitorios de un servicio de radiodifusión público estatal que hicieron fortuna en el conjunto del continente europeo: cobertura nacional, altos estándares de calidad a la hora de establecer la programación, primacía de una guía de servicio público por encima de la comercial y poseer un sistema de control y operaciones centralizado (1924).

Más recientemente, la UNESCO (2001) definía la televisión pública como "una herramienta de información y de educación, accesible a todos y que se dirige a todos, independientemente de la condición social o económica de unos y otros" y, a diferencia de la televisión comercial, que está sometida a imperativos de rentabilidad, se orienta hacia la persona en su calidad de ciudadano y no tanto hacia la audiencia.

Asimismo, se basa en unos principios de los cuales derivan unas funciones específicas, un modo de financiación particular y unos objetivos programáticos determinados. 
En cuanto a los principios, esta misma organización establece cuatro fundamentales: la universalidad, la diversidad, la independencia y la especificidad.

El principio de la universalidad se refiere a la importancia de intentar lograr que el conjunto de su programación resulte accesible a toda la población, no solo técnicamente, sino también desde el punto de vista de la capacidad de la comprensión del contenido. Por su parte, cuando hablamos de diversidad, nos estamos refiriendo a géneros, destinatarios y temas variados, de tal manera que el total de los intereses del público estén atendidos a través del abanico de opciones que ofrezca su programación.

Del mismo modo, un servicio público televisivo debe representar un espacio en el que se pueda actuar libremente a la hora de expresar ideas, sin sufrir presiones, ni comerciales ni políticas. Finalmente, por el principio de especificidad, la televisión pública debe diseñar un tipo de programación diferente que la distinga de los demás servicios de radiodifusión basándose en la innovación y en la capacidad de generar nuevos espacios y géneros que estimulen a otras emisoras.

\section{Los modelos}

Los modelos de financiación de las televisiones públicas en Latinoamérica, hacen referencia al modelo de servicio público se construye sobre una doble desconfianza. En primer lugar, desconfianza en cuanto a la capacidad de los mecanismos del mercado para garantizar la realización de los objetivos en los que se basa y, en segundo lugar, desconfianza en cuanto a la capacidad del Estado para el cumplimiento de esos mismos objetivos agrupados en torno a las principales funciones de una televisión pública: informar, educar y entretener. Teniendo en cuenta esta premisa, no es recomendable ni que una televisión pública esté totalmente en manos del estado controlada por los poderes públicos ni que actúe como si formara parte de una sociedad en las que los medios puedan funcionar como si estuvieran inmersos en un sistema de mercado libre (Becerra, García Castillejo, Santamaría y Arroyo, 2012). 
En Latinoamérica, las políticas estatales apoyaron el nacimiento y consolidación de la televisión comercial y de gestión privada (Toussaint, 2007) dejando la opción pública en una posición más marginal y con dificultades para subsistir debido a tres razones estructurales: la mala administración por falta de estabilidad en la dirección ejecutiva, falta de sostenibilidad económica y una programación poco atractiva y de escasa audiencia (Fuenzalida, 1998).

Tradicionalmente, tal y como hemos apuntado en el apartado anterior, un servicio público de televisión ha de enmarcarse en un contexto de promoción democrática en el que se fomente el pluralismo y la diversidad cultural. Sin embargo, la televisión pública latinoamericana en parte de su historia se registra como un medio gubernamental; para uso propagandístico debido, a la dependencia financiera total que ha tenido del estado (Ortega, 2010).

La vertiente financiera, por tanto, juega un papel importante como uno de los indicadores que debe tener un medio público. Un mecanismo de financiación que evite presiones de quienes aportan fondos, sería el sistema ideal. Esto garantizaría el pluralismo, una de las principales funciones de un medio público.

El panorama mediático público latinoamericano muestra una realidad diversa en relación a los modelos de financiación. Por una parte, está la asignación de recursos anuales provenientes del Presupuesto del Estado. Sin embargo, este sistema encuentra un ambiente poco favorable en muchos países debido a que, un medio de estas características demanda cuantiosos fondos y hay tendencia a la reducción de los mismos en beneficio de otros gastos sociales prioritarios como la salud o la educación.

La autogestión económica representa otro modelo de financiación para la televisión pública. Este sistema trae consigo ventajas pero también limitaciones, sobre todo, si los recursos provienen de la publicidad. Una eficiente gestión económica o la falta de corrupción son algunas de las bondades (Fuenzalida, 2009). No obstante, presenta desventajas como la necesidad de adaptar la programación a la rentabilidad de mercado que demanda la inversión publicitaria. 
En general, desde el punto de vista económico en el contexto latinoamericano, aparece una evolución hacia las formas mixtas de financiamiento procedentes de diversas fuentes. Ejemplo de ello son las televisiones públicas de Colombia, Brasil, Costa Rica o Uruguay.

\section{La financiación}

En el siguiente apartado analizaremos casos que responden a los diferentes modelos de financiación para las televisiones públicas.

Para analizar las televisiones públicas representativas de los diferentes modelos de financiación, empezaremos por la Televisión Nacional de Chile (TVN): es la única televisión pública en América Latina que se autofinancia por medio de publicidad y otros servicios televisivos que se ofrecen a empresas privadas. Sin embargo, este modelo de financiación está ahora en discusión por la falta de sostenibilidad del canal, de ahí que, según el presidente del directorio de esta televisión, Ricardo Solari, se haya solicitado al Parlamento la aprobación de fondos que permitan mejorar el sistema corporativo para competir en el actual mercado de la televisión digital ((Sturm y Nalvarte, 2016).

En 1970 se crea por ley la televisión pública de Chile para que los ciudadanos de esta región pudieran acceder a contenidos informativos, culturales y de entretenimiento. En este momento se concebía un sistema de financiamiento mixto, con ingresos por parte del estado que provenían, por un lado, de la Ley de Presupuesto y, por otro, de la recaudación de lo que por aquel entonces se denominaba Impuesto al Patrimonio (Bachelet, 2016).

Tras años de debilidad económica y de la utilización política del canal durante la dictadura, en 1991 se aprueba una capitalización que permite que el canal resurja y se convierta de nuevo en la representación televisiva de los compatriotas.

A partir de este momento, y gracias a la Ley Orgánica de TVN, que prohíbe el apoyo económico estatal, esta televisión pública se convierte en la única en el mundo que se financia de forma privada. Esta misma ley aprueba también la constitución de un órgano de autoridad, 
denominado Directorio, integrado por siete miembros elegidos mediante acuerdo entre el Presidente de la República y el Poder Legislativo.

Este sistema de autofinanciamiento contribuye a una autonomía que convierte a esta televisión en un canal respetado, independiente, plural y de calidad, sin embargo, se trata de un modelo cada vez más inviable (Valdés, 2016) que respondió a las necesidades de una sociedad que transitaba en ese momento del autoritarismo a una democracia pero que comienza a quedarse obsoleto.

Hoy en día, el autofinanciamiento no es un modelo adecuado, lo que exige buscar otras vías que no comprometan la independencia de TVN y que a la vez respondan a las exigencias de los ciudadanos (Wood, 2016). El porcentaje de share del canal durante 2015 ha sido del 9,8\%, un 3,1\% menos que en el ejercicio anterior (Eurodata, 2016).

Señal Colombia, fundada en 1970, es uno de los tres canales públicos de carácter nacional disponibles en el país andino. Ofrece un contenido educativo y cultural y responde a un modelo de financiación muy diferente al del resto de televisiones públicas de la región latinoamericana.

La actualización de la Constitución del país en 1991 ha supuesto una favorable evolución para la televisión pública. El Constituyente estableció en los artículos 76 y 77 de la Carta que este servicio estaría regido por un ente autónomo. En el desarrollo de ese mandato Constitucional, el legislador promulga la Ley 182 de 1995 que crea formalmente el órgano regulador de la televisión colombiana, la Comisión Nacional de Televisión (CNTV).

Para garantizar su financiación se crea el Fondo para el Desarrollo de la Televisión y los Contenidos (FONTV), administrado por la CNTV (Ortega, 2010). En medio de estas reformas surge el nuevo modelo de financiación para la televisión pública colombiana que, al igual que ocurre con el de TVN de Chile, es único en el mundo. 
El sistema implantado en Colombia para financiar la televisión pública se basa en que sea el mismo sector el que aporte los recursos económicos para el funcionamiento de este servicio público. El funcionamiento del sistema es el siguiente. Los canales privados de televisión de señal abierta, como Caracol y RCN, están obligados por ley a destinar el 1,5\% de sus ingresos anuales al FONTV. Las operadoras de televisión cerrada por suscripción satelital o cable aportan al mismo fondo un porcentaje mensual por suscriptor. En contrapartida a este aporte, la ley no permite la comercialización de Señal Colombia (Arenas, 2015).

Esta alianza establecida por el gobierno con los canales privados para la financiación de la televisión pública beneficia al triángulo de actores. Por un lado, al Estado se libra de tener que obligar a la ciudadanía a realizar un pago para garantizar el servicio público televisivo nacional, por otro, a la televisión pública la exonera de estar sometida a imperativos de rentabilidad. Finalmente, a "la televisión privada le garantiza que la televisión pública no sea comercializada" (Arenas, 2015).

Desde el punto de vista de la audiencia, se trata de un canal comprometido con ella. Los criterios de selección de las producciones, tanto nacionales como internacionales, hacen que su oferta de programación sea sólida y coherente, sin embargo, el share de 2015 estuvo representado por un $1 \%$ frente al $23,8 \%$ del canal privado Caracol, quien obtuvo el índice más elevado de audiencia durante el pasado año (Eurodata, 2016).

TV Cultura de Brasil es un canal especializado en contenidos culturales y artísticos fundado en 1969 y manejado por un consejo de administración compuesto por representantes de la sociedad y del gobierno. Se trata de uno de los canales culturales de referencia en la región latinoamericana (Becerra, García Castillejo, Santamaría y Arroyo, 2012). El modelo de financiación de esta televisión pública generalista es mixto ya que, además de recursos públicos, recurre a la publicidad para garantizar el mantenimiento del medio. 
En Brasil, "la televisión pública se ha desarrollado a través de una amplia red de televisoras educativas y culturales" (Ortega, 2010). La experiencia brasileña en relación a las televisiones educativas tuvo lugar a finales de la década de los 60. Muchos de estos medios trabajan en coordinación, intercambiando algunos programas y produciendo un interesante material de alta calidad (Fuenzalida, 1998). Con el tiempo, y debido fundamentalmente al decreciente aporte de fondos públicos, estas estaciones consideradas educativas han ido evolucionando hacia una televisión pública con mayor diversidad de géneros dentro de su programación para acceder a una audiencia más amplia. Actualmente, existen en Brasil unas 170 emisoras que funcionan como servicio público en la región y que representan la alternativa a la poderosa televisión comercial con O Globo a la cabeza en el mercado televisivo brasileiro.

En su fase inicial, TV Cultura recibía exclusivamente ingresos del gobierno regional de São Paulo, pero poco a poco fue generando otras vías de financiación. En 2010, el presupuesto anual del medio era de 111 millones de dólares y solo el 40\% provenía del estado, el resto procedía de ingresos publicitarios o servicios prestados a terceros (Pérez Tornero y Vilches, 2010).

En cuanto a las audiencias, TV Cultura es un canal que se puede ver en las 5 regiones de Brasil gracias a la cooperación con 95 afiliados, lo que le permite también ampliar su programación nacional basada, fundamentalmente, en cine nacional, deportes, noticieros y conciertos en vivo. Destaca por la producción de numerosos documentales sobre culturas populares de las diversas regiones del país, un contenido al que es difícil de acceder a través de los canales privados latinoamericanos (Becerra, García Castillejo, Santamaría y Arroyo, 2012). Su objetivo fundamental es divulgar contenido educativo. El share de este canal durante el 2015 estuvo representado por un 0,5\% (Eurodata, 2016).

A manera de conclusiones debemos mencionar que los medios públicos latinoamericanos están experimentando un resurgimiento debido a los avances tecnológicos, pero no acaban de definir ni sus funciones ni un claro método de financiamiento. 
El entretenimiento, la información, la educación y la pluralidad son las principales señas de identidad que debe mostrar un medio público de televisión. Además, este tipo de medios deben de contribuir a reforzar la democracia de un país.

La televisión pública no sobrevive sola, por lo que es necesario financiarla, pero tampoco debe estar subordinada a las reglas de la economía de mercado. Para mantener la autonomía política y editorial es importante tener una diversificación de fuentes de financiación.

La autofinanciación, como hemos comprobado a través del análisis del canal público de Chile, presenta bondades como la de generar un recurso económico dinámico en línea con el crecimiento del mercado, al mismo tiempo que otorga independencia del poder político. La gran desventaja es que somete la programación a la demanda de contenidos de la audiencia, generando falta de diversidad de géneros y temas.

El sistema de financiación de Señal Colombia demuestra que los canales públicos que reciben ingresos del sector audiovisual privado tienen una clara ventaja. Obtienen un beneficio indirecto del mercado sin necesidad de someterse a las dinámicas que éste exige.

Los medios públicos bien financiados son reflejo de democracias saludables. En este sentido, las televisiones públicas latinoamericanas deben contar con un sistema de financiación sostenible, transparente y estable que garantice independencia y autonomía, tanto de las fuerzas del mercado como de los poderes políticos representantes de los diferentes países. Por tanto, el modelo de financiación mixto parece representar la mejor opción para estos medios.

\section{Bibliografía}

Arenas, P. (2015): El futuro de la televisión pública educativa y cultural. El caso de Señal Colombia. Boletín Cultural y Bibliográfico, Vol. XLIX, No 87. http://publicaciones.banrepcultural.org/index.php/boletin cult ural/article/viewFile/7390/7732 
Becerra, M., García., Castillejo, A., Santamaría, O., y Arroyo, L.

(2013): Cajas Mágicas. El renacimiento de la televisión pública en América Latina. Madrid: Tecnos.

Bachelet, M. (2016): Indicación Sustitutiva al proyecto que moderniza TVN y crea Canal Cultural Educativo. Prensa Presidencia. https://prensa.presidencia.cl/discurso.aspx?id $=33280$

EURODATA (2016): One TVYear. Eurodata TV Worldwide.

Fuenzalida, V. (1998): Situación de la Televisión Pública en América

Latina. Diálogos de la Comunicación. Ed. N 53.

http://www.consejoinfancia.gob.ar/wp-

content/uploads/2012/05/53ValerioFuenzalida.pdf

Fuenzalida, V. (2009): Nuevas tendencias de la Televisión Pública en

América Latina. En Televisión Pública: experiencias de Alemania y

Latinoamérica. Buenos Aires: Fundación Konrad Adenauer

Stiftung.

Llorente \& Cuenca (2013): Panorama audiovisual en América Latina.

Concentración y renovación tecnológica. Madrid: d+i Llorente \& Cuenca.

Ortega, P. Televisión pública en América Latina. Los valores del mercado y las políticas de Estado. Infoamérica. $\mathrm{N}^{0} 3-4$. http://www.infoamerica.org/icr/n03 04/ortega.pdf

Pérez, J., Vilches., L. (2010): Libro blanco sobre la televisión educativa y cultural en Iberoamérica. Barcelona: Gedisa.

Reith, J. (1924): Broadcast over Britain. Londres: Hodder and Stoughton Limited.

Sturm, A., Nalvarte, P. (2016): Medios Públicos de América Latina buscan modelos exitosos de financiación. Journalism in the Americas. The University of Texas at Austin.

https://knightcenter.utexas.edu/es/blog/00-17441-mediospublicos-de-america-latina-buscan-modelos-exitosos-definanciacion-segundoarti?utm source $=$ feedburner\&utm medium $=$ feed\&utm campai $\mathrm{gn}=\mathrm{Feed} \% 3 \mathrm{~A}+\mathrm{kcbloges}+\% 28$ Periodismo $+\mathrm{en}+\mathrm{las}+\mathrm{Am} \% \mathrm{C} 3 \% \mathrm{~A}$ 9ricas $\% 29$ 
Toussaint, F. (2009): Historia y políticas de la televisión pública. Redes.com. N5.

UNESCO (2001): La Radio y Televisión Pública ¿Por qué? ¿Cómo? Paris.

Valdés, M. (2016): TVN: Modelo para amar. Capital Online. http://www.capital.cl/negocios/2016/02/18/100248-tvnmodelo-para-armar

Waisbord, S. (2014): Who speaks for public media in Latin America? The World Bank.

http://blogs.worldbank.org/latinamerica/who-speaks-publicmedia-latin-america

Wood, M. (2016): TVN: Modelo para amar. Capital Online. http://www.capital.cl/negocios/2016/02/18/100248-tvnmodelo-para-armar

Reconocimientos: Los resultados de este artículo forman parte de las actividades de difusión del proyecto del Programa estatal de Fomento de la Investigación Científica y Técnica de Excelencia, subprograma estatal de Generación de Conocimiento del Ministerio de Economía y Competitividad de España sobre "Indicadores de gobernanza, financiación, rendición de cuentas, innovación, calidad y servicio público de las RTV europeas aplicables a España en el contexto digital" (Referencia CSO2015-66543- P). 


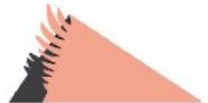 \\ Los autores y las autoras}

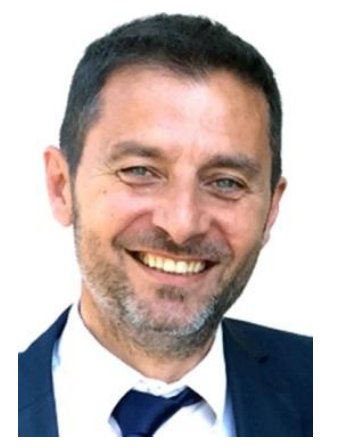

TÚÑEZ LÓPEZ, JOSÉ MIGUEL Universidade de Santiago de Compostela miguel.tunez@,usc.es

Profesor de Comunicación Organizacional en la USC, acreditado como catedrático por la ANECA. IP2 del proyecto Indicadores de gobernanza, financiación, rendición de cuentas, innovación, calidad y servicio público de las RTV europeas aplicables a España en el contexto digital, cofinanciado por FEDER/ UE.

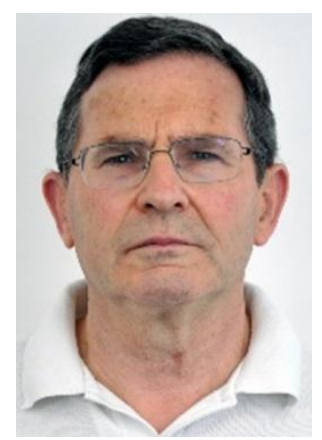

\section{CAMPOS Freire, FranCisCo}

Universidade de Santiago de Compostela francisco.campos@usc.es

Profesor de Gestión de la Empresa Informativa y Audiovisual, acreditado como catedrático por la ANECA. IP del proyecto Indicadores de gobernanza, financiación, rendición de cuentas, innovación, calidad y servicio público de las RTV europeas aplicables a España en el contexto digital.

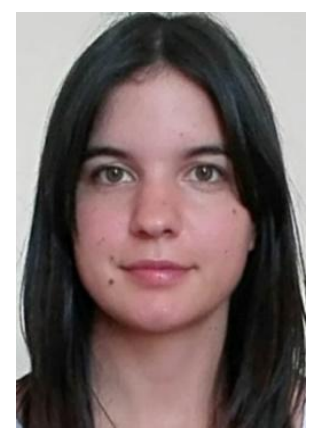

SILVA RodrígueZ, ALBA

Universidade de Santiago de Compostela alba.silva@usc.es

Máster en Comunicación e Industrias Creativas y doctora por la USC. Docente en la facultad de Ciencias de la Comunicación de la USC, miembro del grupo de investigación Novos Medios y secretaria de la revista RAEIC (Revista Española de la Investigación en Comunicación). 


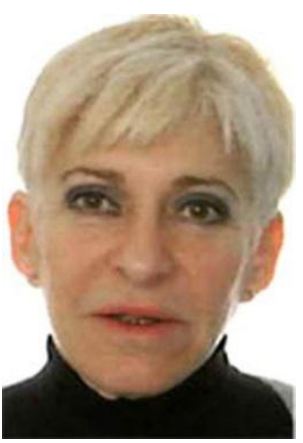

\section{Rosario de MATEO PÉREZ \\ Universidad Autónoma de Barcelona \\ Rosario.DeMateo@uab.cat}

Catedrática de la Universidad Autónoma de Barcelona desde 1994, y profesora de la misma universidad desde 1978. Economista y doctora en Ciencias de la Comunicación. Forma parte del EuroMedia Research Group, grupo internacional dedicado al estudio comparado de los sistemas de medios y políticas de comunicación en Europa.

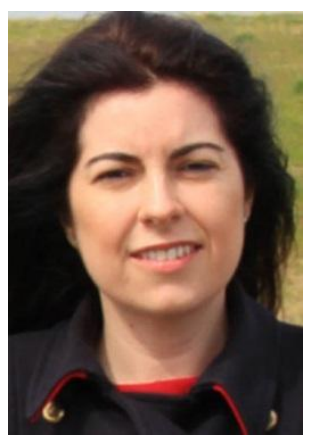

\section{CARMEN COSTA-SÁNCHEZ Universidade da Coruña carmen.costa@udc.es}

Doctora en Comunicación por la USC y profesora de Comunicación Corporativa en la Universidade da Coruña. Co-autora de Comunicación corporativa. Claves y escenarios (ed. UOC) y de Estrategias de Comunicación multimedia (ed. UOC). Miembro del Grupo de Investigación Cultura y Comunicación interactiva.

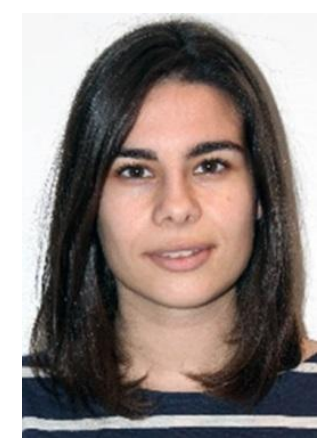

\section{Crespo Pereira, Verónica} Universidade de Vigo veronicacrespopereira@gmail.com

Máster en producción y gestión audiovisual por la Universidad de A Coruña. Su actividad profesional se ha desarrollado en el sector audiovisual. Ejerce como investigadora y docente en la Universidad de Vigo donde lleva a cabo su tesis doctoral vinculada sobre la implementación de la metodología neurocientífica en el campo de la televisión. 


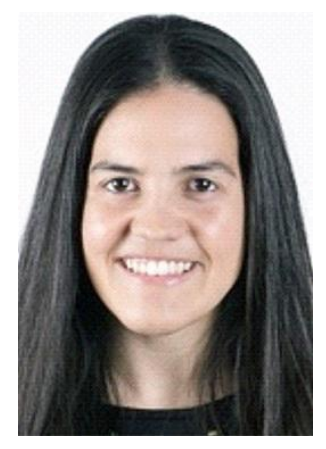

\title{
FERNÁNDEZ LOMBAO, TANIA
}

Universidade de Santiago de Compostela tania.fernandez.lombao@usc.es

Jefa de Programas de la Radio Galega y profesora asociada de la Universidade de Santiago de Compostela en el grado de Ciencias da Cultura e Difusión Cultural. Pertenece al grupo de investigación Novos Medios de la Facultade de Ciencias da Comunicación de la USC. Investiga sobre sobre los medios de servicio públicos europeos.

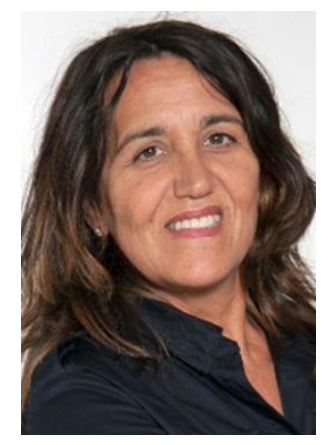

\section{FORMOSO BARRO, FINOCHA Universidade da Coruña Finocha.f@gmail.com}

Profesora de la Universidade da Coruña. Coordinadora del Máster de Producción y Gestión Audiovisual de la UDC y La Voz de Galicia. Trabajó en Mediaset como Delegada de la Producción Ejecutiva de programas de entretenimiento y ficción televisiva. Responsable de la producción de series como Médico de familia o Los Serrano.

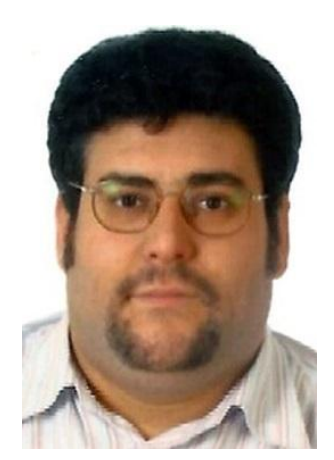

\author{
JUANATEY-BOGA, ÓSCAR \\ Universidade da Coruña \\ oscarjb@udc.es
}

Doctor en Ciencias Económicas y Empresariales por la Universidade da Coruña (UDC). Master MBA en Dirección y Administración de Empresas, Master en Dirección Comercial y Marketing, y Master en Comunicación Empresarial. Profesor del Área de Comercialización e Investigación de Mercados en la UDC. 


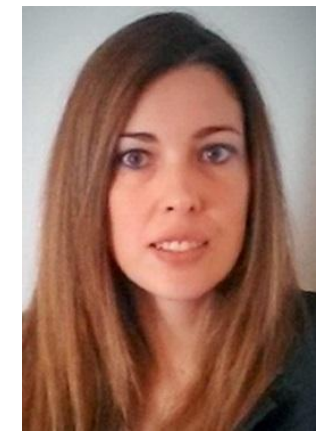

LÓPEZ CEPEDA, ANA MARÍA

Universidad de Castilla-La Mancha

alop.cepeda@gmail.com

Licenciada en Periodismo por la Universidad de Santiago de Compostela, Licenciada en Derecho por la Universidad Nacional de Educación a Distancia y

Doctora en Comunicación y Periodismo por la Universidad de Santiago de Compostela. Profesora en la Facultad de Periodismo de la Universidad de Castilla-La Mancha (UCLM).

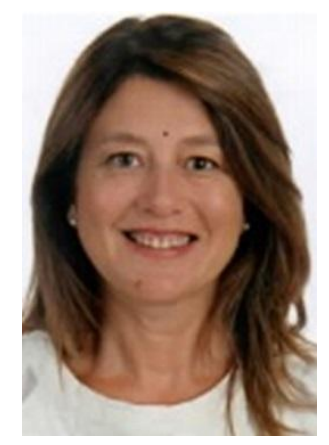

\section{LÓPEZ-GOLÁN, MÓNICA PUCE Sede Ibarra, Ecuador molopez@pucesi.edu.ec}

Licenciada en Comunicación Audiovisual por la Universitat Oberta de Catalunya (Barcelona). Máster en Comunicación e Industrias Creativas por la Universidad de Sntiago de Compostela. Directora de la Escuela de Comunicación Social de la Pontificia Universidad Católica del Ecuador Sede Ibarra.

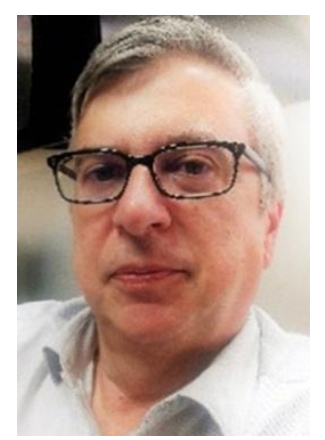

MARTÍNEZ FERNÁNDEZ, VALENTIN ALEJANDRO Universidade da Coruña valentin.martinez@udc.es

Profesor Titular de la Universidad en la Facultad de Economía y Empresa y en la Facultad de Ciencias de la Comunicación de la Universidad de A Coruña. Ha sido Director del diario El Ideal Gallego. Licenciado por la Universidad Complutense de Madrid. Máster MBA en Dirección y Administración de Empresas. 


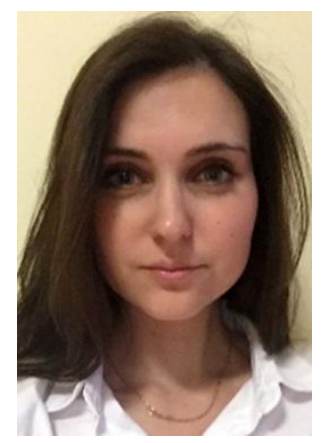

\section{PÉrez Seijo, SARa}

Universidade de Santiago de Compostela sara.entienza@hotmail.com

Máster en Periodismo y Comunicación: Nuevas Tendencias en Producción, Gestión y Difusión del Conocimiento por la Universidad de Santiago de Compostela (USC). Actualmente es investigadora en la Red Internacional de Investigación de Gestión de la Comunicación (R2014/026). Su línea de estudio se centra en las narrativas inmersivas en los medios.

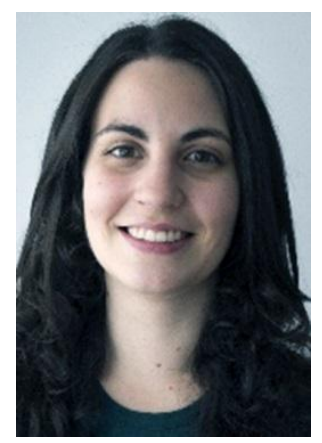

\section{RODRÍGUEz CASTRO, MARTA} Universidade de Santiago de Compostela marta.rodriguez.castro@rai.usc.es

Máster en Investigación aplicada a medios de comunicación por la Universidad Carlos III de Madrid. Doctoranda en Comunicación e Información Contemporánea en la USC. Su investigación se centra en la gobernanza y las pruebas de valor público de la televisión pública europea y los medios de proximidad.

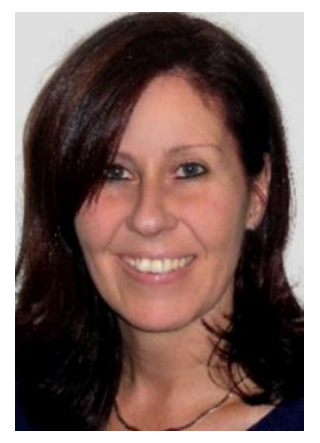

\section{RODRÍGUEZ FERNANDEZ, MARÍA MAGDALENA Universidade da Coruña mmrodriguez@udc.es}

Doctora en Ciencias Económicas y Empresariales por la Universidad de A Coruña. Profesora del Área de Comercialización e Investigación de Mercados, con docencia en la Facultades de Economía y Empresa, Ciencias de la Comunicación y Sociología en la UDC. Investiga en comunicación, marketing, nuevas tecnologías y turismo. 


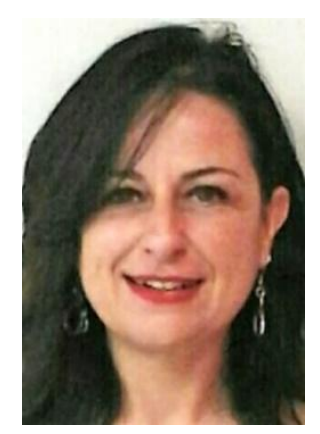

\section{Rodríguez VÁzQUEZ, Clide}

Universidade da Coruña

crodriguezv@udc.es

Doctora por la Universidad de A Coruña, España;

Máster en Dirección y Planificación del Turismo por la

Universidad de A Coruña; Grado en Turismo y

Diplomada en Turismo por la Universidad de A Coruña. Profesora del Área de Comercialización e Investigación de Mercados en la Universidad de la Coruña.

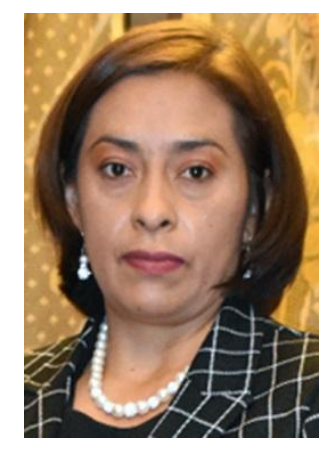

\section{UlloA ERAZO, NANCY GABRIELA PUCE Sede Ibarra, Ecuador nulloa@pucesi.edu.ec}

Máster Internacional en Desarrollo Integral de Destinos Turísticos por Universidad de Las Palmas de Gran Canaria. Doctora en Comunicación e Información Contemporánea por la USC. Investigadora en comunicación organizacional. Docente en la Ponticifica Universidad Católica del Ecuador, Sede Ibarra. 